UNIVERSIDADE DE SÃO PAULO

ESCOLA DE ENFERMAGEM

RONÉDIA MONTEIRO BOSQUE

AVALIAÇÃO DOS CENTROS DE ATENÇÃO PSICOSSOCIAL EM ÁLCOOL E OUTRAS DROGAS DO ESTADO DO AMAPÁ

São Paulo 


\section{AVALIAÇÃO DOS CENTROS DE ATENÇÃO PSICOSSOCIAL EM ÁLCOOL E OUTRAS DROGAS DO ESTADO DO AMAPÁ}

Versão corrigida da Tese de Doutorado apresentada ao Programa de PósGraduação em Enfermagem da Escola de Enfermagem de São Paulo da Universidade de São Paulo, para obtenção do título de Doutora em Ciências.

Área de Concentração: Ciências da Saúde. Orientadora: Prof. ${ }^{\text {a }}$ Dr ${ }^{\mathrm{a}}$ Márcia Aparecida Ferreira de Oliveira

\section{VERSÃO CORRIGIDA}

A versão original encontra-se disponível na Biblioteca da Escola de Enfermagem da Universidade de São Paulo e na Biblioteca Digital de Teses e Dissertações da Universidade de São Paulo. 
AUTORIZO A REPRODUÇÃO E DIVULGAÇÃO TOTAL OU PARCIAL DESTE

TRABALHO, POR QUALQUER MEIO CONVENCIONAL OU ELETRÔNICO, PARA

OS FINS DE ESTUDO E PESQUISA, DESDE QUE CITADA A FONTE.

Assinatura:

Data:

Catalogação na Publicação (CIP)

Biblioteca "Wanda de Aguiar Horta"

Escola de Enfermagem da Universidade de São Paulo

Bosque, Ronédia Monteiro

Avaliação dos centros de atenção psicossocial em álcool e outras drogas do estado do Amapá/ Ronédia Monteiro Bosque. São Paulo, 2017.

$180 \mathrm{p}$.

Tese (Doutorado) - Escola de Enfermagem da Universidade de São Paulo.

Orientadora: Prof. ${ }^{\text {a }}$ Dr. ${ }^{a}$ Márcia Aparecida Ferreira de Oliveira

Área de concentração: Cuidado em Saúde.

1. Avaliação de Serviços de Saúde. 2. Transtornos Relacionados ao Uso de Álcool. 3. Transtornos Relacionados ao Uso de Substâncias. 4. Serviços de Saúde Mental. I. Título. 
Nome: Ronédia Monteiro Bosque

Título: Avaliação dos centros de atenção psicossocial em álcool e outras drogas do estado do Amapá

Tese apresentada ao Programa de Pós-Graduação em Enfermagem Escola de Enfermagem da Universidade de São Paulo para obtenção do título de Doutor em Ciências.

Aprovado em:

\section{Banca Examinadora}

Prof. Dr. Instituição:

Julgamento: Assinatura:

Prof. Dr. Instituição:

Julgamento: Assinatura:

Prof. Dr. Instituição:

Julgamento: Assinatura:

Prof. Dr. Instituição:

Julgamento: Assinatura:

Prof. Dr. Instituição:

Julgamento: Assinatura: 


\section{Dedicatória}

A todos os usuários e familiares dos CAPSad do Estado do Amapá, que durante as entrevistas compartilharam comigo suas histórias de vida, seus sofrimentos e alegrias. Muito obrigada pelo tempo e atenção disponibilizada e por me ensinarem o que realmente devemos valorizar nesta vida.

Aos meus pais, Aldenor (in memorian) e Conceição Bosque, por serem exemplo de pessoas guerreiras, que mesmo com todas as dificuldades conseguiram vencer e proporcionar o melhor aos filhos. Todo meu amor e gratidão a vocês, meus amados pais. Espero representar para meus filhos, pelo menos um pedaço do que vocês representam para mim.

Ao meu marido Augusto que desde o início me fez acreditar que eu seria capaz e conseguiria chegar ao final dessa jornada, que me tranquilizava nos momentos de saudade, e principalmente por ter me ajudado a construir o maior "bem" que eu possuo: nossa família! Obrigada por me fazer feliz sempre! Amo-te

E por fim a eles, meus pequenos e amados filhos, Murilo e Antônio, que são minha fonte de energia. É por eles, e para eles que busco sempre a perfeição, a ser sempre uma pessoa melhor. Espero que eles se tornem homens "do bem", que se sintam sempre amados e que espalhem esse amor por onde forem. 


\section{Agradecimentos}

Meus agradecimentos a todos os trabalhadores, usuários e familiares que me receberam e disponibilizaram seu tempo para este estudo.

Aos residentes Flavia Layana, Tarine Barbosa e Renan Machado e a amiga Renata Kellen, que foram a campo auxiliar na coleta de dados.

Ao colegiado do curso de Educação Física da UNIFAP, em nome do meu amigo Dilson Belfort. Obrigada por todo incentivo e momentos de discussões sobre diversas temáticas que auxiliaram na construção deste estudo.

Aos meus colegas do Dinter, em especial a querida amiga Nelma Nunes da Silva, a qual dividimos várias angústias, tristezas e alegrias durante essa jornada. Meu muito obrigada, minha amiga, por todo apoio que você me deu. "Tamo junto compa". Aos colegas que fiz em São Paulo, em especial à Rosana Ribeiro e Heloisa Claro, que estavam sempre disposta a responder as dúvidas que sempre surgiam durante todo o estudo.

$\mathcal{A}$ todos os professores do programa que nos proporcionaram momentos de conhecimentos e trocas de experiências.

A professora Yara de Carvalho, a qual me apresentou uma educação física até então desconhecida, me fazendo ter um olhar mais amplo e perceber que podemos e devemos conhecer outras áreas, sem medo e sem preconceitos.

E um agradecimento especial a minha querida professora e orientadora Márcia Aparecida. Detentora de um sorriso contagiante, que transmite uma energia positiva, e nos faz acreditar que tudo dará certo. Obrigada pelo acolhimento e por toda paciência que teve em decorrência das minhas dificuldades, principalmente nesta área da saúde mental, até então desconhecida por mim, e pela qual tornei-me completamente apaixonada. Muito obrigada professora, meus eternos agradecimentos! 
Bosque RM. Avaliação dos Centros de Atenção Psicossocial em Álcool e outras Drogas do Estado do Amapá [tese]. São Paulo: Escola de Enfermagem, Universidade de São Paulo; 2017

\section{RESUMO}

Introdução: Os CAPS constituem a principal estratégia do processo de reforma psiquiátrica, por serem instituições destinadas a acolher os pacientes com transtornos mentais, estimular sua integração social e familiar e apoiá-los em suas iniciativas de busca da autonomia. Por serem um serviço de saúde com pouco mais de uma década de existência, torna-se relevante a avaliação desses equipamentos com o intuído de melhorar a qualidade do tratamento ofertado. Objetivo: Descrever e analisar os Centros de Atenção Psicossocial de Álcool e outras Drogas do estado do Amapá. Metodologia: Trata-se de um estudo avaliativo, que utiliza de métodos quantitativos transversais, descritivos e exploratórios, realizados nos CAPSad do Estado do Amapá, constituídos no total, por dois serviços. A amostra do estudo constituiu-se de 32 trabalhadores, 60 usuários e 28 familiares. Para a coleta de dados foram aplicados; um questionário sócio demográfico e a Escala de Satisfação - SATIS-BR para todos os sujeitos; a Escala de Mudança Percebida - EMP para usuários e familiares e a Escala de Atitude Frente ao Álcool, Alcoolismo e Alcoolista - EAFAAA para os trabalhadores. Os dados foram processados de forma descritiva pelo Programa Statistical Package for Social Sciences (SPSS), versão 20,0 para Windows. Resultados: os CAPSad do Amapá seguem a maioria das normativas exigidas pelo Ministério da Saúde. Entretanto, o CAPSad de Santana ainda precisa ajustar alguns itens, como o número mínimo de profissionais exigidos, além da oferta de alimentação para os usuários, o que acaba por influenciar na oferta de mais oficinas e grupos terapêuticos. Apesar disso, foram obtidos bons níveis de satisfação global para usuários $(3,98)$ e familiares $(4,0)$ e nível de satisfação intermediário para os trabalhadores $(3,55)$ em relação aos aspectos avaliados do serviço. Em relação à mudança percebida após o início do tratamento, tanto os usuários quanto familiares obtiveram índices elevados na EMP, sendo as médias de 2,68 e 2,63 respectivamente. Os resultados obtidos a partir da EAFAAA sugerem que os profissionais dos CAPSad apresentam atitudes positivas frente ao usuário de AOD, com o escore médio de 3,38. Conclusão: os resultados indicam que apesar das fragilidades encontradas nos CAPSad do Estado do Amapá, os mesmos conseguem cumprir com o seu papel acolhedor, capaz de fornecer acompanhamento clínico na busca pela reinserção social dos usuários. Entretanto, necessita-se de mais investimentos para esses serviços de saúde, o que trará mais qualidade ao serviço ofertado. 
Descritores: Avaliação de Serviços de saúde. Transtornos Relacionados ao Uso de Álcool, Transtornos Relacionados ao Uso de Substâncias, Serviços de Saúde Mental. 
Bosque RM. Evaluation of the Psychosocial Care Centers for Alcohol and Other Drugs of the state of Amapá [thesis]. São Paulo: School of Nursing, University of São Paulo; 2017

\section{ABSTRACT}

Introduction: The CAPS represent the main strategy in the process of psychiatric reformation, since they are institutions destined to receive patients with mental disorders, to stimulate their social and family integration, and to support them in their initiatives towards autonomy. Because they are a health service with a little more than a decade of existence, it becomes relevant to evaluate this equipment in order to improve the quality of the offered treatment. Objective: to describe and to analyze the Psychosocial Care Centers for Alcohol and Other Drugs (CAPS) of the state of Amapá. Methodology: This is an evaluative study, that utilizes cross-sectional quantitative, descriptive, and exploratory methods, performed at the CAPSad of the state of Amapá, constituted by two services in total. The sample of the study was composed by 32 workers, 60 users and 28 relatives. For data collection, the following were applied; a sociodemographic questionnaire and the Satisfaction Scale - SATIS-BR for all the subjects; the Perceived Change Scale - EMP for users and relatives, and the Scale of Attitude Towards Alcohol, Alcoholism and Alcoholic - EAFAAA for the workers. The data were processed in a descriptive manner by the Statistical Package for Social Sciences (SPSS) program, version 20,0 for Windows. Results: The CAPSad of Amapá follow most of the regulations demanded by the Ministry of Health. However, the CAPSad of Santana still needs to adjust some items, such as the minimum number of professionals required, besides the food supply for the users, what ends up influencing the offer of more workshops and therapeutic groups. Despite that, the research obtained good levels of global satisfaction for users $(3,98)$ and relatives $(4,0)$, and intermediate level of satisfaction for the workers $(3,55)$ related to the evaluated aspects of the service. Regarding the perceived change after the treatment start, both users and relatives obtained high indexes on the EMP, where the averages were 2,68 and 2,63 respectively. The results obtained from the EAFAAA suggest that the CAPSad professionals present positive attitudes towards the user of AOD, with average score of 3,38 . Conclusion: The results indicate that despite the weaknesses found in the CAPSad of the state of Amapá, they can fulfill their hospitable role, being capable of offering clinical monitoring in the pursuance of the social reintegration of the users. However, more investments for these health services are needed, which will bring more quality to the offered service. 
Descriptors: Evaluation of the Health Services. Disorders Related to the Use of Alcohol, Disorders Related to the Use of Substances, Mental Health Services. 


\section{LISTA DE TABELAS}

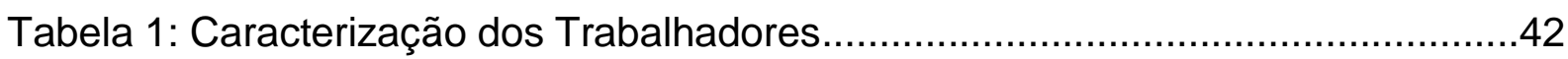

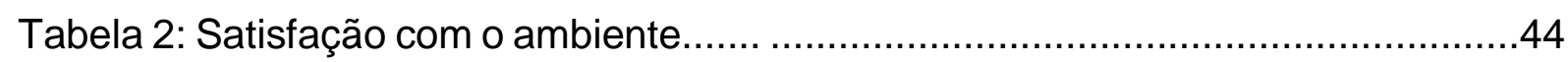

Tabela 3: Atendimentos individuais, grupais e atividades comunitárias......................45

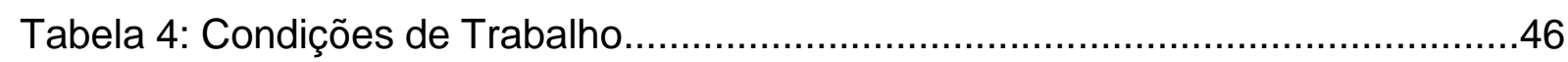

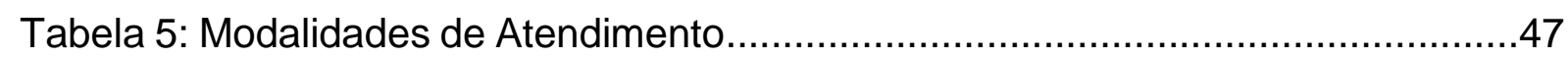

Tabela 6: Modalidades de Atendimento Individual.................................................48

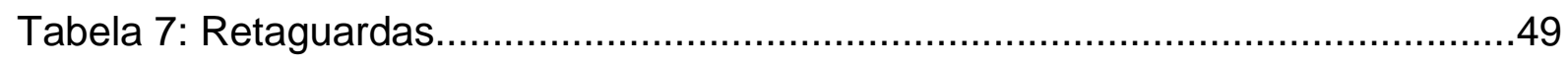

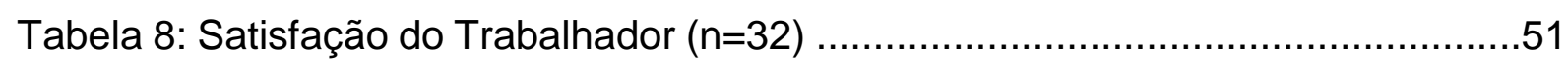

Tabela 9: Escala de atitudes frente ao álcool, alcoolismo e alcoolista $(n=32)$............51

Tabela 10: Supervisão, apoio e avaliação global do atendimento prestado.................52

Tabela 11: Caracterização usuários.................................................................53

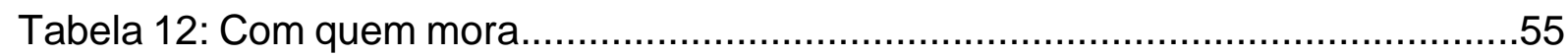

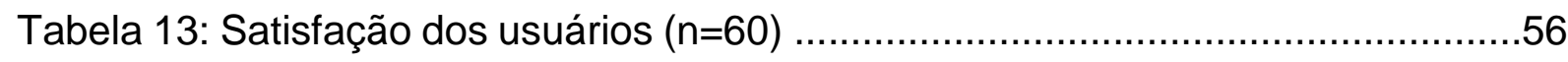

Tabela 14: Escala de mudança percebida dos usuários.........................................57

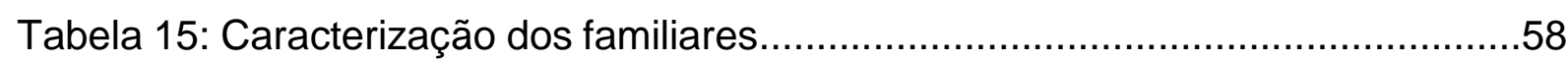

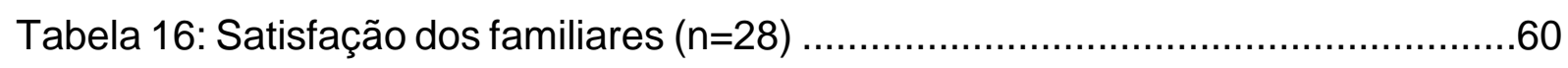

Tabela 17: Escala de mudança percebida na perspectiva dos familiares....................61 


\section{LISTA DE SIGLAS}

AOD

CAPS

CAPSad

CAPSi

CEP

DP

EEUSP

EAFAAA

EMP

MS

MTSM

OMS

PEAD

PT

PTI

PTS

RAS

RAPS

$\mathrm{RD}$

RPB

SATIS-BR

SRT

SUS

SPAS

TCLE

TR

UAs

UNIFAP

UNODOC

$\mathrm{WHO}$
Álcool e outras Drogas

Centros de Atenção Psicossocial

Centro de Atenção Psicossocial de Álcool e outras Drogas

Centros de Atenção Psicossocial para Infância e Adolescência

Comitê de Ética em Pesquisa

Desvio Padrão

Escola de Enfermagem da Universidade de São Paulo

Escala de Atitudes frente ao álcool, alcoolismo e alcoolista

Escala de Avaliação da Percepção de Mudança

Ministério da Saúde

Movimento dos Trabalhadores de Saúde Mental

Organização Mundial da Saúde

Plano Emergencial de Ampliação de Acesso ao Tratamento e Prevenção em Álcool e outras Drogas

Portaria

Plano Terapêutico Individual

Projeto Terapêutico do Serviço

Rede de Atenção à Saúde

Rede de Atenção Psicossocial

Redução de Danos

Reforma Psiquiátrica Brasileira

Escalas de Avaliação da Satisfação em Serviços de Saúde Mental Serviços Residenciais Terapêuticos

Sistema Único de Saúde

Substâncias psicoativas

Termo de Consentimento Livre e Esclarecido

Terapeuta de referencia

Unidade de Acolhimento

Universidade Federal do Amapá

Nations Office On Drugs and Crime

World Health Organization 


\section{SUMÁRIO}

1 INTRODUÇÃO

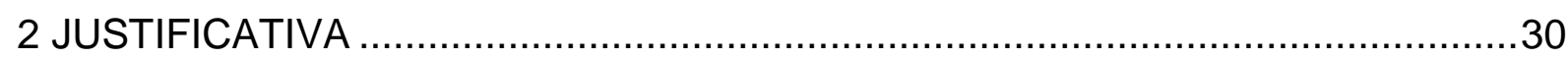

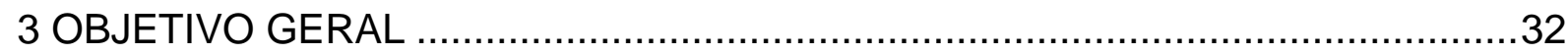

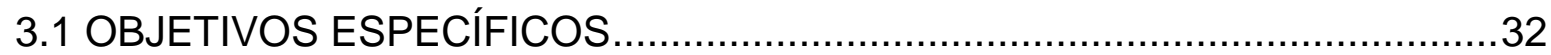

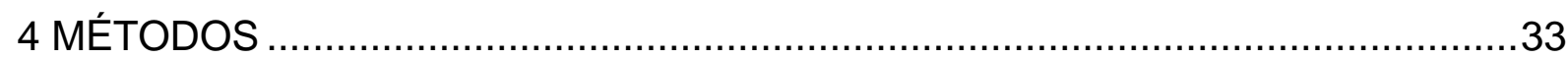

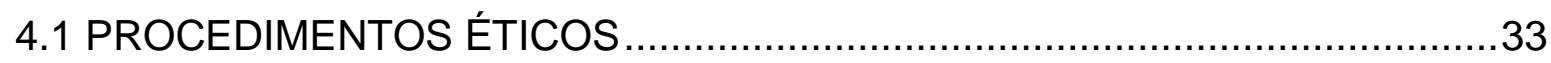

4.4 CRITÉRIOS PARA A INCLUSÃO E EXCLUSÃO DE PARTICIPANTES..........34

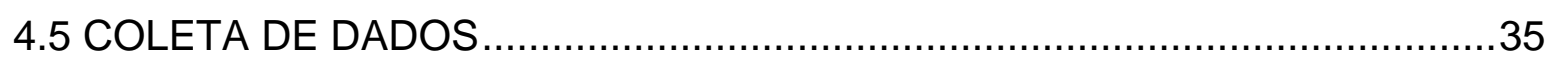

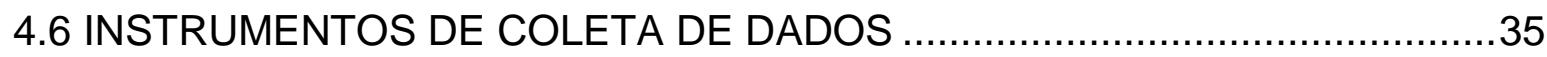

4.7 SELEÇÃO E TREINAMENTO DOS ENTREVISTADORES............................36

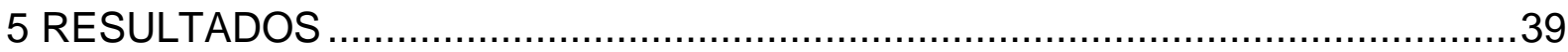

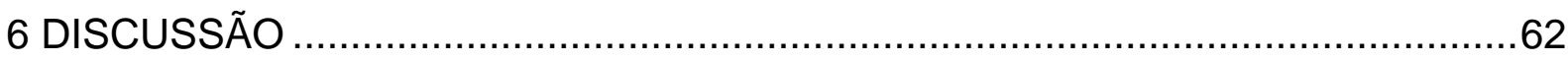

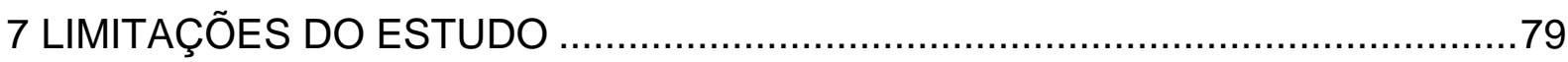

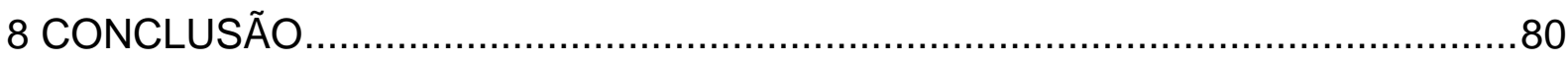

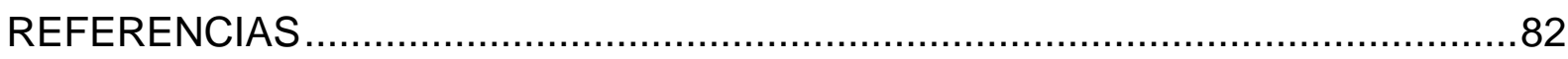

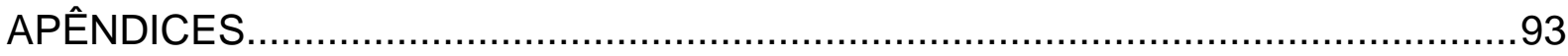

APÊNDICE 1 - Pedido de autorização institucional ...........................................93

APÊNDICE 2 - Termo de consentimento livre e esclarecido - Coordenador e

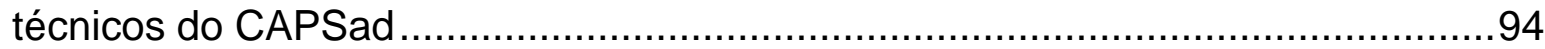

APÊNDICE 3 - Carta convite do responsável legal dos participantes da pesquisa.

APÊNDICE 4 - Termo de consentimento livre e esclarecido - Do participante ou

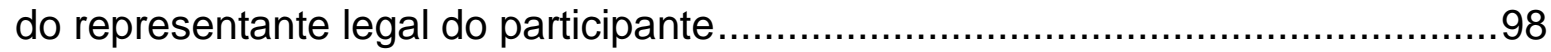

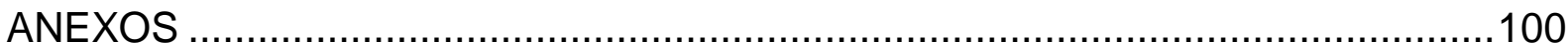

ANEXO 1 - Parecer do Comitê de Ética em Pesquisa........................................100

ANEXO 3 - Instrumento para os trabalhadores do serviço. ...............................118

ANEXO 4 - Instrumento para os usuários do serviço.........................................134

ANEXO 5 - Instrumento para os familiares dos usuários do serviço....................151

ANEXO 6 - Autorização para utilização dos instrumentos. ................................163 


\section{INTRODUÇÃO}

\subsection{DADOS EPIDEMIOLÓGICOS}

Apesar da relação entre substâncias psicoativas (SPAS) e o homem ser antiga, nas últimas décadas o consumo abusivo e a dependência têm se configurado como uma demanda de saúde pública, diante de um cenário marcado pela acelerada transição socioeconômica que vem ocorrendo em vários países (UNODC, 2016).

O uso indiscriminado tanto de drogas lícitas quando de drogas ilícitas, pode trazer danos biológicos, psicológicos, sociais, econômicos, culturais, étnico-legais e morais. Apesar disto, estima-se que 1 em cada 20 adultos, cerca de 247 milhões de pessoas com idade entre 15 e 64 anos, consumiram pelo menos uma droga ilícita em 2014. Estima-se ainda, que aproximadamente 29 milhões de pessoas são consideradas usuários problemáticos, ou seja, que sofrem de transtornos relacionados ao uso (UNODC, 2016).

Ao compararmos esses dados com os do ano de 2012, percebemos que houve um aumento de 4 milhões de usuários que consumiram droga ilícita pelo menos uma vez no último ano e de 2 milhões de usuários problemáticos. Entretanto, ao relacionarmos com o crescimento populacional global, podemos considerar que 0 número de ambos se manteve estável (UNODOC, 2016).

De acordo com a Organização Mundial da Saúde- OMS (2016), apenas 1 em cada 6 pessoas acessam serviços de tratamento a cada ano, número este ainda considerado baixo para a grande demanda que ocorre ano após ano.

Em 2014, aproximadamente 207.400 mil pessoas morreram em decorrência do uso indiscriminado de drogas. Além disso, o consumo de SPAS é considerado um importante fator de risco para a transmissão de doenças infecciosas. Entre as pessoas que injetam drogas (cerca de 12 milhões), 1 em cada 7 vive com o HIV e 1 em cada 2 com a Hepatite C (UNODOC, 2016).

A América Latina, durante muito tempo, e ainda hoje, é vista como uma das principais regiões problemáticas relacionadas ao fornecimento e consumo de drogas no mundo. $O$ uso e o tráfico da cocaína aumentaram na América do Sul, e isto se estendeu também para a África. Em contrapartida, o uso da maconha sofreu um leve decréscimo entre os anos de 2011 e 2012, e nos últimos anos vem mantendo-se estável. Calcula-se que 162 milhões de pessoas no mundo façam uso com frequência 
da maconha, e destes, cerca de 23,2\% (37,6 milhões) estão localizadas na América Latina (OPS, 2009 e UNODOC, 2016).

Ao analisarmos os dados relacionados a cocaína, podemos perceber que o problema é ainda mais sério., uma vez que cerca de 14,3 milhões de pessoas da população mundial, fazem uso de cocaína, e destes mais da metade (8,6 milhões) estão na América Latina (OPS, 2009).

A respeito do álcool, considerada a substância lícita mais consumida mundialmente, a WHO (2014) estima que 3,3 milhões de pessoas morreram no mundo em 2012, em decorrência de seu uso abusivo. Este número é equivalente a 5,9\% de todas as mortes, sendo maior que a proporção de óbitos por HIV/AIDS (2,8\%), violência $(0.9 \%)$ ou tuberculose $(1,7 \%)$.

O consumo abusivo de álcool possui uma relação causal com mais de 200 tipos de doenças e lesões, cerca $5,1 \%$ da carga global, dentre elas podemos citar as doenças cardiovasculares e diabetes, câncer, doenças gastrointestinais (principalmente a cirrose) e doenças mentais e comportamentais (WHO, 2014).

No que se refere ao Brasil, de acordo com o II Levantamento Domiciliar sobre o Uso de Drogas Psicotrópicas, o país apresenta dados semelhantes. Cerca de 22,8\% da população pesquisada, com idades entre 12 e 65 anos, já fez uso na vida de algum tipo de droga ilícita e 12,3\% são dependentes do álcool (Carlini et al, 2006).

O Brasil foi apontado como uma das nações emergentes onde o consumo de estimulantes como a cocaína (tanto na forma intranasal ou fumada), está aumentando enquanto na maioria dos países o consumo está diminuindo. Cerca de $3,8 \%$ da população adulta já consumiu pelo menos uma vez na vida e 1,7\% fez uso nos últimos 12 meses (Bastos; Bertoni, 2014)

Ainda sobre o Brasil, pode-se afirmar que o consumo de crack desencadeou questões desafiadoras a serem resolvidas pelo poder público em especial nos serviços de saúde, segurança pública e assistência social. De acordo com a Pesquisa Nacional sobre o uso do crack, o consumo de forma regular em âmbito nacional corresponde a $0,81 \%$ da população geral de todas as capitais brasileiras e o Distrito Federal, o que equivale a aproximadamente 370 mil usuários regulares em números absolutos (Bastos; Bertoni, 2014).

Ao analisarmos os dados acima por região do país, relacionados proporcionalmente ao número populacional dos estados, encontramos uma estimativa 
de $0,68 \%$ de usuários de crack e/ou similares na região norte, sendo este percentual maior que o da região sudeste (Bastos; Bertoni, 2014).

Os usuários de crack constituem um grupo com especificidades distintas, dentre os demais usuários de substâncias ilícitas, com características e necessidades individuais que requerem uma abordagem especial, por possuírem um acelerado processo de deterioração física e psíquica (Dualibi; Ribeiro; Laranjeira, 2008) e que vem crescendo progressivamente em todas as regiões do país (Vargen; Cruz; Santos, 2011).

O consumo de drogas ilícitas, muitas vezes está associado ao prejuízo de desenvolvimento econômico e social, bem como na promoção do crime, instabilidade, insegurança e propagação do HIV e hepatite (UNODOC, 2016).

\subsection{POLÍTICAS DE ATENÇÃO AOS USUÁRIOS DE ÁlCOOL E OUTRAS DROGAS}

Para compreendermos a atual política de atenção aos usuários de álcool e outras drogas, traçaremos um breve histórico da política de saúde mental no país.

A Reforma Psiquiátrica Brasileira (RPB) é considerada o marco da assistência à saúde mental no país, consequência do crescimento durante décadas, de um movimento social desigual e constante, jamais visto no Brasil e no mundo, em torno da luta por Direitos Humanos fundamentais das pessoas em sofrimento psíquico (Pitta, 2011).

Anteriormente RPB, pessoas em sofrimento psíquico eram relegadas à hospitais psiquiátricos, pois acreditava-se que não havia tratamento sem a devida internação (Rodrigues, 2005). Desta forma, fica claro que o doente mental era muito mais excluído socialmente do que tratado.

No Brasil, os hospitais psiquiátricos foram inspirados nas ideias de Pinel e nos moldes europeus. No ano de 1852, por ordem do então imperador D. Pedro II, foi criado na cidade do Rio de Janeiro o primeiro hospital psiquiátrico do Brasil. O intitulado Hospício Dom Pedro II surgiu com a necessidade de um reordenamento urbano, onde pessoas que perturbavam a ordem pública e social deveriam ser excluídas da sociedade (Rocha, 2005; Wachs, 2008). Assim, outros hospitais psiquiátricos foram surgindo pelo país. Em geral gerenciados por pessoas e instituições religiosas. 
Com o advento da República, os hospitais passaram a ser menos religiosos, tornando-se mais profissionais. Equipes médicas e de enfermagem passaram a monopolizar o gerenciamento dos hospícios e técnicas mais cientificas/medicamentosas começaram a ser usadas com maior frequência (Amarantes, 1995).

Após a segunda guerra mundial, quando milhares de doentes mentais morreram de fome e maus tratos em um hospital psiquiátrico na França, começaram a se intensificar pelo mundo, os questionamentos sobre os tratamentos que estes hospitais davam aos seus pacientes. Essas inquietações também chegaram ao Brasil, e na década de 70 começaram a surgir críticas severas ao modelo assistencial que aqui era disponibilizado. Essas críticas foram intensificadas pelo modelo vigente de saúde que o Brasil estava passando. Segundo Paulin e Turato (2004) após a criação dos institutos de aposentaria e pensão, inicia-se uma privatização na assistência mental, diminuindo os leitos que atendiam a pacientes mentais nos hospitais públicos e o aumento nos hospitais privados.

A partir dessa conjuntura, nasce o Movimento da Reforma Sanitária, onde a população exigia melhores condições de assistência à saúde pública. E em 1978 é criado o Movimento dos Trabalhadores de Saúde Mental - MTSM (Bichaff, 2006), o qual foi um marco para a consolidação das mudanças em assistência mental.

Com a criação do MTSM, a luta pela dignidade e cidadania do "louco" começa a ganhar forças, influenciadas pelos ideais italianos de desinstitucionalização dos doentes mentais. Segundo Amarantes (2007, p. 81), "desinstitucionalização não é apenas um processo de desospitalização, mas de invenção de práticas assistenciais territoriais; um processo prático de desconstrução dos conceitos e das práticas psiquiátricas".

Em 1987 acontece a I Conferência Nacional de Saúde Mental do Brasil, onde em seu relatório final aparecem algumas recomendações como: reversão da tendência "hospitalocêntrica e psiquiatrocêntrica", priorizando assim o sistema extrahospitalar e multiprofissional; diminuição progressiva dos leitos em hospitais psiquiátricos tradicionais e proibição de criação de novos leitos, bem como de novos hospitais psiquiátricos; criação de leitos psiquiátricos em hospitais gerais públicos ou serviços inovadores alternativos à internação; implantação de recurso assistencial 
alternativo aos asilares como hospital-dia, hospital-noite, pré-internações, lares protegidos, núcleos autogestionários e trabalhos protegidos (Brasil, 1988).

Após essas recomendações, em 1989 surge o projeto de lei 3657/89 de autoria do então deputado Paulo Delgado, que propõe como lei as recomendações feitas na I Conferência Nacional de Saúde Mental, onde o principal ponto foi a proibição dos hospitais psiquiátricos bem como a sua progressiva extinção, e a sua substituição por outras modalidades assistenciais. O referido projeto foi aprovado na câmara e encaminhado para o senado, o qual levou 12 anos para ser aprovado, em decorrência das frequentes modificações que segundo Rodrigues (2005) eram de interesse dos donos dos hospitais privados da época. Em 06 de abril de 2001 é aprovada a lei federal 10.216. Entretanto, outras leis estaduais que continham o mesmo teor já haviam sido aprovadas e colocadas em exercício.

No campo da assistência aos usuários de álcool e outras drogas (AOD), podemos observar uma enorme lacuna no decorrer da história. Tal fato remete ao aspecto que as abordagens, intervenções e políticas nesta área, foram original e predominantemente desenvolvidas no âmbito da justiça e segurança pública (Machado; Miranda, 2007).

A questão das drogas foi relegada a uma concepção mais punitiva, constituída por leis e decretos que proibiam e criminalizavam o uso e o comércio. Os tratamentos adotados para os usuários de SPA eram baseados em práticas de natureza medicamentosa, disciplinar ou de cunho religioso-moral, onde reforçava-se o isolamento social (Brasil, 2007).

As orientações previstas na lei 6368/76 que reafirmava a tendência de abordar o uso e a dependência de drogas no campo médico-psiquiátrico, favoreceram o surgimento da assistência à saúde para usuários de AOD. Como consequência, a partir da década de 80 , foram criados os primeiros centros de tratamento (públicos e religiosos) no Brasil (Machado; Miranda, 2007).

A partir deste contexto de lutas, a última década foi marcada pela implantação de serviços substitutivos ao hospital psiquiátrico, com destaque aos Centros de Atenção Psicossocial (CAPS), os Serviços Residenciais Terapêuticos (SRT), o Auxílio de Reabilitação Psicossocial "De volta pra casa", os quais ao longo do tempo reduziram expressivamente a quantidade de leitos em hospitais psiquiátricos. 
Dentre todos os serviços instituídos, a criação dos CAPS, a partir da portaria GM/MS 336/2002, possui especial relevância no cenário das novas práticas em saúde mental no Brasil (Brasil, 2002). Por ser considerado um dos principais equipamentos de saúde dentro das políticas de saúde mental do país, além de ser o objeto de estudo desta pesquisa, abordaremos com mais detalhes suas principais características em um tópico subsequente.

Uma discussão mais sistemática sobre AOD no campo da saúde pública, bem como em outros setores, inicia-se a partir de 2003, surgindo assim em 2004, a Política do Ministério da Saúde para Atenção Integral aos Usuários de Álcool e outras Drogas (PT GM/MS 2.197/2004) (Brasil, 2004).

Este documento contém diretrizes de uma política que visa estruturar e fortalecer uma rede de assistência que aborda de forma integral e articulada o desafio de prevenir, tratar e reabilitar os usuários de AOD como um problema de saúde pública, ofertando tratamentos para além dos serviços de saúde, como por exemplo, os dispositivos de assistência psicossocial (Brasil, 2004).

$O$ documento ressalta ainda a importância de se levar em consideração a singularidade dos usuários, passando a estabelecer a lógica ampliada da concepção de Redução de Danos (RD), além dos conceitos de "território" e "rede", operacionalizando uma busca ativa e sistemática das necessidades a serem atendidas de forma integrada ao meio sociocultural em que estão inseridos os usuários.

Adiante, no ano de 2005, diversas iniciativas foram criadas no campo de AOD, entre elas destacam-se: a) Aprovação das Normas de Funcionamento e Credenciamento/Habilitação dos Serviços Hospitalares de Referência para a Atenção Integral aos Usuários de Álcool e outras Drogas (PT GM/MS 1.612/05), a qual propunha financiamento para leitos destinados aos usuários de AOD em hospitais gerais; b) incentivos financeiros para os CAPSad que desenvolvessem ações de Redução de Danos (PT GM/MS 1.059/05); c) incentivo financeiro para os municípios que desenvolvessem projetos de inclusão social pelo trabalho destinado a pessoas com transtorno mentais ou transtornos decorrentes do uso de AOD (PT GM/MS 1.169/05).

Nesta mesma direção, em 2009, o Ministério da Saúde (MS) lançou o Plano Emergencial de Ampliação de Acesso ao Tratamento e Prevenção em Álcool e outras 
Drogas - PEAD (PT GM/MS 1.190/2009), com a intenção de alcançar prioritariamente crianças, adolescentes e jovens em situação de grave vulnerabilidade social por meio de ações de prevenção, promoção e tratamento dos riscos e danos associados ao consumo prejudicial de SPA (Brasil, 2009).

No ano seguinte, através do decreto 7.179/2010, o governo lança o Plano Integrado de Enfrentamento ao Crack, fundamentado na integração e na articulação permanente entre as políticas e ações de saúde, assistência social, segurança pública, educação, desporto, cultura, direitos humanos, juventude, entre outras, em consonância com os pressupostos, diretrizes e objetivos da Política Nacional sobre Drogas (Brasil, 2010).

Ainda em 2010, o MS estabelece diretrizes para a organização da Rede de Atenção à Saúde (RAS) através da portaria GM/MS 4.279/10. A RAS é definida como arranjos organizativos de ações e serviços de saúde de diferentes densidades tecnológicas, que integradas por meio de sistemas de apoio técnico, logístico e de gestão, buscam garantir a integralidade do cuidado (Brasil, 2010b).

A implementação da RAS visa garantir uma maior eficácia na produção de saúde, melhoria na eficiência da gestão do sistema de saúde no espaço regional, além de contribuir para o avanço do processo de efetivação do Sistema Único de Saúde SUS. Fundamenta-se na compreensão da Atenção Primária à Saúde como primeiro nível de atenção, destacando a função resolutiva dos cuidados primários sobre os problemas mais comuns de saúde e, a partir disso, o cuidado é realizado e coordenado em todos os pontos de atenção (Brasil, 2010b).

Assim, em consonância com a RAS, surge a partir da portaria GM/MS 3088/2011, a Rede de Atenção Psicossocial (RAPS) cuja a finalidade é a criação, ampliação e articulação de pontos de atenção à saúde para pessoas com sofrimento ou transtorno mental e com necessidades decorrentes do uso de crack, álcool e outras drogas, no âmbito do SUS (Brasil, 2011).

A RAPS tem como objetivo a ampliação do acesso à atenção psicossocial da população em geral, promover a vinculação das pessoas em sofrimento/transtornos mentais e com necessidades decorrentes do uso de crack, álcool e outras drogas, bem como de suas famílias aos pontos de atenção, e garantir a articulação e integração dos pontos de atenção das redes de saúde no território, qualificando o 
cuidado por meio do acolhimento, do acompanhamento contínuo e da atenção às urgências (Brasil, 2011b).

Além disso, a RAPS é composta por serviços e equipamentos variados, tais como: os Centros de Atenção Psicossocial (CAPS); os Serviços Residenciais Terapêuticos (SRT); os Centros de Convivência e Cultura, as Unidade de Acolhimento (UAs), e os leitos de atenção integral (em Hospitais Gerais e nos CAPS III). Faz parte dessa política o programa de Volta para Casa, que oferece bolsas para pacientes egressos de longas internações em hospitais psiquiátricos (Brasil, 2011b).

A RAPS teve impacto importante na Política de Saúde Mental, após alterações na lógica de funcionamento do SUS. Dentro dessa perspectiva, o Plano "Crack, é Possível Vencer" surge em 07 de dezembro de 2011 em complementação às ações do Plano Integrado de Enfrentamento ao Crack, com foco nos serviços da RAPS que fazem atendimento às pessoas com necessidades decorrentes do uso de crack, álcool e outras drogas. O plano tem três frentes de atuação, a prevenção, o cuidado e a autoridade, com o objetivo aumentar a oferta de tratamento de saúde e atenção aos usuários de drogas, além de enfrentar o tráfico e as organizações criminosas e ampliar atividades de prevenção (Brasil, 2011c).

Destaca-se ainda dentro deste contexto político de saúde mental, a portaria 130/2012 GM/MS que redefine o Centro de Atenção Psicossocial de Álcool e outras Drogas 24h (CAPS AD III) e os respectivos incentivos financeiros. Assim, fica instituído o CAPS AD III como o ponto de atenção do componente da atenção especializada da RAPS destinado a proporcionar a atenção integral e contínua a pessoas com necessidades relacionadas ao consumo de álcool, crack e outras drogas, com funcionamento nas 24 (vinte e quatro) horas do dia e em todos os dias da semana, inclusive finais de semana e feriados (Brasil, 2012).

\subsection{OS CENTROS DE ATENÇÃO PSICOSSOCIAL EM ÁLCOOL E OUTRAS DROGAS (CAPSAD)}

Os CAPS constituem a principal estratégia do processo de reforma psiquiátrica, por serem instituições destinadas a acolher os pacientes com transtornos mentais, estimular sua integração social e familiar, apoiá-los em suas iniciativas de busca da autonomia, além de oferecer-lhes atendimento médico e psicológico. Possui como principal característica, a busca pela integração dos usuários a um ambiente social e 
cultural concreto, designado como seu "território", o espaço da cidade onde se desenvolve a vida quotidiana de usuários e familiares (Brasil, 2004b).

O principal objetivo dos CAPS é oferecer atendimento à população de sua área de abrangência, realizando o acompanhamento clínico e a reinserção social dos usuários através do acesso ao trabalho, lazer, exercícios dos direitos civis e fortalecimento dos laços familiares e comunitários. Nasce com o intuito de ser um serviço substitutivo às internações em hospitais psiquiátricos (Brasil, 2004b).

Com a portaria GM/MS 336/2002, fica estabelecido os Centros de Atenção Psicossocial poderão constituir-se nas seguintes modalidades de serviços: CAPS I, CAPS II e CAPS III definidos por ordem crescente de porte/complexidade e abrangência populacional, capacitadas para atender pacientes com transtornos mentais severos e persistentes em sua área territorial em regime de tratamento intensivo, semi intensivo e não intensivo. A referida portaria define ainda as características de cada modalidade em termos de recursos humanos, atividades, horário de funcionamento, capacidade operacional, funções que desempenham e direciona a criação de serviços específicos para a área da infância e adolescência (CAPSi) além da área de álcool e outras drogas (CAPS AD) (Brasil, 2004).

Os CAPS I são os centros de menor porte indicados para populações entre 20.000 e 70.000 habitantes. Possuem equipe mínima de 9 profissionais (nível médio e superior) e possui como clientela adultos com transtornos mentais severos e persistentes e transtornos decorrentes do uso de álcool e outras drogas. Funcionam durante os cinco dias úteis da semana das $8 \mathrm{~h}$ às 18h (Brasil, 2002).

Os CAPS II são os centros de médio porte, indicados para populações de 70.000 a 200.000 mil habitantes. A equipe mínima é de 12 profissionais (nível médio e superior) e possui como clientela, adultos com transtornos mentais severos e persistentes. Funcionam durante os cinco dias úteis da semana das $8 \mathrm{~h}$ às $18 \mathrm{~h}$, podendo comportar um 3ํㅡㄴ turno (18h as 21h) (Brasil, 2002).

Os CAPS III são os serviços de maior porte da rede CAPS, indicados para os municípios com mais de 200.000 habitantes, com funcionamento $24 \mathrm{~h}$ em todos os dias da semana, inclusive feriados. Devem possuir no máximo 5 leitos com o intuito de realizar quando necessário atendimento noturno (internações curtas, de algumas horas, no máximo 7 dias). A equipe mínima deve ser de 16 profissionais (nível médio e superior) além da equipe noturna e de final de semana (Brasil, 2002). 
O CAPSi Il é especializado para o atendimento de crianças e adolescentes com transtornos mentais em municípios com mais de 200.000 habitantes ou a depender do gestor local. A equipe mínima para atendimento deve ser de 11 profissionais (nível médio e superior). Funcionam durante os 5 dias úteis da semana, das $8 \mathrm{~h}$ às $18 \mathrm{~h}$, podendo comportar um $3^{\circ}$ turno (18h as $21 \mathrm{~h}$ ) (Brasil, 2002).

O CAPSad II é especializado no atendimento de pessoas que fazem uso prejudicial de álcool e outras drogas em cidades com mais de 70.000 habitantes. A equipe mínima para atendimento deve ser de 13 profissionais (nível médio e superior). Funcionam durante os 5 dias úteis da semana, das $8 \mathrm{~h}$ às $18 \mathrm{~h}$, podendo comportar um $3^{\circ}$ turno (18h as 21h) (Brasil, 2002).

Os CAPS devem ser um ambiente facilitador, estruturado e acolhedor, abrangendo várias modalidades de tratamento, onde cada usuário deverá ter seu Plano Terapêutico Individual - PTI, ou seja, um conjunto de atendimentos que respeite a sua particularidade, que personalize 0 atendimento de cada pessoa na unidade $\mathrm{e}$ fora dela e proponha atividades durante a permanência diária no serviço, segundo suas necessidades (Brasil, 2004b).

Além disso, todo CAPS deve possuir o Projeto Terapêutico do Serviço - PTS, o qual deve levar em consideração as diferentes contribuições técnicas dos profissionais dos CAPS, as iniciativas de familiares e usuários e o território onde se situa, com sua identidade, sua cultura local e regional (Brasil, 2004b).

Ainda de acordo com a portaria GM/MS 336/2002, o regime de tratamento poderá ser:

a) Intensivo: quando o usuário possui atendimento diário, oferecido quando a pessoa se encontra com grave sofrimento psíquico, em situação de crise ou dificuldades intensas no convívio social e familiar, precisando de atenção contínua;

b) Semi Intensivo consiste no atendimento ao usuário até 12 dias no mês, quando o sofrimento e a desestruturação psíquica da pessoa diminuíram, melhorando as possibilidades de relacionamento, mas a pessoa ainda necessita de atenção direta da equipe para se estruturar e recuperar sua autonomia;

c) Não Intensivo oferecido quando a pessoa não precisa de suporte contínuo da equipe para viver em seu território e realizar suas atividades na família e/ou no trabalho, podendo ser atendido até três dias no mês.

Todos os regimes de tratamento acima podem ser domiciliares (Brasil, 2004). 
Como características de atendimento, o CAPSad II deve:

a) constituir-se em serviço ambulatorial de atenção diária, de referência para área de abrangência populacional definida pelo gestor local;

b) sob coordenação do gestor local, responsabilizar-se pela organização da demanda e da rede de instituições de atenção a usuários de álcool e drogas, no âmbito de seu território;

c) possuir capacidade técnica para desempenhar o papel de regulador da porta de entrada da rede assistencial local no âmbito de seu território e/ou do módulo assistencial, definido na Norma Operacional de Assistência à Saúde (NOAS), de acordo com a determinação do gestor local;

d) coordenar, no âmbito de sua área de abrangência e por delegação do gestor local, as atividades de supervisão de serviços de atenção a usuários de drogas, em articulação com o Conselho Municipal de Entorpecentes;

e) supervisionar e capacitar as equipes de atenção básica, serviços e programas de saúde mental local no âmbito do seu território e/ou do módulo assistencial;

f) realizar, e manter atualizado, o cadastramento dos pacientes que utilizam medicamentos essenciais para a área de Saúde Mental regulamentados pela Portaria/GM/MS no 1.077, de 24 de agosto de 1999, e medicamentos excepcionais, regulamentados pela Portaria/SAS/MS № 341, de 22 de agosto de 2001, dentro de sua área assistencial;

g) manter de 2 (dois) a 4 (quatro) leitos para desintoxicação e repouso.

Quanto a assistência prestada ao paciente, o CAPSad II inclui as seguintes atividades:

a) atendimento individual (medicamentoso, psicoterápico, de orientação, entre outros);

b) atendimento em grupos (psicoterapia, grupo operativo, atividades de suporte social, entre outras);

c) atendimento em oficinas terapêuticas executadas por profissional de nível superior ou nível médio;

d) visitas e atendimentos domiciliares;

e) atendimento à família; 
f) atividades comunitárias enfocando a integração do dependente químico na comunidade e sua inserção familiar e social;

g) os pacientes assistidos em um turno (4 horas) receberão uma refeição diária; os assistidos em dois turnos (8 horas) receberão duas refeições diárias;

h) atendimento de desintoxicação.

De acordo com os dados do Ministério da Saúde - MS (2015), até dezembro de 2014, o Brasil contava com 2209 CAPS em funcionamento, destes, 378 são CAPSad (309 CAPSad II e 69 CAPSad III). A cobertura nacional é de 0,86 CAPS/100 mil habitantes, a qual é considerada muito boa (Brasil, 2015).

Ao analisarmos a cobertura no estado do Amapá, o MS (2015) avalia como 0,47 CAPS/100mil habitantes, a qual é considerada regular/baixa. Constam cadastrados 3 CAPS: 1 CAPSi, 1 CAPSad II e 1 CAPSad III. (Brasil, 2015)

\subsection{O CAMPO DE AVALIAÇÃO EM SERVIÇOS DE SAÚDE MENTAL}

A avaliação no campo da saúde se constitui de uma prática antiga, sendo os primeiros estudos datados por volta de 1910, os quais foram direcionadas à prática médica e ao controle do exercício profissional. Entretanto, foi somente após a segunda guerra que essas avaliações se expandiram, em virtude de monitorar a eficácia dos recursos e da tecnologia investidos na área da saúde pelo Estado (Adami; Maranhão, 1995; Contandriopoulos, 2006).

Avaliar consiste em julgar valores a respeito de uma intervenção ou sobre qualquer um de seus componentes, com o objetivo de ajudar na tomada de decisões e consequentemente na busca pela qualidade do serviço prestado (Contandriopoulos et al, 1997). Assim, o conceito de qualidade nos serviços de saúde adquire características próprias, pois o produto/serviço (assistência à saúde) é consumido no ato de sua produção (Dias; Ramos; Costa, 2010).

No geral, a qualidade do produto/serviço em saúde é avaliada por meio da satisfação dos usuários, o que a torna fator essencial na sobrevivência das organizações. Nesse sentido, a criação de indicadores de desempenho institucional é extremamente importante para a avaliação da qualidade, uma vez que proporciona mensurar, monitorar e identificar oportunidades de melhoria de serviços e de 
mudanças positivas em relação ao alcance da qualidade a um custo razoável (D’innocenzo; Adami; Cunha, 2006).

O campo de avaliação em saúde pode ser delimitado em três grandes grupos: a avaliação tecnológica que está ligada na segurança, efetividade e custo de tecnologias de produto ou de processos; a avaliação de programas que está ligada em conjuntos articulados de atividades voltados para uma população alvo; e a avaliação de qualidade que está ligada em serviços assistenciais de saúde (Nemes, 2001).

A incorporação dos diferentes pontos de vistas dos diferentes tipos de atores (profissionais de saúde, gestores, os planejadores, o mercado e a política), ocasionam um dos principais desafios no processo de avaliação em serviços de saúde, por não conseguirem chegar a um consenso quanto a pertinência dos resultados que a avaliação produz. Desta forma, é necessário a criação de condições para um julgamento avaliativo verdadeiramente crítico, com a implementação de estratégias que favoreçam a formação e o aprendizado, o debate, a reflexão e a abertura de novas frentes de intervenção (Contandriopoulos, 2006).

Nesse contexto, é necessário implantar e institucionalizar as avaliações em todos os níveis de sistema de saúde, estabelecendo assim uma verdadeira cultura de avaliação na intenção de verificações contínuas da qualidade dos serviços (Contandriopoulos, 2006).

Dentre os serviços de saúde, o campo da saúde mental, de maneira geral, não possui tradição em avaliação, em comparação com outras áreas de atenção à saúde. Avaliar a extensão de cobertura, de números de consultas, internações e procedimentos laboratoriais, por si só, não parece satisfazer critérios de boa qualidade em saúde mental (Oliveira et al, 2014). É necessária uma abordagem qualitativa que contemple a pluralidade e interdisciplinaridade das relações entre intersubjetividade, gestão, formação profissional e clínica (Campos et al, 2009).

Nesse cenário, os processos avaliativos adquirem função política de servir como instrumento de potencialização das práticas substitutivas ao modelo hospitalocêntricos tradicional, a partir da reformulação e expansão do modelo assistencial em saúde mental (Wetzel; Kantorski, 2004).

A desinstitucionalização é um dos pilares do movimento da Reforma Psiquiátrica, que visa desconstruir todo o aparato manicomial que segrega e exclui os 
sujeitos envolvidos. A reinserção social e a garantia de cidadania são os preceitos dessa reforma, com vistas a melhorar a qualidade de vida dos usuários dos serviços de saúde mental

Logo, realizar avaliações da qualidade dos serviços de saúde mental torna-se essencial no sentido de apresentar as experiências cotidianas que envolvem tanto profissionais quanto os usuários e seus familiares, permitindo assim, retroalimentações com o objetivo de reverter e/ou minimizar entraves, bem como potencializar a assistência prestada (Costa; Colugnati; Ronzani, 2015).

Portanto, um processo avaliativo de Caps deve monitorar as ações, acompanhando a construção de um serviço que se proponha a atender a inserção do usuário com maior resolubilidade, com uma intervenção pautada na diversidade de saberes de uma equipe multiprofissional e na utilização de múltiplos recursos (Oliveira et al, 2014).

A avaliação da qualidade dos serviços de saúde mental está relacionada a diferentes fatores, como: estrutura física; compreensão dos profissionais acerca das necessidades do usuário; capacitação profissional; relação dos profissionais com os usuários; interação com a família; entendimento acerca da aplicabilidade de políticas públicas nos serviços e integração da rede de atenção primária à saúde, de acordo com que é preconizado pelo SUS (Oliveira et al, 2014).

Nos últimos anos, vem crescendo o número de estudos que avaliam os serviços de saúde mental no Brasil, tanto de forma qualitativa como quantitativa, trazendo em sua maioria, indicativos sobre a eficácia e efetividade das estratégias substitutivas.

Assim, com o intuito de descrever a estrutura física, recursos humanos e modalidades de atenção existentes nos centros de atenção psicossocial do município de São Paulo, estudos encontraram diferentes modelos de atenção psicossocial, desde a constituição de "equipamentos-síntese" dos quais os usuários não recebem alta, até serviços que encaminham e dão alta após a estabilização dos sintomas dos usuários, numa tentativa de construção de uma rede de cuidados (Nascimento; Galvanese, 2009).

Em estudo realizado nos CAPS III de Campinas, Campos et al (2009) identificaram pontos fortes e fragilidades no que concerne à atenção à crise, articulação com a rede básica, formulação de projetos terapêuticos, gestão e organização em equipes de referência, formação educacional e sofrimento psíquico. 
Tomasi et al (2010), observaram reduções significativas na ocorrência de crises, uso de medicamentos e número de internações psiquiátricas entre os usuários com maior tempo de CAPS e em atendimento intensivo. Entre os não intensivos, o uso de medicamentos também diminuiu e a participação em grupos e oficinas terapêuticas aumentou.

Nos estudos de Silva et al (2012), os usuários relataram melhoras em relação ao humor, problemas pessoais, interesse pela vida, autoconfiança, qualidade do sono, estabilidade emocional e capacidade de suportar situações difíceis.

Jaegger et al (2004), ao avaliarem o grau de satisfação de usuários de residências terapêuticas, observaram a importância destes dispositivos no cuidado e inserção comunitária.

Com o objetivo de apreender a dinâmica do serviço, a forma como os atores interagem e os sentidos que eles constroem em relação à sua prática em um CAPS de Porto Alegre, Schneider et al (2009), pode problematizar a atenção em saúde mental nesse CAPS, além de contribuir para o processo emancipatório dos sujeitos envolvidos.

Em outro estudo, os pesquisadores identificaram como premissas do serviço, a liberdade de ir e vir e a reabilitação psicossocial, considerando como principais características das novas tecnologias estudadas: o acolhimento, a escuta, o responsabilizar-se pela trajetória do indivíduo, e o plano terapêutico, que deve considerar a individualidade do sujeito e a inserção da família/comunidade (Kantorski; Machado; Oliveira, 2000).

Schmidt e Figueiredo (2009) propõem os eixos acesso, acolhimento e acompanhamento como elementos fundamentais para a análise da assistência e para a qualificação permanente dos serviços. Ressaltam ainda, que o acompanhamento se reafirma como um importante indicador em avaliação de qualidade de CAPS, ao mesmo tempo em que é balizador no cotidiano do trabalho em equipe.

Em um estudo que discutiu como se dá a avaliação das práticas de cuidar envolvendo arte no âmbito do CAPS, constatou-se que ainda não há uma uniformidade dos modos de avaliação das atividades que envolvem a arte (Tavares; Sobral, 2005).

Em âmbito geral, a maioria das pesquisas mostrou que os usuários e familiares apresentaram níveis de satisfação elevados com os serviços substitutivos. No geral, 
essa satisfação está atrelada ao cuidado integral, a forma acolhedora e humanizadora da escuta, a ruptura com o isolamento social, o estabelecimento de vínculos, melhoras nas condições clínicas e na qualidade de vida (Duarte; Kantorski, 2011; Kantorski et al, 2009; Surjus e Campos, 2011, Bandeira et al, 2011; Costa et al, 2011).

Neste campo de avalição em serviços de saúde mental, ainda são escassos os trabalhos que avaliam o CAPS ad, tornando assim relevante o desenvolvimento de pesquisas que estabeleçam indicadores para a avaliação desses serviços. 


\section{JUSTIFICATIVA}

Algumas iniciativas de estudos que tentam preencher um vazio teórico-técnico de como proceder na prática, com vistas a incluir usuários e familiares, como elementos articulados aos processos de planejamento e avaliação de serviços tem se justificado por conta do efetivo controle da população em relação aos serviços ofertados com base na definição de padrões de boa qualidade de serviços, a fim de que possam ampliar sua capacidade de exercer seus direitos de cidadania advogando suas necessidades.

À medida que a sobrevivência deixa de ser um desafio, e que os indivíduos reconhecendo-se como cidadãos, passam a requerer uma atenção à sua saúde de melhor qualidade, dimensões como custos, acesso, controle social e qualidade do cuidado prestado nos serviços de saúde, aparecem como prioridades para as políticas de saúde de países desenvolvidos.

No processo de trabalho em saúde, em que se trata de um lado, usuários, cuidadores e organizações de saúde e, de outro lado, resultado dessa equação expressa no cuidado produzido, pressupõe-se a urgência de conhecer esses componentes para que, munidos desse conhecimento, seja possível advogar a potencialização da qualidade social, tecnológica, política e econômica do que é recebido e produzido em cada território.

Os transtornos mentais associados ao uso prejudicial de álcool e outras drogas vêm agravando-se, como o do uso de crack que está em ascendência nos estados brasileiros. O fenômeno acontece em um cenário em que as respostas institucionais não se adaptaram às problemáticas apresentadas em estudos epidemiológicos existentes: uma precária rede de cuidados primários e intermediários inseridos na comunidade, em contraposição à excessiva oferta de leitos psiquiátricos, particularmente, para álcool e outras drogas e que tem crescente implantação, além de serviços não caracterizados como sendo de saúde, como as chamadas comunidades terapêuticas, mas, que são contratados por gestões estaduais e municipais.

Sendo assim, um processo avaliativo dos CAPSad deve levar em conta que os mesmos, de forma isolada e fora de uma estrutura em rede, podem dar respostas parciais não apenas em razão de suas limitações internas, mas também por não estarem inseridos em uma proposta política mais ampla. Na revisão da literatura 
brasileira, foram encontrados apenas 3 estudos avaliativos de CAPSad II e III, todos realizados na região sudeste.

Diante do exposto, o presente estudo se faz necessário, pela premência de se olhar para essas novas modalidades públicas de atenção, que estão sendo implantadas no País na última década, a fim de monitorar essas ações e aferir sua validade. Os proponentes entendem que a avaliação de serviços, por si só, assim como a gestão, as políticas e a prática não são suficientes para alavancar alguma mudança.

O sentido e a intensidade da determinação são modelados pelo funcionamento de um serviço que se propõe a atender e a inserir socialmente os usuários de álcool e outras drogas, com maior resolubilidade, com uma intervenção pautada na diversidade de saberes de uma equipe multiprofissional, em particular do professor de educação física, e na utilização de múltiplos recursos, capazes de assegurar ou desencadear melhores condições de saúde. 


\section{OBJETIVO GERAL}

Descrever e analisar os Centros de Atenção Psicossocial de Álcool e outras Drogas do estado do Amapá.

\subsection{OBJETIVOS ESPECÍFICOS}

1. Descrever e analisar a estrutura dos CAPSad do estado do Amapá;

2. Descrever e analisar o processo de trabalho e a organização da atenção em saúde mental oferecida pelos CAPSad do estado do Amapá

3. Descrever e analisar o resultado da atenção em saúde mental oferecida pelos CAPSad do estado do Amapá. 


\section{MÉTODOS}

Trata-se de uma pesquisa avaliativa, que utiliza de métodos quantitativos transversais, descritivos e exploratórios.

\subsection{PROCEDIMENTOS ÉTICOS}

Esse estudo faz parte de uma pesquisa matricial de avaliação dos CAPSad em três estados brasileiros: São Paulo, Minas Gerais e Amapá. Desta forma, o projeto de Avaliação dos CAPSad dos referidos estados foi submetido e aprovado pelo CEP EEUSP, com o no. 1.001/2011 (Anexo I).

Inicialmente foi solicitado aos Coordenadores de saúde mental do estado do Amapá e do município de Santana autorização para execução da pesquisa no interior dos CAPSad. Em seguida, os coordenadores, membros das equipes técnicas, usuários e familiares dos CAPSad de Macapá e Santana foram informados sobre a pesquisa, sendo-lhes entregue uma carta explicativa, e posteriormente foi solicitado a assinatura do Termo de Consentimento Livre e Esclarecido (TCLE) pelos participantes. (Apendice I).

A carta explicativa acerca do estudo continha: o título; objetivos; relevância para sua execução; a isenção de ônus financeiro ou sanções a quem não desejar participar ou que desistir de participar, durante sua execução. (Apendice II).

Após a obtenção dos TCLEs dos participantes deu-se início à coleta de dados.

\subsection{PERÍODO DE REALIZAÇÃO DO ESTUDO E LOCAIS ONDE FOI REALIZADO}

O estudo foi realizado entre os anos de 2013 e 2016, sendo a coleta de dados realizada nos CAPSad do Estado do Amapá, totalizando assim, 2 CAPSad devidamente credenciados no Ministério da Saúde.

Os CAPSad estão localizados no município de Macapá (Espaço Acolher) e Santana (Espaço Vida Viva), sendo o período da coleta de dados entre agosto de 2014 a junho de 2016. 


\subsection{AMOSTRA}

Os CAPSad do Amapá possuem no total 36 trabalhadores (28 no CAPSad Macapá, e 11 no CAPSad Santana), sendo entrevistados todos que estavam dentro do critério de inclusão. Foram entrevistados os trabalhadores da equipe de limpeza, manutenção e equipe clínica dos CAPS, resultando em uma amostra final de 32 trabalhadores (24 CAPSad Macapá e 8 CAPSad Santana). Considerou-se perda, os trabalhadores que se recusaram a participar da pesquisa, além dos que possuíam menos de um ano no serviço.

Com os usuários, foi utilizada uma amostra aleatória com reposição para os 2 serviços. Foram sorteados 30 usuários em cada serviço. Após 5 tentativas de contato com os usuários, caso não fosse possível o contato, foi considerada perda e realizouse novo sorteio para reposição, chegando a uma amostra final de 60 usuários nos dois serviços.

Com os familiares, foi solicitado a cada um dos 60 usuários que indicassem um amigo ou familiar para participar da pesquisa. Nos casos onde não quisessem indicar familiar ou caso o contato não fosse possível após 5 tentativas, considerou-se perda. A amostra total de familiares foi de 28 indivíduos.

\subsection{CRITÉRIOS PARA A INCLUSÃO E EXCLUSÃO DE PARTICIPANTES}

Para participarem do estudo, coordenadores e membros da equipe técnica dos CAPSad deveriam ter no mínimo um ano de trabalho no serviço. Foram excluídos, aqueles que estavam afastados por licença-médica, maternidade, prêmio e outros no período da coleta de dados.

Para estabelecer este período de um ano de trabalho no serviço, levou-se em consideração a justificativa dada por outro estudo avaliativo realizado nos CAPS dos Estados da Região Sul entre os anos de 2006 e 2009. Para aquele estudo, os autores consideraram que um profissional era técnico-cientificamente capacitado, quando estava inserido no processo de trabalho dos CAPS, há pelo menos um ano (Kantorski, 2007).

Foram considerados os seguintes critérios de inclusão para os usuários dos CAPSad: indivíduos com idades entre 18 e 65 anos e com capacidade cognitiva para responderem aos instrumentos; estarem cadastrados e participando das atividades dos CAPSad há no mínimo seis meses e; serem portadores de transtornos mentais 
graves e persistentes, decorrentes do uso abusivo e da dependência ao álcool e outras drogas.

\subsection{COLETA DE DADOS}

Após a assinatura do TCLE dos Coordenadores de saúde mental, os pesquisadores entraram em contato com as coordenações de CAPSad. Com a anuência do coordenador e a assinatura do TCLE, foram agendadas as visitas em dias e horários convenientes ao funcionamento dos serviços.

A coleta de dados, como já descrita, foi realizada em três etapas, realizada pelos pesquisadores, além de residentes em saúde mental treinados previamente pelos proponentes do projeto.

Para os coordenadores e profissionais, os formulários foram aplicados pelos pesquisadores do estudo, nos locais de trabalho de cada sujeito, com agendamento prévio. Os usuários e familiares foram entrevistados pelos pesquisadores nos CAPSad e nos domicílios sorteados para a amostra dos serviços e com agendamento.

Após cinco tentativas de entrar em contato com o usuário e familiar, e caso não conseguisse agendar horário ou caso o usuário e/ou familiar não comparecesse por cinco vezes no horário agendado, foram considerados "perdas" da amostra.

Foi realizada também a coleta de alguns dados referentes ao usuário de seu respectivo prontuário.

\subsection{INSTRUMENTOS DE COLETA DE DADOS}

Os instrumentos adaptados pelos pesquisadores após o estudo piloto foram previamente elaborados por autores de outro estudo (Kantorski, 2007). Os instrumentos foram construídos com base na Portaria $n^{\circ}$. 336/2002 do Ministério da Saúde e por meio das Escalas de Avaliação da Satisfação em Serviços de Saúde Mental -SATIS-BR (Bandeira; Pitta; Mercier, 2000, Bandeira et al, 2002, Bandeira; Silva, 2012), da Escala de Avaliação da Mudança Percebida - EMP (Mercier et al, 2004) e pela Escala de Atitudes frente ao álcool, alcoolismo e alcoolista - EAFA (Vargas, 2011). 
As Escalas de Avaliação da Satisfação em Serviços de Saúde Mental - SATISBR integram um conjunto de três escalas para avaliação de Serviços de Saúde Mental: Escalas de Avaliação da Satisfação dos usuários e familiares com os Serviços de Saúde Mental - SATIS-BR (Bandeira et al, 2002, Bandeira; Silva, 2012) e a Escala de Avaliação da Satisfação de Profissionais em Serviços de Saúde Mental - SATIS-BR (Bandeira; Pitta; Mercier, 2000)

Essas escalas foram elaboradas pela Divisão de Saúde Mental da OMS e posteriormente foram validadas para o Brasil por Bandeira e colaboradores entre 2000 e 2002 e atualizadas em 2012.

A Escala de Avaliação de Mudança Percebida (EMP) (Mercier et al, 2004) foi elaborada no Canadá e validada para uso no Brasil (Bandeira et al, 2009).

A Escala de Atitudes frente ao álcool, alcoolismo e alcoolista - EAFA foi construída em sua primeira versão em 2005 (Vargas, 2005). Esta escala foi construída com o objetivo de avaliar os principais grupos de atitudes dos profissionais de saúde frente ao álcool e ao alcoolismo (fator moral, fator doença, fator etiológico, fator profissional e fator humano) (Pillon; Laranjeira; Dunn, 1998). Diversos estudos de validação da escala mostraram valores elevados de consistência interna e validade, permitindo afirmar que 0 instrumento apresenta bons parâmetros psicométricos (Vargas, 2011).

\subsection{SELEÇÃO E TREINAMENTO DOS ENTREVISTADORES}

Para compor a equipe de entrevistadores, os pesquisadores optaram por residentes de educação física, na área de saúde mental, da Residência Multiprofissional em Saúde Coletiva da Universidade Federal do Amapá - UNIFAP.

Após esta seleção, foi realizado o treinamento com o objetivo preparar esses estudantes para o trabalho de campo quantitativo.

\subsection{ESTUDO PILOTO}

Como informado anteriormente, o presente estudo faz parte de uma pesquisa matricial de avaliação de CAPSad em três Estados. Assim, antes da realização da presente pesquisa, foi realizado um estudo piloto no CAPSad da Vila Madalena, no Estado de São Paulo, a fim testar o protocolo de pesquisa e eventuais modificações para o estudo principal. 
O estudo piloto foi realizado com os quatro segmentos: coordenador, trabalhadores, usuários (incluindo avaliação de prontuários) e familiares, aplicando-se todos os instrumentos, que resultaram em um relatório para apresentação e discussão das dificuldades encontradas. Embora este estudo tenha optado por utilizar os instrumentos propostos pelo AVALIA CAPS da região Sul do Brasil (Kantorski, 2007), não apresentavam especificidade para serem aplicados nos CAPSad, uma vez que naquele estudo, os CAPS avaliados foram do tipo I e II.

Após o estudo piloto, os instrumentos foram adaptados de modo a atender às necessidades e contrastes dos CAPSad.

O estudo piloto serviu também para treino referente à coleta de dados para os pesquisadores envolvidos no presente projeto.

O CAPSad da Vila Madalena, onde foi desenvolvido o estudo piloto foi desconsiderado para a coleta de dados da pesquisa, uma vez que a população utilizada no pré-teste não deve ser incluída na pesquisa, para evitar interferência nos resultados.

Durante o estudo piloto, percebeu-se a dificuldade em utilizar formulários de papel para a coleta e posteriormente confeccionar de forma manual os bancos de dados. Frente a isto, decidiu-se pelo uso de formulários eletrônicos. Para isso, utilizamos da plataforma Google Drive, que possui formulários eletrônicos que importam, à medida que os dados são coletados, todas as informações para um banco de dados em planilha.

\subsection{TRATAMENTO E ANÁLISE DOS DADOS}

Os bancos de dados para os trabalhadores, usuários e familiares exportados do Google Drive, foram processados utilizando o programa IBM Statistical Package for Social Sciences (SPSS), versão 20,0 para Windows ${ }^{\circledR}$.

Foi realizada uma análise descritiva dos dados, testes de médias e cálculos dos intervalos de confiança para cada uma das variáveis quantitativas. Com o objetivo de testar a hipótese de que os CAPSad são bem avaliados pelos usuários e seus familiares, os autores utilizaram a escala SATIS-BR e testamos as médias de respostas para cada um dos serviços. O escore é dado por meio das médias das 
respostas, e quanto mais próximo este valor de cinco, melhor é a satisfação (Bandeira et al, 2011).

Com o objetivo de analisar se os usuários e familiares perceberam mudanças após o tratamento no serviço, empregamos a escala de mudança percebida, e testamos as médias das respostas dos serviços. O escore é dado por meio das médias das respostas, e quanto mais próximo este valor de 3 , melhor é a percepção de mudança (Bandeira et al, 2011b). 


\section{RESULTADOS}

\subsection{CENTRO DE ATENÇÃO PSICOSSOCIAL DE ÁLCOOL E OUTRAS DROGAS: DESCRIÇÃO DOS SERVIÇOS}

\subsubsection{CAPSad Macapá}

O CAPSad de Macapá intitulado de "Espaço Acolher", possui natureza jurídica pública com administração direta, cadastrado e funcionando como CAPSad II em regime ambulatorial. É um serviço estadual administrado pela Secretaria Estadual de Saúde, através da Coordenação Estadual de Saúde Mental. Teve seu início em junho de 2011, funcionando apenas no turno diurno, de segunda a sexta das $8 \mathrm{~h}$ às $18 \mathrm{~h}$.

O serviço contempla acolhimento diurno, acesso livre dos usuários ou com hora marcada. Toda a equipe técnica de saúde incluindo os residentes em saúde mental e com exceção dos médicos faz acolhimento no serviço, o qual funciona através de uma escala.

No período de coleta dos dados, o serviço estava sem coordenação, a mesma estava sendo exercida pela coordenadora estadual de saúde mental (cargos acumulativos), entretanto como a mesma havia assumido a menos de um ano a função, não foi possível entrevista-la. O serviço possui projeto terapêutico institucional.

A equipe é composta da seguinte forma: 3 psicólogos, 1 terapeuta ocupacional, 2 médicos psiquiátricos, 2 médicos generalistas, 3 enfermeiros, 3 técnicos/auxiliar de enfermagem, 1 pedagogo, 1 assistente social, 1 farmacêutico, 10 técnicos administrativos e 1 funcionário de serviços gerais.

O número de pacientes inscritos ativos no serviço no período da coleta de dados foi de 243, com idades entre 17 anos e 6 meses a 80 anos

O serviço está alocado em uma casa alugada e adaptada para o funcionamento do CAPSad. A estrutura física do CAPSad Macapá se configura numa casa de médio/ porte, de apenas um piso, com aproximadamente $250 \mathrm{~m}^{2}$ de área construída sendo assim dividida: uma sala de recepção, uma sala para oficina, uma sala para realização de terapias de grupo, duas salas para atendimento individuais, uma sala de enfermagem, dois banheiros, uma sala de coordenação, uma sala para reunião de 
equipe, uma cozinha, e uma sala para farmácia. O espaço ainda dispõe de amplo quintal e varanda. Entretanto, não dispõe de leitos e nem sala para desintoxicação.

O serviço oferece café da manhã, almoço e lanche da tarde para os usuários.

Os prontuários ficam organizados na sala de reuniões em armários, não existindo registro digital dos pacientes. Para iniciar esta pesquisa, foi necessário fazer levantamento manual, por prontuário, para identificar cada um dos usuários, bem como seus endereços e contato telefônico.

O serviço possui uma pequena farmácia no próprio local. As medicações são dispensadas conforme indicação no prontuário, exclusivamente por recomendação médica.

Os critérios de acesso aos CAPSad são: ter acima de 17 anos e meio de idade e ter grau de dependência provável. Além disso, são inseridos no serviço pessoas em vulnerabilidade social além de demanda judicial.

Há atendimento à família, sendo ofertados orientação individual e grupal. Além disso, o serviço também realiza visitas domiciliares com o objetivo de busca ativa, tanto do usuário quanto do familiar (quando solicitado pelo paciente). O serviço possui um transporte compartilhado com a coordenadoria de saúde mental, o que geralmente ocasiona um choque de horários na hora de utilização do serviço.

O serviço conta com reuniões de equipe semanais, onde é discutido o caso dos usuários que são inseridos no serviço, seguido da elaboração do seu Projeto Terapêutico Singular (PTS), além da avaliação dos PTS dos usuários já inscritos no serviço.

O serviço não possui projetos de geração de renda e também não possui associação de usuários.

\subsubsection{CAPSad Santana}

O CAPSad de Santana intitulado de "Espaço Vida Viva", possui natureza jurídica pública com administração direta, cadastrado e funcionando como CAPSad II em regime ambulatorial. É um serviço municipal administrado pela Secretaria Municipal de Saúde de Santana, através da Coordenação Municipal de Saúde Mental de Santana. Teve seu início em 15 de setembro de 2005 funcionando apenas no turno diurno, de segunda a sexta das $8 \mathrm{~h}$ às $18 \mathrm{~h}$. 
O serviço está alocado em uma casa alugada para o funcionamento do CAPSad e possui projeto terapêutico institucional.

O serviço contempla acolhimento diurno, acesso livre dos usuários ou com hora marcada. Toda a equipe técnica de saúde (com exceção do professor de educação física e do médico) faz acolhimento no serviço.

A equipe é composta da seguinte forma: 1 médico psiquiátrico, 2 psicólogos, 2 assistentes sociais, 2 técnicos de enfermagem, 1 pedagogo e 1 educador físico, 1 técnico administrativo e 1 funcionários de serviços gerais. O número de pacientes inscritos ativos no serviço no período da coleta de dados foi de 129 , com idades entre 16 a 80 anos

A estrutura física do CAPSad Santana se configura numa casa de médio porte, de apenas um piso, com aproximadamente $220 \mathrm{~m}^{2}$ de área construída tendo: uma sala de recepção, uma sala de coordenação/administração, uma sala para atividades coletivas, duas salas para atendimento individuais, dois banheiros, uma cozinha. $\mathrm{O}$ espaço ainda dispõe de amplo quintal com piscina.

O serviço não possui sala e nem leitos de desintoxicação, e também não possui farmácia no local, além disso, não é ofertado alimentação para os pacientes.

Os critérios de acesso aos CAPSad são: ter acima de 17 anos e meio de idade e ter grau de dependência provável. Além disso, são inseridos no serviço pessoas em vulnerabilidade social além de demanda judicial.

Há atendimento à família, sendo ofertada orientação individual e grupal. O serviço também realiza visitas domiciliares com o objetivo de busca ativa, tanto do usuário quanto do familiar. O serviço possui um transporte para fazer esse serviço.

O serviço não possui projetos de geração de renda e também não possui associação de usuários.

\subsection{CARACTERIZAÇÃO DOS TRABALHADORES DOS CAPSAD DO ESTADO DO AMAPÁ}

Os resultados apresentados a seguir, referem-se aos dados sociodemográficos dos trabalhadores que compõem as equipes dos CAPSad do Estado do Amapá.

Há predominância do sexo feminino, de cor parda, solteiro e que se encontram na faixa etária de 30 a 39 anos. Quanto a escolaridade, a maioria dos trabalhadores 
possuem pós-graduação completa, com 1 (um) ano no serviço, carga horaria semanal de 30h, recebendo salários de 1 (um) a 3 (três) salários mínimos.

Tabela 1: Caracterização Trabalhadores

\begin{tabular}{|c|c|c|c|}
\hline & & $\mathrm{N}$ & $\%$ \\
\hline \multirow[t]{2}{*}{ Sexo } & Feminino & 18 & $56,2 \%$ \\
\hline & Masculino & 14 & $43,8 \%$ \\
\hline \multirow[t]{4}{*}{ Etnia: } & Branca & 3 & $9,4 \%$ \\
\hline & Indígena & 1 & $3,1 \%$ \\
\hline & Negra & 6 & $18,8 \%$ \\
\hline & Parda & 22 & $68,8 \%$ \\
\hline \multirow[t]{4}{*}{ Faixa etária } & $<30$ & 10 & $31,2 \%$ \\
\hline & $>50$ & 2 & $6,2 \%$ \\
\hline & 30 a 39 & 13 & $40,6 \%$ \\
\hline & 40 a 50 & 7 & $21,9 \%$ \\
\hline \multirow[t]{3}{*}{ Estado civil: } & casado/com companheiro & 15 & $46,9 \%$ \\
\hline & Divorciado & 1 & $3,1 \%$ \\
\hline & Solteiro & 16 & $50,0 \%$ \\
\hline \multirow{7}{*}{ Qual o seu maior grau de escolaridade? } & 1 -ensino médio incompleto & 1 & $3,10 \%$ \\
\hline & 2 - ensino médio completo & 3 & $9,40 \%$ \\
\hline & 3 - curso técnico completo & 2 & $6,20 \%$ \\
\hline & 4 - ensino superior incompleto & 5 & $15,60 \%$ \\
\hline & 5 - ensino superior completo & 3 & $9,40 \%$ \\
\hline & 6 - pós graduação incompleta & 3 & $9,40 \%$ \\
\hline & 7 - pós graduação completa & 15 & $46,90 \%$ \\
\hline (SATIS3). Há quanto tempo trabalha em & 1 ano & 21 & $65,6 \%$ \\
\hline \multirow[t]{2}{*}{ CAPS ad? } & Entre 2 a 4 anos & 10 & $31,2 \%$ \\
\hline & Entre 5 a 7 anos & 1 & $3,1 \%$ \\
\hline Há quanto tempo você trabalha neste & 1 ano & 22 & $68,8 \%$ \\
\hline \multirow[t]{2}{*}{ CAPS ad? } & Entre 2 a 4 anos & 9 & $28,1 \%$ \\
\hline & Entre 5 a 7 anos & 1 & $3,1 \%$ \\
\hline \multirow[t]{12}{*}{ Profissão } & Administrativo/Manutenção & 10 & $31,2 \%$ \\
\hline & Assistente Social & 2 & $6,2 \%$ \\
\hline & Educador físico & 1 & $3,1 \%$ \\
\hline & Enfermeiro & 4 & $12,5 \%$ \\
\hline & Farmacêutico & 1 & $3,1 \%$ \\
\hline & Massoterapeuta & 1 & $3,1 \%$ \\
\hline & Médico & 3 & $9,4 \%$ \\
\hline & Pedagogo & 2 & $6,2 \%$ \\
\hline & Psicólogo & 3 & $9,4 \%$ \\
\hline & Técnico/auxiliar de enfermagem & 4 & $12,5 \%$ \\
\hline & Terapeuta Ocupacional & 1 & $3,1 \%$ \\
\hline & 1 a 3 salários mínimos & 19 & $59,4 \%$ \\
\hline
\end{tabular}




\begin{tabular}{lllr} 
Qual foi o seu salário bruto no último mês, & 12 a 15 salários mínimos & 2 & $6,2 \%$ \\
no CAPS ad, incluindo horas extras (em & 4 a 7 salários mínimos & 9 & $28,1 \%$ \\
reais): & 8 a 11 salários mínimos & 2 & $6,2 \%$ \\
Qual a sua carga horária no CAPS ad? & 20 & 2 & $6,2 \%$ \\
& 30 & 18 & $56,2 \%$ \\
& 40 & 12 & $37,5 \%$ \\
\hline Total & & 32 & $100 \%$ \\
\hline
\end{tabular}

Fonte: CAPSad, Macapá-AP, 2017

Entre os trabalhadores, o sexo feminino obteve uma leve predominância com $56,2 \%$ e a raça/cor autodeclarada predominante foi a parda com $68,8 \%$, seguido de negros com $18,8 \%$.

Em relação a faixa etária, trabalhadores com idades entre 30 a 39 anos são a maioria $(40,6 \%)$, seguida dos que se encontram abaixo de 30 anos (31,2\%). Esses resultados nos mostram que os trabalhadores são adultos jovens, abaixo da meia idade. Já o estado civil obteve resultados mais equilibrados, solteiros representam $50 \%$, seguido dos casados com $46,9 \%$.

Quanto a escolaridade dos trabalhadores, $46,9 \%$ possui pós-graduação completa, $15,6 \%$ nível superior incompleto seguido por pós-graduação incompleta e nível superior completo ( $9,4 \%$ cada).

A maioria dos trabalhadores (65,6\%) possuem apenas 1 ano de experiência em CAPSad, e por terem tido essa experiência no mesmo CAPSad em que estão atuando, o tempo de serviço onde foi coletado os dados também foi de um ano $(68,8 \%)$.

Os dados referentes às funções exercidas pelos profissionais nos CAPSad do Amapá estão assim distribuídos: $31,2 \%$ exercem funções administrativas, seguidos de enfermeiros e técnicos/auxiliar de enfermagem (12,5\% cada), psicólogos e médicos $(9,4 \%$ cada), pedagogo e assistente social ( $6,2 \%$ cada), educador físico, farmacêutico e massoterapeuta ( $3,1 \%$ cada).

Observa-se que $59,4 \%$ dos trabalhadores receberam de 1 a 3 salários mínimos no último mês e $28,1 \%$ receberam de 4 a 7 salários mínimos. A carga horária nos CAPSad predominante foi de $30 \mathrm{~h}$ semanais $(56,2 \%)$ seguida por $40 \mathrm{~h}$ semanais (37,5\%).

Quanto ao vínculo empregatício, $50 \%$ são contratos emergências e os outros $50 \%$ são funcionários estatutários. 
A tabela a seguir apresenta os dados referentes à satisfação dos trabalhadores com o ambiente do serviço. Os itens avaliados pelos trabalhadores foram: ventilação, iluminação, higiene e área física.

Tabela 2: Satisfação com o Ambiente

\begin{tabular}{lllr}
\hline \multirow{2}{*}{ Ventilação adequada } & & $\mathrm{N}$ & $\%$ \\
& $\mathrm{Não}$ & 18 & $56,2 \%$ \\
\cline { 2 - 4 } Iluminação adequada & Sim & 14 & $43,8 \%$ \\
& $\mathrm{Não}$ & 20 & $62,5 \%$ \\
Higiene adequada & Sim & 12 & $37,5 \%$ \\
& Não & 16 & $50,0 \%$ \\
Área física adequada & Sim & 16 & $50,0 \%$ \\
& Não & 21 & $65,6 \%$ \\
\hline Total & Sim & 11 & $34,4 \%$ \\
\hline
\end{tabular}

Fonte: CAPSad, Macapá-AP, 2017

De acordo com 56, 2\% dos trabalhadores, os CAPSad não são adequados em relação à ventilação. Dentre as justificativas citadas, encontramos a falta de janela em alguns ambientes e a constante queima de aparelhos de ar condicionado, bem como a demora para consertá-los.

A iluminação também foi considerada inadequada pela maioria dos trabalhadores (62,5\%). Como justificativas, destacam-se a constante queima de lâmpadas e a não reposição das mesmas, além de novamente a falta de janelas que proporcionem luz natural para o ambiente.

O item área física também foi avaliado negativamente pela maioria dos trabalhadores (65,6\%), em especial os do CAPSad de Macapá que informaram a falta de espaço físico para as oficinas, bem como a estrutura física da casa inadequada, a qual segundo eles, encontra-se necessitada de inúmeros reparos.

Outro ponto bastante ressaltado pelos trabalhadores, foi a falta de manutenção no telhado da casa, o qual possui inúmeras goteiras, o que consequentemente ocasiona diversos problemas durante o período de chuva, inviabilizando o uso dos espaços. 
Tabela 3: Atendimentos individuais, grupais e atividades comunitárias

\begin{tabular}{|c|c|c|c|}
\hline & & $\mathrm{N}$ & $\%$ \\
\hline \multirow[t]{2}{*}{ Você realizou atendimentos individuais? } & Não & 4 & $12,5 \%$ \\
\hline & $\operatorname{Sim}$ & 28 & $87,5 \%$ \\
\hline \multirow[t]{6}{*}{ Quantos atendimentos individuais } & 0 & 4 & $12,5 \%$ \\
\hline & De 1 a 10 & 8 & $25,0 \%$ \\
\hline & De 11 a 40 & 13 & $40,6 \%$ \\
\hline & De 41 a 100 & 4 & $12,5 \%$ \\
\hline & Mais de 100 & 2 & $6,2 \%$ \\
\hline & Não sabe & 1 & $3,1 \%$ \\
\hline \multirow[t]{2}{*}{ Você realizou atendimentos em grupo? } & Não & 12 & $37,5 \%$ \\
\hline & Sim & 20 & $62,5 \%$ \\
\hline \multirow[t]{3}{*}{ Grupos (quantidade) } & 0 & 12 & $37,5 \%$ \\
\hline & De 1 a 10 & 13 & $40,6 \%$ \\
\hline & De 11 a 40 & 7 & $21,9 \%$ \\
\hline \multirow[t]{2}{*}{ Você participou de reuniões de equipe } & Não & 3 & $9,4 \%$ \\
\hline & Sim & 29 & $90,6 \%$ \\
\hline \multirow[t]{4}{*}{ Reuniões equipe (quantidade) } & 0 & 3 & $9,4 \%$ \\
\hline & De 1 a 5 & 21 & $65,6 \%$ \\
\hline & De 6 a 20 & 7 & $21,9 \%$ \\
\hline & De 21 a 30 & 1 & $3,1 \%$ \\
\hline Você participou de atividades & Não & 24 & $75,0 \%$ \\
\hline comunitárias? & $\operatorname{Sim}$ & 8 & $25,0 \%$ \\
\hline \multirow[t]{4}{*}{ Atividades comunitárias (quantidade) } & 0.0 & 24 & $75,0 \%$ \\
\hline & 1.0 & 6 & $18,8 \%$ \\
\hline & 2.0 & 1 & $3,1 \%$ \\
\hline & 5.0 & 1 & $3,1 \%$ \\
\hline \multicolumn{2}{|l|}{ Total } & 32 & $100 \%$ \\
\hline
\end{tabular}

Fonte: CAPSad, Macapá-AP, 2017

A realização de atendimentos individuais foi relatada por $87.5 \%$ dos trabalhadores, os quais realizaram em sua maioria (40,6\%) entre 11 a 40 atendimentos. Já os atendimentos grupais foram relatados por $62,5 \%$, variando de 1 a 10 atendimentos na maioria dos casos $(40,6 \%)$.

Destaca-se a participação de $90,6 \%$ dos trabalhadores nas reuniões de equipe, e $65,6 \%$ informaram que as mesmas ocorreram entre 1 a 5 vezes no último mês. Salienta-se que ambos os serviços possuem reuniões semanais de equipe, onde é analisado e discutido os casos dos pacientes. 
Quanto à estrutura organizacional de trabalho, $71,9 \%$ informaram que o serviço utiliza uma abordagem multiprofissional, 21,9\% indicaram a abordagem interdisciplinar e 6,2\% não souberam informar.

Já as atividades comunitárias foram realizadas por apenas $25 \%$ dos trabalhadores, sendo a participação em eventos da área, o mais citado.

Tabela 4: Condições de trabalho

\begin{tabular}{|c|c|c|c|}
\hline & & $\mathrm{N}$ & $\%$ \\
\hline Desde que você entrou neste & Melhoraram muito & 2 & $6,2 \%$ \\
\hline \multirow[t]{3}{*}{ emprego, as condições de trabalho: } & Melhoraram Pouco & 12 & $37,5 \%$ \\
\hline & Não mudaram & 9 & $28,1 \%$ \\
\hline & Pioraram & 9 & $28,1 \%$ \\
\hline Falta de ferramenta adequada para $o$ & Não & 7 & $21,9 \%$ \\
\hline trabalho & $\operatorname{Sim}$ & 25 & $78,1 \%$ \\
\hline \multirow[t]{2}{*}{ Falta de segurança } & Não & 5 & $15,6 \%$ \\
\hline & $\operatorname{Sim}$ & 27 & $84,4 \%$ \\
\hline \multirow[t]{2}{*}{ Risco permanente de vida } & Não & 13 & $40,6 \%$ \\
\hline & Sim & 19 & $59,4 \%$ \\
\hline \multirow[t]{2}{*}{ Outras situações que incomodam } & Não & 16 & $50,0 \%$ \\
\hline & $\operatorname{Sim}$ & 16 & $50,0 \%$ \\
\hline Pode escolher individualmente a & Não & 9 & $28,1 \%$ \\
\hline forma de fazer suas atividades & $\operatorname{Sim}$ & 23 & $71,9 \%$ \\
\hline Pode escolher de forma coletiva/em & Não & 1 & $3,1 \%$ \\
\hline $\begin{array}{l}\text { equipe a forma de fazer suas } \\
\text { atividades }\end{array}$ & \multicolumn{2}{|c|}{ atividades } & $96,9 \%$ \\
\hline \multirow[t]{2}{*}{ Pode fazer reuniões } & Não & 4 & $12,5 \%$ \\
\hline & $\operatorname{Sim}$ & 28 & $87,5 \%$ \\
\hline \multirow[t]{2}{*}{ Pode fazer cursos } & Não & 4 & $12,5 \%$ \\
\hline & Sim & 28 & $87,5 \%$ \\
\hline \multirow[t]{2}{*}{ Outras atividades de organização } & Não & 6 & $18,8 \%$ \\
\hline & $\operatorname{Sim}$ & 26 & $81,2 \%$ \\
\hline Pode conversar com os colegas & Sim & 32 & $100,0 \%$ \\
\hline \multirow[t]{2}{*}{ Pode usar suas ideias } & Não & 1 & $3,1 \%$ \\
\hline & $\operatorname{Sim}$ & 31 & $96,9 \%$ \\
\hline \multirow[t]{2}{*}{ Pode discutir casos com os colegas } & Não & 2 & $6,2 \%$ \\
\hline & Sim & 30 & $93,8 \%$ \\
\hline Total & & 32 & $100 \%$ \\
\hline
\end{tabular}

Fonte: CAPSad, Macapá-AP, 2017

As condições de trabalho também foram avaliadas pelos trabalhadores do serviço, desta forma, $43,7 \%$ declararam que houve melhorias (poucas melhorias 
$37,5 \%$ e muitas melhorias 6,2\%). Entretanto, 56,2\% informaram que não houve mudanças nas condições de trabalho, ou que as mesmas pioraram ( $28,1 \%$ cada).

A falta de ferramentas adequada para o trabalho foi informada por $78,1 \%$ dos trabalhadores, 84,4\% relataram a falta de segurança e ainda 59,4\% afirmam sofrer risco permanente de vida.

Dentro do item sobre outras situações que incomodam relatados por $50 \%$ dos trabalhadores, a falta de coordenador no serviço foi a mais citada. O CAPSad de Macapá sofre com a falta de uma pessoa na coordenação, bem como a alta rotatividade desde cargo, que geralmente é ocupado por indicação política.

A maioria dos trabalhadores afirma que podem escolher tanto individualmente $(71,9 \%)$ como coletivamente/equipe $(96,9 \%)$ a forma de fazer suas atividades. Se houver necessidade de solicitar reuniões, bem como fazer cursos, 87,5\% (cada) relataram ter liberdade para isso.

Todos os trabalhadores informaram que podem conversar com os colegas durante o serviço, e 96,9\% podem usar suas ideias além de discutir casos com os colegas quando necessário (93,8\%).

Tabela 5: Modalidades de Atendimento (Oficinas/atividades terapêuticas oferecidas nos CAPSad)

\begin{tabular}{lcrr}
\hline & & $N$ & $\%$ \\
\hline Grupos terapêuticos & Não & 1 & $3,1 \%$ \\
& Sim & 31 & $96,9 \%$ \\
Oficinas terapêuticas & Não & 3 & $9,4 \%$ \\
& Sim & 29 & $90,6 \%$ \\
Atendimento individual & Não & 1 & $3,1 \%$ \\
& Sim & 31 & $96,9 \%$ \\
Atividades na comunidade & Não & 12 & $37,5 \%$ \\
& Sim & 20 & $62,5 \%$ \\
Outras atividades não contempladas acima & Não & 24 & $75,0 \%$ \\
& Sim & 8 & $25,0 \%$ \\
& & 32 & $100,0 \%$ \\
\hline
\end{tabular}

Fonte: CAPSad, Macapá-AP, 2017 
Dentre as modalidades de atendimento, 96,9\% realizam grupos terapêuticos, $90,6 \%$ oficinas terapêuticas, $96,9 \%$ atendimento individual e $62,5 \%$ atividades na comunidade.

Dentre as oficinas terapêuticas ofertadas estão: as expressivas, culturais e atividades manuais/artesanais. Quanto aos grupos terapêuticos, os mais utilizados foram: atividades esportivas, grupos de leitura e debate, confecção de jornal, grupos de orientação geral, grupo de orientação para redução de danos, grupos de família e grupos culturais (música e teatro).

Tabela 6: Modalidades de atendimento individual (abordagens terapêuticas)

\begin{tabular}{lcrc}
\hline & & $N$ & $\%$ \\
\hline Consulta & & 4 & $12,5 \%$ \\
& Não & 15 & $46,9 \%$ \\
Entrevista Motivacional & Sim & 13 & $40,6 \%$ \\
& Não & 7 & $21,9 \%$ \\
Psicoeducação & Sim & 25 & $78,1 \%$ \\
& Não & 17 & $53,1 \%$ \\
Psicoterapias & Sim & 15 & $46,9 \%$ \\
& Não & 22 & $68,8 \%$ \\
Comunicação Terapêutica & Sim & 10 & $31,2 \%$ \\
& Não & 10 & $31,2 \%$ \\
Aconselhamento & Sim & 22 & $68,8 \%$ \\
& Não & 6 & $18,8 \%$ \\
Relacionamento terapêutico & Sim & 26 & $81,2 \%$ \\
& Não & 10 & $31,2 \%$ \\
Outros & Sim & 22 & $68,8 \%$ \\
& Não & 26 & $81,2 \%$ \\
\hline Total & Sim & 6 & $18,8 \%$ \\
\hline
\end{tabular}

Fonte: CAPSad, Macapá-AP, 2017

Em relação aos atendimentos individuais, os trabalhadores informaram que realizam as seguintes abordagens terapêuticas: consultas (40,6\%), entrevista motivacional $(78,1 \%)$, psicoeducação $(46,9 \%)$, psicoterapias $(31,2 \%)$, comunicação terapêutica $(68,8 \%)$, aconselhamentos $(81,2 \%)$, relacionamentos terapêuticos (68,8\%), além de $18,8 \%$ fazerem atendimento familiar, farmacoterapia, e reorientação ocupacional. 
Tabela 7: Retaguardas

\begin{tabular}{|c|c|c|c|}
\hline & & $\mathrm{N}$ & $\%$ \\
\hline Total & & 32 & $100 \%$ \\
\hline Há retaguarda para urgência & Não & 14 & $43,8 \%$ \\
\hline \multirow[t]{2}{*}{ psiquiátrica? } & Não sei & 2 & $6,2 \%$ \\
\hline & Sim & 16 & $50,0 \%$ \\
\hline Há retaguarda para urgência & Não & 13 & $40,6 \%$ \\
\hline \multirow[t]{2}{*}{ clínica? } & Não sei & 2 & $6,2 \%$ \\
\hline & Sim & 17 & $53,1 \%$ \\
\hline Como são indicadas as & A pedido da família & 2 & $6,2 \%$ \\
\hline internações para a dependência & A pedido do próprio usuário & 2 & $6,2 \%$ \\
\hline \multirow{6}{*}{$\begin{array}{l}\text { química dos usuários desse } \\
\text { serviço? }\end{array}$} & Após discussão de caso em & 17 & $53,1 \%$ \\
\hline & reunião de equipe & & \\
\hline & Discussão em equipe ou pelo & 1 & $3,1 \%$ \\
\hline & médico & & \\
\hline & Pelo médico & 8 & $25,0 \%$ \\
\hline & Por via judicial & 2 & $6,2 \%$ \\
\hline
\end{tabular}

Fonte: CAPSad, Macapá-AP, 2017

A existência de retaguarda para urgências psiquiátricas foi relatada por $50 \%$ dos trabalhadores. Ressalta-se que dentre os trabalhadores do CAPSad Santana, nenhum relatou retaguarda para o referido serviço. Os trabalhadores do CAPSad Macapá informaram que a retaguarda do mesmo é o Hospital de Emergência do Estado, o qual encontra-se a uma quadra do serviço.

Quanta a existência de retaguarda para urgência clínica, 53,1\% dos trabalhadores informaram que a mesma existe, sendo novamente o Hospital de Emergência do Estado, o local indicado. A não existência de retaguarda para este tipo de urgência foi informado novamente por todos os trabalhadores do CAPSad Santana.

As indicações para internações dos usuários do serviço ocorrem normalmente após discussão de caso em reunião de equipe $(53,1 \%)$, seguida por indicação médica (25\%).

De acordo com os trabalhadores, além do consumo e dependência de AOD, bem como o impacto que isto ocasiona na vida do usuário, o critério de inclusão no serviço está relacionado também à vulnerabilidade social e demanda judicial.

Os critérios de alta do serviço mais apontados pelos trabalhadores são: a melhora nas condições globais de vida do usuário $(56,25 \%)$ e a interrupção total do consumo de AOD (25\%). 
Segundo os trabalhadores, é considerado abandono do serviço, quando os usuários não comparecem ao CAPSad por 60 dias consecutivos $(56,25 \%)$ e por 30 dias consecutivos $(21,87 \%)$.

Dentre os modelos de assistências utilizada no serviço, $59,37 \%$ dos trabalhadores informaram que o serviço utiliza tanto a abstinência total quanto a redução de danos, já $31,25 \%$ disseram q a modalidade adotada pelo serviço é a redução de danos.

A realização de busca ativa pelo serviço foi constatada por $71,87 \%$, sendo essas buscas realizadas tanto por contato telefônico como visitas domiciliares. Ao realizarem as buscas, os trabalhadores relataram que o motivo mais encontrado para o abandono do tratamento pelos usuários foi: a desistência do tratamento $(71,87 \%)$, o retorno do usuário às atividades sociais $(65,62 \%)$, a internação em hospitais ou comunidades terapêuticas $(56,25 \%)$ e melhora do quadro segundo a percepção do usuário (46, 87\%).

Apesar de o serviço ofertar a busca ativa, $68,75 \%$ dos trabalhadores relatou que no último mês não fizeram nenhuma visita domiciliar, e entre os motivos para este fato estão: a falta de veículos, a falta de demanda e por acreditar que esta não é a sua função.

Ainda segundo $62,5 \%$ dos trabalhadores, não existem ações no campo de geração de renda, e dentre os motivos elencados para justificar tal fato está a falta de parceria com outras instituições, além da falta de ferramentas para implementação de projetos nessa área.

Quanto a estrutura organizacional de trabalho, $71,87 \%$ dos trabalhadores informaram que foi adotada a abordagem multidisciplinar.

\subsubsection{Satisfação do Trabalhador}

Para avaliar a satisfação dos trabalhadores dos CAPSAad do Amapá, utilizouse a escala SATIS-BR, seguindo as questões validadas no Brasil por Bandeira, Pitta e Mercier (2000). A aplicação da escala, visava identificar o quadro global de satisfação, conforme os fatores da escala global apresentados na tabela abaixo. 
Tabela 8: Satisfação do trabalhador $(n=32)$

\begin{tabular}{lcc}
\hline & Média & Desvio Padrão \\
\hline Qualidade dos serviços & 3,65 & 0,50 \\
Participação da equipe no serviço & 3,67 & 0,46 \\
Condições de trabalho & 3,33 & 0,37 \\
Relacionamento no serviço & 3,90 & 0,48 \\
Satisfação Global & 3,55 & 0,37 \\
\hline
\end{tabular}

Fonte: CAPSad, Macapá-AP, 2017

O fator 1 da escala avalia a satisfação da equipe com relação à qualidade dos serviços oferecidos aos usuários, obtendo a média de 3,65 (dp 0,50), sendo esta média semelhante a obtida no fator 2 que avalia a satisfação da equipe com relação à sua participação no serviço, 3,67 (dp 0,46).

$O$ fator 3 que avalia a satisfação da equipe com relação as condições de trabalho no serviço foi a que obteve a média mais baixa, 3,33 ( $d p$ 0,37) e o fator 4 que avalia a satisfação da equipe a respeito do seu relacionamento no serviço foi o que obteve a média mais alta, 3,90 (dp 0,48).

De uma forma global, todos os itens foram avaliados como intermediários, com a média geral de 3,55 (dp 0,37), em uma escala tipo likert de 1 a 5 .

A tabela a seguir apresenta os escores obtidos na EAFAAA como um todo e cada um dos fatores da escala pelos profissionais dos CAPSad do Amapá que responderam à pesquisa $(n=32)$.

Tabela 9: Escala de Atitudes Frente ao Álcool, Alcoolismo e Alcoolista. $(\mathrm{n}=32)$

\begin{tabular}{lcccccc}
\hline & Média & $\begin{array}{c}\text { Desvio } \\
\text { Padrão }\end{array}$ & $\begin{array}{c}\text { Escore } \\
\text { mínimo } \\
\text { possível }\end{array}$ & $\begin{array}{c}\text { Escore } \\
\text { mínimo } \\
\text { observado }\end{array}$ & $\begin{array}{c}\text { Escore } \\
\text { máximo } \\
\text { possível }\end{array}$ & $\begin{array}{c}\text { Escore } \\
\text { Máximo } \\
\text { observado }\end{array}$ \\
\hline FATOR 1 & 3,72 & 0,58 & 1 & 1,85 & 5 & 4,65 \\
FATOR 2 & 3,66 & 0,90 & 1 & 1,40 & 5 & 5,00 \\
FATOR 3 & 2,67 & 0,60 & 1 & 1,73 & 5 & 4,27 \\
FATOR 4 & 3,19 & 0,76 & 1 & 1,44 & 5 & 4,44 \\
GLOBAL & 3,38 & 0,49 & 1 & 2,14 & 5 & 4,12 \\
\hline
\end{tabular}

Fonte: CAPSad, Macapá-AP, 2017

O escore da atitude geral da EAFAAA teve média de 3,38 (dp 0,49), variando de 2,14 a 4,12 
O escore do fator 1 que avalia a atitude do trabalhador e o relacionar-se com o alcoolista, foi a que recebeu a melhor avaliação, com uma média de 3,72 (dp 0,58), com as respostas, variando de 1,85 a 4,65.

O escore do fator 2 que avalia as atitudes frente ao alcoolista teve uma média de 3,66 (dp 0,90), sendo esta a que obteve a maior variação de resposta, com médias entre 1,4 e 5.

O escore do fator 3 que avalia as atitudes frente ao alcoolismo (etiologia) teve a pior avaliação, tendo média de 2,67 (dp 0,60), com variação de médias de 1,73 a 4,27 , o que caracteriza uma tendência negativa frente às atitudes.

O escore do fator 4 que avalia as atitudes frente ao uso do álcool teve um média de 3,19 (dp 0,76), com variação de médias de 1,44 a 4,44.

Tabela 10: Supervisão, apoio e avaliação global do atendimento prestado

\begin{tabular}{|c|c|c|c|c|c|}
\hline & Média & Mediana & $\begin{array}{l}\text { Desvio } \\
\text { Padrão }\end{array}$ & Mínimo & Máximo \\
\hline $\begin{array}{l}\text { Supervisão pela secretaria } \\
\text { municipal de saúde }\end{array}$ & 3 & 3 & 2 & 0 & 8 \\
\hline $\begin{array}{l}\text { Supervisão pela coordenação } \\
\text { municipal de saúde mental }\end{array}$ & 4 & 4 & 3 & 0 & 10 \\
\hline Supervisão entre equipe: & 6 & 7 & 3 & 0 & 10 \\
\hline $\begin{array}{l}\text { Supervisão pela comunidade } \\
\text { em que atua: }\end{array}$ & 2 & 2 & 2 & 0 & 8 \\
\hline $\begin{array}{l}\text { Supervisão pela Organização } \\
\text { Social (parceira): }\end{array}$ & 2 & 2 & 2 & 0 & 9 \\
\hline $\begin{array}{l}\text { Apoio pela secretaria } \\
\text { municipal de saúde }\end{array}$ & 3 & 3 & 2 & 0 & 8 \\
\hline $\begin{array}{l}\text { Apoio pela coordenação } \\
\text { municipal de saúde mental }\end{array}$ & 4 & 4 & 3 & 0 & 9 \\
\hline Apoio entre equipe & 7 & 8 & 2 & 0 & 10 \\
\hline $\begin{array}{l}\text { Apoio pela comunidade em } \\
\text { que atua }\end{array}$ & 3 & 3 & 2 & 0 & 8 \\
\hline $\begin{array}{l}\text { De maneira global, qual a sua } \\
\text { avaliação do atendimento } \\
\text { prestado pelo CAPS ad? }\end{array}$ & 7 & 7 & 2 & 4 & 10 \\
\hline
\end{tabular}

A existência de supervisão nos CAPSad foi relatada por $75 \%$ dos trabalhadores, e a qualidade dessa supervisão foi mensurada em uma escala de 0 a 10, sendo 0 a ausência de supervisão e 10 como qualificada. 
A qualificação da supervisão exercida pelas Secretarias de Saúde (Estadual e Municipal) foi considerada baixa, com uma média de 3, variando entre 0 e 8.

As Coordenações de Saúde Mental (Estadual e Municipal) também obtiveram nota baixa, com uma média de 4 e variação entre 0 e 10.

A supervisão entre equipes foi a que obteve a nota mais alta, com a média de 6 e variação entre 0 e 10

A supervisão pela comunidade que atua, bem como por organizações sociais obteve as piores notas, com a média de 2 pontos.

Quanto ao apoio exercido, as Secretarias de Saúde e as Coordenações de Saúde Mental também obtiveram notas baixas, com média de 3 e 4 respectivamente. Já o apoio entre as esquipes recebeu a nota mais alta novamente, com a média de 7.

De maneira global, a avaliação do atendimento prestado pelo CAPSad, na visão dos trabalhadores, teve uma média de 7 (sete), e uma variação de 4 a 10 pontos.

Em relação à questão de existirem outros cuidados de que o usuário necessita, mas que não recebe no CAPSad, $81,25 \%$ dos trabalhadores referiram que com certeza há e especificaram os seguintes serviços: geração de renda, suporte profissional e social, salas para desintoxicação, funcionamento do CAPSad 24h e residência terapêutica. A oferta de alimentação também foi informada, entretanto apenas pelos trabalhadores do CAPSad Santana.

\subsection{Caracterização dos Usuários dos CAPSad do Amapá}

A seguir será apresentado os dados referente aos usuários dos CAPSad do Amapá. Inicialmente é apresentado os dados sociodemográficos, seguido dos dados relacionados a satisfação com o serviço e a escala de mudança percebida.

Tabela 11: Caracterização usuários

\begin{tabular}{|c|c|c|c|}
\hline & & $\mathrm{N}$ & $\%$ \\
\hline \multirow[t]{2}{*}{ Sexo } & Feminino & 10 & $16,7 \%$ \\
\hline & Masculino & 50 & $83,3 \%$ \\
\hline \multirow[t]{3}{*}{ Raça/cor } & Branco & 16 & $26,7 \%$ \\
\hline & Negro & 5 & $8,3 \%$ \\
\hline & Pardo & 39 & $65 \%$ \\
\hline \multirow[t]{3}{*}{ Faixa etária } & 20 a 30 & 10 & $16,7 \%$ \\
\hline & 31 a 40 & 23 & $38,3 \%$ \\
\hline & 41 a 50 & 12 & $20,0 \%$ \\
\hline
\end{tabular}




\begin{tabular}{|c|c|c|c|}
\hline & 51 a 60 & 11 & $18,3 \%$ \\
\hline & 61 a 70 & 4 & $6,7 \%$ \\
\hline \multirow[t]{4}{*}{ Estado Civil } & Casado ou vive com companheiro & 18 & $30,0 \%$ \\
\hline & Divorciado & 15 & $25,0 \%$ \\
\hline & Solteiro & 26 & $43,3 \%$ \\
\hline & Viúvo & 1 & $1,7 \%$ \\
\hline \multirow[t]{9}{*}{ Escolaridade } & Sem escolaridade & 2 & $3,3 \%$ \\
\hline & Ensino fundamental incompleto & 19 & $31,7 \%$ \\
\hline & Ensino fundamental completo & 8 & $13,3 \%$ \\
\hline & Ensino médio incompleto & 8 & $13,3 \%$ \\
\hline & Ensino médio completo & 14 & $23,3 \%$ \\
\hline & Curso técnico incompleto & 2 & $3,3 \%$ \\
\hline & Ensino superior incompleto & 3 & $5,0 \%$ \\
\hline & Ensino superior completo & 3 & $5,0 \%$ \\
\hline & Pós graduação completa & 1 & $1,7 \%$ \\
\hline Jornada de & Afastamento/Licença & 2 & $3,3 \%$ \\
\hline \multirow[t]{9}{*}{ Trabalho } & Aluguéis & 1 & $1,7 \%$ \\
\hline & Aposentado & 1 & $1,7 \%$ \\
\hline & Jornada integral remunerada & 11 & $18,3 \%$ \\
\hline & Jornada parcial remunerada & 4 & $6,7 \%$ \\
\hline & LOAS & 2 & $3,3 \%$ \\
\hline & não trabalha & 18 & $30,0 \%$ \\
\hline & Pensionista & 2 & $3,3 \%$ \\
\hline & seguro-desemprego & 1 & $1,7 \%$ \\
\hline & trabalho eventual & 18 & $30,0 \%$ \\
\hline \multirow[t]{4}{*}{ Renda Familiar } & Até 2 salários mínimos & 45 & $75,0 \%$ \\
\hline & Entre 10 a 20 salários mínimos & 1 & $1,7 \%$ \\
\hline & Entre 2 a 4 salários mínimos & 10 & $16,7 \%$ \\
\hline & Entre 4 a 10 salários mínimos & 4 & $6,7 \%$ \\
\hline Total & & 60 & $100 \%$ \\
\hline
\end{tabular}

Fonte: CAPSad, Macapá-AP, 2017

O sexo masculino constitui $83,3 \%$ dos usuários dos CAPSad do Amapá e a raça/cor autodeclarada predominante foi a parda com $65 \%$, seguido dos brancos com $26,7 \%$. Os usuários que se autodeclararam negros constituíram a minoria, com $8,3 \%$.

Usuários com idades entre 31 e 40 anos são a maioria (38,3\%), seguido dos que se encontram na faixa entre 41 a 50 anos (20\%). Percebe-se assim, uma população de usuários de pessoas adultas maduras, com a média de idade de 41,9 anos. 
Quanto ao estado civil, constatou-se que os solteiros constituem $43,3 \%$, seguido dos casados/companheiro (a) com $30 \%$ e divorciados com $25 \%$.

Os usuários possuem em sua maioria baixa escolaridade, apenas 6,7\% possuem curso superior, e a maioria $(31,7 \%)$ possui o ensino fundamental incompleto.

A renda familiar no último mês de $75 \%$ dos usuários não ultrapassou dois salários mínimos, sendo que $60 \%$ deles não trabalham ou realizam apenas trabalho eventual (30\% cada).

Tabela 12: Com quem mora

\begin{tabular}{lcc}
\hline & $\mathrm{N}$ & $\%$ \\
\hline filho(a) & 1 & $1,7 \%$ \\
cônjuge/companheiro & 4 & $6,7 \%$ \\
cônjuge/companheiro(a) e filhos & 14 & $23,3 \%$ \\
Família que Ihe acolheu & 1 & $1,7 \%$ \\
Filhos & 1 & $1,7 \%$ \\
mãe, pai & 2 & $3,3 \%$ \\
mãe, pai, irmãos & 17 & $28,3 \%$ \\
outro membro da família & 11 & $18,3 \%$ \\
sozinho(a) & 9 & $15,0 \%$ \\
\hline Total & 60 & $100,0 \%$ \\
\hline
\end{tabular}

Fonte: CAPSad, Macapá-AP, 2017

O quadro acima indica que 46,6\% vivem com algum membro da família, $28,3 \%$ vivem com os pais e irmãos e 18,3\% com outros membros da família e $23,3 \%$ moram com o cônjuge/companheiro (a).

Referente a ser ou não a primeira admissão no serviço, $58,3 \%$ afirmaram ser a primeira admissão;

Acerca do tempo que o usuário frequenta o serviço, 46,7\% afirmaram que frequentam entre 1 a 2 anos e 21,6\% frequentam entre 3 a 5 anos.

Em relação ao conhecimento do seu diagnóstico, 91,6\% dos usuários afirmaram que conhecem, e dentre os mais encontrados temos o uso do álcool com $55 \%$, uso de drogas com $51,6 \%$, uso de tabaco com $31,6 \%$, esquizofrenia com $13,3 \%$, transtorno depressivo maior com $11,6 \%$ e transtorno bipolar com 3,3\%

Observa-se um número elevado de usuários (43,3\%) que afirmam não ter conhecimento do seu Técnico de Referência (TR) no serviço, enquanto 56,7\% afirmam conhecerem o seu TR. 
De acordo com os dados obtidos, $80 \%$ dos usuários não participam do processo de avaliação das atividades e $88.4 \%$ estão de acordo e totalmente de acordo em participar.

\subsubsection{Satisfação do Usuário}

Para avaliar a satisfação do usuário com o serviço ofertado, foi utilizado a SATIS-BR, sendo os resultados apresentados na tabela a seguir, de acordo com as questões validadas no Brasil por Bandeira e Silva (2012).

Tabela 13: Satisfação dos usuários $(n=60)$

\begin{tabular}{lcc}
\hline & Média & Desvio Padrão \\
\hline Competência e Compreensão da & 4,14 & 0,12 \\
Equipe & & 0,25 \\
Ajuda recebida e Acolhida da equipe & 4,14 & 0,05 \\
Condições física e conforto do & 3,14 & \\
CAPSad & & 0,11 \\
FATOR 4 & 4,09 & 0,20 \\
\hline SATISGLOBAL & 3,98 & \\
\hline
\end{tabular}

Fonte: CAPSad, Macapá-AP, 2017

Os resultados encontrados permitem afirmar que a satisfação global recebeu uma avaliação positiva com a média 3,98 ( $d p$ 0,20), sendo a mesma repetida na maioria dos itens avaliados relacionados à satisfação, em uma escala tipo Likert de 1 a 5. Quanto maior a média, dos escores obtidos pelos pacientes, na aplicação da escala, maior é o seu grau de satisfação com o serviço.

O fator 1 da escala avaliou a satisfação dos usuários com relação à competência da equipe, além da capacidade de escuta dos profissionais e a compreensão dos mesmos a respeito do problema apresentado por ele. Tal fator foi avaliado com nota 4,14 (dp 0,12).

O fator 2 avaliou a satisfação do usuário com a ajuda recebida no serviço, a qualidade da acolhida dos profissionais, e o respeito e dignidade da equipe ao relacionar-se com o ele. A avaliação desse fator também obteve uma nota positiva, com a média de 4,15 (dp 0,25).

O fator 3 avaliou a satisfação do paciente com as condições física do serviço, incluindo o conforto, a aparência e as condições das instalações. Apesar de esse 
fator ter recebido uma nota mediana, foi o fator que obteve a nota mais baixa em relação aos outros, com a média de 3,14 (dp 0,05).

O fator 4 buscou comparar os resultados obtidos na SATIS-BR com os dados da CSQ-8 (Client Satisfaction Questionarie), que constitui uma escala padronizada de avaliação da satisfação dos usuários com os serviços de saúde mental, desenvolvida por Larsen, Attkisson, Hargreaves e Nguyen (1979). Essa comparação entre as respostas das escalas visa reavaliar constantemente a validade concomitante da escala utilizada no estudo. Assim, o referido fator obteve uma nota positiva, com uma média de 4,09 (dp 0,11).

Apesar da boa avaliação do serviço pelos usuários, 88,3\% deles afirmaram que o CAPSad pode ser melhorado. Os fatores indicados para a melhoria do serviço foram: estrutura física, contratação de mais profissionais, atendimento $24 \mathrm{~h}$, oferta de oficinas diversificadas.

Dentre os itens que os pacientes menos gostam nos CAPSad, a estrutura física foi a mais apontada, com $31,7 \%$, e dentre os itens que mais gostam, o atendimento foi o mais apontado com $53,3 \%$.

De acordo com os dados obtidos, $80 \%$ dos usuários não participam do processo de avaliação das atividades e $88.4 \%$ estão de acordo e totalmente de acordo em participar.

\subsubsection{Escala de Mudança Percebida na perspectiva do usuário}

Para avaliar a mudança percebida na perspectiva do usuário, foi utilizado a escala EMP-BR, sendo os resultados apresentados na tabela abaixo, de acordo com as questões validadas no Brasil por Bandeira et al (2011).

O instrumento utiliza uma escala tipo Likert de 1 a 3 , onde considera-se mudanças positivas o escore 3 , sem mudanças o escore 2 , e mudanças negativa 0 escore 1.

Tabela 14: Escala de Mudança Percebida dos Usuários $(n=60)$

\begin{tabular}{lcc}
\hline & Média & Desvio Padrão \\
\hline EMP GLOBAL & 2,68 & 0,06 \\
Atividade Física e Saúde & 2,67 & 0,07 \\
Aspectos Psicológicos e Sono & 2,70 & 0,07 \\
Relacionamento e Estabilidade & 2,66 & 0,04 \\
emocional & & \\
\hline Fonte: CAPSad, Macapá-AP, 2017 & &
\end{tabular}


De acordo com as respostas dos usuários, o escore médio para a mudança percebida obteve a média 2,68 (dp 0,06).

O fato que avalia as mudanças na dimensão "Atividade e Saúde Física”, obteve a média 2,67 (dp 0,07). Na dimensão "Aspectos Psicológicos e Sono" obteve a média 2,70 (dp 0,07), e a dimensão "Relacionamento e Estabilidade Emocional" obteve a média 2,66 (dp 0,04).

Os dados referentes às porcentagens de pacientes que perceberam melhoram após o início do tratamento também apresentam um resultado global alto. No total, $78,3 \%$ sentiram melhora na sua vida de maneira geral, desde o início do tratamento.

\subsection{Caracterização dos Familiares dos usuários dos CAPSad do Amapá}

A seguir será apresentado os dados referente aos familiares dos usuários dos CAPSad do Amapá. Inicialmente será apresentado os dados sociodemográficos, seguido dos dados relacionados a satisfação com o serviço e a escala de mudança percebida a partir da perspectiva do familiar do usuário.

Tabela 15: Caracterização dos Familiares

\begin{tabular}{llcc}
\hline & & $N$ & $\%$ \\
\hline Vínculo & Cônjuge & 9 & $32,1 \%$ \\
& Filhos & 3 & $10,7 \%$ \\
& Irmão & 3 & $7,2 \%$ \\
& Mãe & 2 & $42,8 \%$ \\
Pai & Sogra & 12 & $3,6 \%$ \\
Raça/ cor & Feminino & 1 & $3,6 \%$ \\
& Masculino & 1 & $85,7 \%$ \\
Faixa etária & Branca & 1 & $14,3 \%$ \\
& Negra & 24 & $10,7 \%$ \\
& Parda & 4 & $17,9 \%$ \\
& 19 a 30 & 3 & $71,4 \%$ \\
& 31 a 40 & 5 & $10,7 \%$ \\
& 41 a 50 & 20 & $10,7 \%$ \\
& 51 a 60 & 3 & $10,7 \%$ \\
& 61 a 75 & 3 & $32,2 \%$ \\
& Casado ou vive com companheiro & 22 & $35,7 \%$ \\
& Separado/divorciado & 2 & $78,7 \%$ \\
& Solteiro & 2 & $7,1 \%$ \\
& & 9 & $7,1 \%$ \\
\hline
\end{tabular}




\begin{tabular}{|c|c|c|c|}
\hline & Viúvo & 2 & $7,1 \%$ \\
\hline Se sim, até que série o (a) Sr. (a) & Sem escolaridade & 3 & $10,7 \%$ \\
\hline \multirow[t]{6}{*}{ estudou? } & Ensino fundamental incompleto & 6 & $21,4 \%$ \\
\hline & Ensino fundamental completo & 5 & $17,9 \%$ \\
\hline & Ensino médio incompleto & 2 & $7,1 \%$ \\
\hline & Ensino médio completo & 8 & $28,6 \%$ \\
\hline & Ensino superior completo & 1 & $3,6 \%$ \\
\hline & Pós Graduação completa & 3 & $10,7 \%$ \\
\hline O (a) senhor (a) tem trabalho & Não & 20 & $71,4 \%$ \\
\hline remunerado? & Sim & 8 & $28,6 \%$ \\
\hline Qual a renda da sua família no & Até 2 salários mínimos & 16 & $57,1 \%$ \\
\hline \multirow[t]{2}{*}{ último mês? } & Entre 2 a 4 salários mínimos & 12 & $42,9 \%$ \\
\hline & Total & 28 & $100 \%$ \\
\hline
\end{tabular}

Fonte: CAPSad, Macapá-AP, 2017

Entre os familiares dos usuários, as mães constituíram a maioria dos entrevistados, $42,8 \%$, seguidos dos cônjuges com $32,1 \%$, sendo a predominância do sexo feminino com $85,7 \%$.

De acordo com os dados encontrados, a maioria dos familiares tem acima de 50 anos, sendo $35,7 \%$ entre 61 e 75 anos e $32,2 \%$ entre 51 e 60 anos, e segundo a raça/cor, $71,4 \%$ se consideram pardos. Quanto o estado civil, os casados ou que vivem com companheiros (as) constituíram $78.7 \%$ da amostra.

Em relação ao grau de escolaridade, familiares com o ensino médio completo constituíram a maioria com $28,6 \%$, seguidos dos que possuem o ensino fundamental incompleto com $21,4 \%$.

Em se tratando de trabalho remunerado, $71,4 \%$ relataram não possuir. Quanto a renda familiar do último mês, $100 \%$ dos familiares não recebem mais do que 4 salários mínimos, sendo predominante $(57,1 \%)$ a renda de até 2 salários mínimos.

Em relação aos cuidados com o usuário, $57,1 \%$ dos familiares entrevistados informarem serem os únicos que cuidam, e 67,6\% se sentem sobrecarregados com esses cuidados. Ao serem questionados em quais situações eles se sentem mais sobrecarregados, foi relatado: quando o usuário está sob o efeito do álcool e/ou outras drogas e quando ele apresenta as crises de abstinência. 


\subsubsection{Satisfação dos Familiares dos Usuários}

Para avaliar a satisfação dos familiares dos usuários com o serviço ofertado, foi utilizado a SATIS-BR, sendo os resultados apresentados na tabela a seguir, de acordo com as questões validadas no Brasil por Bandeira et al (2002).

Tabela 16: Satisfação dos Familiares ( $\mathrm{n}=28)$

\begin{tabular}{lcc}
\hline & Média & Desvio Padrão \\
\hline SATISGLOB & 4,00 & 0,57 \\
Resultados do Tratamento & 4,04 & 0,81 \\
Acolhida e Competência da Equipe & 4,00 & 0,52 \\
Privacidade e Confidencialidade do serviço & 3,96 & 0,57 \\
\hline
\end{tabular}

Fonte: CAPSad, Macapá-AP, 2017

Os dados indicam que os familiares se mostraram satisfeitos com o serviço ofertado, com uma média global de 4 (dp 0,57), em uma escala tipo Likert de 1 a 5. Quanto maior a média, dos escores obtidos pelos pacientes na aplicação da escala, maior é o seu grau de satisfação com o serviço.

O fator 1 referente a "Resultados do Tratamento" recebeu a maior média, com 4,04 (dp 0,81). Entretanto, o fator 3 referente aos "Privacidade e Confidencialidade do serviço" foi o que recebeu a menor média com 3,96 (dp 0,57). O fator 2 com a média de 4 (dp 0,52) é referente a "Acolhida e Competência da Equipe".

Embora a avaliação global dos familiares ter sido positiva, 78,6\% informaram que este serviço poderia ser melhorado e citaram alguns pontos como: ampliação e melhorias na estrutura física, qualificação profissional dos trabalhadores, atendimento 24h e oferta de atividades para a qualificação profissional dos usuários.

Dentre os itens que os familiares mais gostam nos CAPSad, o atendimento foi o mais citado $(71,4 \%)$, em contrapartida, a estrutura física foi indicado como o que menos gostam nos CAPSad (50\%)

\subsubsection{Escala de Mudança Percebida na perspectiva dos familiares dos usuários.}

Para avaliar a mudança percebida na perspectiva do familiar, foi utilizado a escala EMP-BR, sendo os resultados apresentados na tabela abaixo, de acordo com as questões validadas no Brasil por Bandeira, Felício e Cesari (2010). 
O instrumento utiliza uma escala tipo Likert de 1 a 3 , onde considera-se mudanças positivas o escore 3 , sem mudanças o escore 2 , e mudanças negativa 0 escore 1.

Tabela 17: Escala de mudança percebida na perspectiva dos familiares

\begin{tabular}{lcc}
\hline & Média & Desvio Padrão \\
\hline EMPGLOB & 2,63 & 0,37 \\
Ocupação & 2,59 & 0,42 \\
Dimensão Psicológica & 2,68 & 0,37 \\
Relacionamentos & 2,66 & 0,47 \\
Saúde Física & 2,57 & 0,41 \\
\hline
\end{tabular}

Fonte: CAPSad, Macapá-AP, 2017

Pode-se observar que o escore médio global de percepção de mudança foi de 2,63 (dp 0,37). Os resultados das subescalas mostraram que as médias foram positivas, variando entre 2,57 e 2,68.

O fator 4 referente a "Saúde Física" foi a dimensão que obteve o escore mais baixo com 2,57 (dp 0,41). Já o fator 2 referente aos "Aspectos Psicológicos" foi o qual obteve a nota mais alta, 2,68 (dp 0.37).

O fator 1 referente a "Ocupação" e o fator 3 referente ao "Relacionamento" obtiveram as médias 2,59 (dp 0,42) e 2,66 (dp 0,47) respectivamente.

Os dados referentes às porcentagens de melhora dos usuários sob a perspectiva dos familiares após o início do tratamento também apresentaram resultado global elevado. No total, $82,1 \%$ perceberam melhoras no aspecto geral da vida de seu familiar, desde o início de tratamento. 


\section{DISCUSSÃO}

O Amapá possui atualmente dois CAPSad, sendo ambos cadastrados como CAPSad II, apesar do MS informar em seu relatório que o Estado possui um CAPSad III (Brasil, 2015). Desta forma, os horários de funcionamento dos CAPSad estão de acordo com o proposto na portaria GM/MS 336/2002.

A gestão dos serviços é diferente para cada CAPSad. Em Macapá, o serviço está subordinado ao Governo Estadual, enquanto o CAPSad de Santana à prefeitura do Município.

Ambos os serviços dispõem do acolhimento como atendimento inicial, sendo feito por todos os profissionais com exceção do médico (CAPSad Macapá e CAPSad Santana) e do professor de educação física (CAPSad Santana).

A Política Nacional de Humanização em suas diretrizes preconiza que o acolhimento deve ser feito por todos os profissionais do serviço, entretanto esta não é a realidade nos CAPSad do Amapá.

No geral, os médicos não fazem acolhimento por cumprirem sua carga horária apenas com atendimento individual. Isto se dá ao fato dos mesmos possuir duplo vínculo ou dividirem sua carga horaria em outros serviços de saúde. Quanto ao professor de educação física, lotado no CAPSad Santana, não foi justificado a sua não participação no acolhimento.

Ressalta-se a importância de todos os funcionários realizarem o acolhimento, pois este é um modo de desenvolver os processos de trabalho em saúde de forma a atender os usuários que procuram os serviços, ouvindo os seus pedidos e assumindo uma postura capaz de acolher, escutar e dar respostas mais adequadas aos usuários (Azevedo e Barbosa, 2007).

Em relação às infraestruturas dos serviços, o MS preconiza que a estrutura dos CAPSad seja compreendida da seguinte forma: recepção como espaço de acolhimento; salas de atendimento individualizado; salas de atividades coletivas; espaço de convivência; banheiros com chuveiro e com sanitário adaptado para pessoas com deficiência; sala de aplicação de medicamentos (sala de medicação) e posto de enfermagem; quarto coletivo com acomodações individuais (para acolhimento noturno com 02 camas) e banheiro (suítes); quarto de plantão (previsto apenas para CAPS 24h); sala administrativa; sala de reunião; almoxarifado; sala para arquivo; refeitório; copa (cozinha); banheiro com vestiário para funcionários; depósito 
de material de limpeza; rouparia; abrigo de recipientes de resíduos (lixo) e abrigo externo de resíduos sólidos; área externa para embarque e desembarque de ambulância; área externa de convivência (Brasil, 2013).

Os CAPSad do Amapá estão alocados em casas alugadas e adaptadas para o funcionamento do serviço. Entretanto, ambos possuem algumas deficiências em relação à estrutura física como: número insuficiente de salas para atender a demanda, falta de salas adequadas para realização de oficinas e realização de atividades grupais; os locais não são adaptados para pessoas com deficiência e, sobretudo, a inexistência em ambos os serviços tanto de sala como de leitos para a desintoxicação.

Em relação aos recursos humanos, a portaria GM/MS336/2002 afirma que os CAPSad II devem possuir a seguinte equipe: um médico psiquiatra; um enfermeiro com formação em saúde mental, um médico clínico; quatro profissionais de nível superior entre as seguintes categorias profissionais: psicólogo, assistente social, enfermeiro, terapeuta ocupacional, pedagogo ou outro profissional necessário ao projeto terapêutico; seis profissionais de nível médio dentre técnico e/ou auxiliar de enfermagem, técnico administrativo, técnico educacional e artesão (Brasil, 2002).

Ao compararmos a relação acima com as equipes técnicas dos CAPSad do Amapá, constata-se que o CAPSad Macapá condiz com as diretrizes propostas, tendo profissionais a mais do que é preconizado pela portaria, o que vem a ser um ponto forte do serviço. Entretanto o CAPSad Santana apresenta um quadro inadequado, sem a presença dos seguintes profissionais: médico generalista, enfermeiro, além de possuírem apenas 3 profissionais de nível médio.

Outro ponto que não condiz a portaria GM/MS 336/2002 é a não oferta de alimentação aos usuários do CAPSad Santana.

Um número bastante reduzido de oficinas e grupos terapêuticos é realizado no CAPSad Santana, havendo mais oferta de atendimentos individuais (consultas) do que atividades grupais.

Atividades de reabilitação psicossocial são preconizadas pelas portarias 3088/2011 e 130/2012, com o objetivo de resgatar e auxiliar a construção da autonomia, alfabetização ou reinserção escolar, acesso à vida cultural, autocuidado, manejo de medicação, inclusão pelo trabalho, ampliação de redes sociais, dentre outros. Além disso, atividades de geração de renda devem ser ofertadas por serem 
consideradas essenciais no tratamento, em especial no que diz respeito à reinserção no mercado de trabalho.

Entretanto, nenhum dos CAPSad promove atividades de geração de renda e nem possuem parcerias com outros serviços que possuam tais atividades, o que também pode ser considerado um ponto fraco dos serviços.

\section{TRABALHADOR}

Constatou-se a prevalência de trabalhadores do sexo feminino, na faixa etária de 30 a 39 anos, com nível superior e pós-graduação completa, o que nos indica uma população adulta com alto nível de escolaridade. Outros estudos nacionais que analisaram o perfil sócio demográfico dos trabalhadores de saúde mental encontraram resultados semelhantes (Kantorski et al, 2009b; Leal, Bandeira, Azevedo, 2012; Rebouças, Legay, Abelha, 2007). Além disso, os trabalhadores em sua maioria são solteiros, resultado semelhante ao de Camilo et al (2012).

Pode-se afirmar assim, que os profissionais destes serviços apresentam formação que segue as normativas das legislações vigentes (Brasil, 2004).

Os resultados encontrados informam que a maioria dos trabalhadores possuem pouco tempo no serviço, 1 ano. Este fato pode ser explicado pelo pouco tempo de funcionamento do CAPSad Macapá, sendo este o maior detentor de trabalhadores inseridos no estudo. Além disso, este serviço ao ser inaugurado, contou com trabalhadores de contratos temporários, os quais foram substituídos após concurso público ocorrido em 2012. Assim, os atuais trabalhadores foram inseridos no serviço após 2013, o que resultou em um tempo curto no serviço.

O CAPSad Santana, por possuir um tempo maior de existência, apresentou resultados onde os trabalhadores encontram-se a mais tempo no serviço, $62,5 \%$ deles estão a mais de dois anos no serviço.

Um dado importante a ser analisado é o vínculo empregatício dos funcionários. Constatou-se que $50 \%$ deles são oriundos de contratos temporários emergenciais. Este fato nos remete a pensar na rotatividade que o serviço está suscetível a sofrer, pois a cada mudança de gestor tanto estadual quanto municipal, geralmente há mudança no quadro dos funcionários de contratos temporários. 
Quanto a isso, Stancato e Zilli (2010) alertam para a importância dos serviços manterem certo equilíbrio nas taxas de rotatividade, pois uma movimentação excessiva, proveniente da intensificação de saídas de trabalhadores, provoca desequilíbrios na composição do quadro de pessoal, acarreta custos e, em última análise, impõe efeitos indesejáveis, tanto na qualidade como na quantidade dos serviços prestados.

Outros estudos também alertam sobre o problema da rotatividade, em especial em outros países como Estados Unidos, onde pesquisas demostram que de cada cinco a sete anos muda-se toda a força de trabalho em saúde mental (Blankertz; Robinson, 1997). Além disso, segundo Rebouças, Legay, Abelha (2007), indivíduos mais velhos possuem uma tendência mais acentuada a permanecerem no serviço.

Os profissionais lotados no serviço como técnicos administrativos/manutenção, constituíram a maioria dos trabalhadores, em especial no CAPSad Macapá. Os dados encontrados divergem de outros estudos, os quais os técnicos de enfermagem e psicólogos constituíram a maioria entre os trabalhadores de serviços de saúde mental (Prates, 2016; Clementino et al, 2016; Leal, Bandeira, Azevedo, 2012). Entretanto, pode-se observar que alguns profissionais técnicos administrativos participam das oficinas ministradas pelos profissionais de saúde, auxiliando-os. Tal fato pode ser considerado como desvio de função.

Os resultados obtidos quanto ao nível satisfação com o ambiente de trabalho demonstrou-se insatisfatório em relação à ventilação, iluminação e área física. Com relação à iluminação e a ventilação, tanto a estrutura física das casas não proporcionar luz e ventilação natural, quanto a falta de manutenção nos equipamentos foram indicados como os principais fatores dados à insatisfação. Dentre todos os itens, a área física obteve o índice mais elevados relacionados a insatisfação.

De Marco et al (2008) aponta que o nível de satisfação profissional poderia ser maior se houvessem mais investimentos para a melhoria da infraestrutura física dos serviços em geral como ter um local mais apropriado, limpo e agradável para atendimento dos usuários, ou seja, quantidade de salas e tamanhos adequados à demanda de pacientes.

A respeito disso, Braga, Torres e Ferreira (2015), afirmam que a precarização de espaço físico bem como da ausência de manutenção preventiva de equipamentos pode acarretar estresse ocupacional, devido à insatisfação vivenciada no cotidiano. 
Com relação às condições de trabalho, podemos perceber através dos resultados obtidos no estudo, que a maioria dos trabalhadores dos CAPSad $(56,2 \%)$ relataram a falta de melhorias bem como a piora nas condições de trabalho e outros $37,5 \%$ informaram que o serviço teve poucas melhorias.

Melhorias constantes nas condições de trabalho devem fazer parte das políticas institucionais dos serviços de saúde, pois de acordo com Medeiros et al (2006) as precárias condições de trabalho no serviço público geram sofrimento, pois o trabalhador se vê impotente em relação a qualidade da assistência prestada ao cliente gerando insatisfação e ainda um rompimento no seu processo de trabalho.

A falta de ferramenta adequada para realização do serviço e a falta de segurança foram itens apontados pelos trabalhadores dos CAPSad do Amapá. A respeito disso, Stancato e Zilli (2010) afirmam que um serviço deve ser equilibrado em relação ao quantitativo de funcionários, entretanto situações que gere condições de trabalho deficientes além de insegurança física, social, financeira e emocional ao profissional desencadeiam um elevado nível de stress e insatisfação, e uma baixa na qualidade de prestação do serviço ofertado à população.

De acordo com a portaria GM/MS 336/2002, os CAPSad II devem prestar assistência ao paciente a partir das seguintes atividades: atendimento individual (medicamentoso, psicoterápico, de orientação, entre outros); atendimento em grupos (psicoterapia, grupo operativo, atividades de suporte social, entre outras); atendimento em oficinas terapêuticas executadas por profissionais de nível superior ou nível médio, visitas domiciliares, atendimento à família; atividades comunitárias enfocando a integração do doente mental na comunidade e sua inserção familiar e social; pacientes assistidos em um turno (4h) receberão uma alimentação diárias; os assistidos em dois turnos (8h) receberão duas refeições diárias (Brasil, 2004).

Ao analisarmos os resultados da pesquisa, podemos concluir que os serviços possuem a maioria das atividades elencadas na portaria citada no parágrafo acima, entretanto, alguns pontos precisam ser discutidos. O primeiro ponto seria a não oferta de alimentação aos pacientes no CAPSad Santana. O segundo ponto seria a baixa inserção dos profissionais nas atividades junto à comunidade, apenas $25 \%$ o fazem. E quanto às visitas domiciliares, foi constatado que $68,75 \%$ dos profissionais não as fizeram no último mês. 
As visitas domiciliares são instrumentos para a realização de assistência no domicílio. É constituída pelo conjunto de ações sistematizadas para viabilizar o cuidado a pessoas com algum nível de alteração no estado de saúde (dependência física ou emocional) ou para realizar atividades vinculadas aos programas de saúde. Tal instrumento auxilia na adesão deste indivíduo ao serviço, indo além do acompanhamento do usuário, pois engloba também a família neste cuidado (Carvalho, Amaral e Magalhães, 2011; Brasil, 2004).

De acordo com Antunes et al (2012), a visita domiciliar possibilita que o profissional crie vínculo e parceria com a família e assim possa desenvolver as potencialidades de cada um de acordo com a sua singularidade. É durante a visita domiciliar que o profissional pode se inserir no contexto familiar e prestar assistência a todos os envolvidos, constituindo assim um momento no qual se estabelece vínculo através do acolhimento e da escuta qualificada, movimentando as relações.

Quanto à estrutura organizacional de trabalho, houve o predomínio de uma abordagem multiprofissional (71,9\%), em detrimento a abordagem interdisciplinar $(21,9 \%)$. Entende-se por abordagem multidisciplinar a justaposição de várias disciplinas em torno de um mesmo tema ou problema, sem o estabelecimento de relações entre os profissionais representantes de cada área no plano técnico ou científico. Já a abordagem interdisciplinar representa o grau mais avançado de relação entre áreas de conhecimento, se considerarmos o critério de real entrosamento entre elas, compartilhando de uma mesma plataforma de trabalho, operando sob conceitos em comum (Furtado, 2007).

As características organizacionais dos CAPSad no que se referem ao apoio tanto pelas Secretaria de Saúde (Estadual e Municipal) quanto pelas Coordenações de Saúde Mental (Estadual e Municipal) receberam avaliações negativas, com médias de 3 e 4 respectivamente. Quanto a isso, podemos inferir um dado preocupante, pois corroboramos com Siqueira e Gomide Junior (2008) ao postularem que quanto mais o trabalhador percebe o suporte da organização, mais se compromete com ela. Desta forma, o não recebimento de apoio e suporte organizacional desfavorece o desencadeamento de compromissos afetivos com o serviço e consequentemente com a qualidade da assistência.

A portaria GM/MS 1174/2005 instituiu a supervisão clínico-institucional para os CAPS. Neste sentido, a avaliação feita pelos trabalhadores a respeito da supervisão 
tanto pelas Secretarias de Saúde, quanto pelas Coordenações de Saúde Mental, obteve média baixa, 3 e 4 respectivamente. De acordo com o Art. 3 da portaria acima citada, a supervisão institucional tem o intuito de assessorar, discutir e acompanhar o trabalho realizado pela equipe, o projeto terapêutico do serviço, os projetos terapêuticos individuais dos usuários, as questões institucionais e de gestão do CAPS, além de outras questões relevantes para a qualidade da atenção realizada (Brasil, 2005).

Em relação à supervisão, Severo, L'abbate e Campos (2014) explicam que a supervisão institucional é um dos dispositivos usados para subverter as linhas de poder instituídas nos serviços, sendo assim, uma ferramenta de educação permanente. Ela precisa ser um espaço de resolução bem como de problematização, no qual não se impõem os ideais do supervisor e nem se desprivilegia o desejo e o conhecimento dos trabalhadores das equipes. A troca de saberes entre equipe $e$ supervisor é uma das variáveis que compõe o grau de satisfação do trabalhador com o serviço.

Um dos indicadores de qualidade dos serviços de saúde mental é o nível de satisfação dos profissionais que nele atuam (Borges et al, 2002). Uma avaliação positiva do profissional está relacionada a diversos aspectos do serviço como condições de trabalho, relacionamento com os colegas da equipe, qualidade do tratamento oferecido aos usuários, aspectos estruturais e organizacionais e participação e envolvimento nas decisões tomadas no serviço. Um baixo nível de satisfação pode afetar o relacionamento com os pacientes e interferir no próprio tratamento oferecido (Ishara, Bandeira e Zuardi, 2008).

A escala SATIS-BR é considerada como um importante indicador de qualidade dos serviços de saúde mental, pois a qualidade do atendimento prestado ao usuário está diretamente ligada a satisfação dos profissionais da equipe (Wykes et al, 1997, Bandeira, Ishara e Zuardi, 2007). Baixa satisfação no trabalho pode levar ao aumento da rotatividade de pessoal e aumento dos níveis de absenteísmo, o que pode reduzir a eficiência dos serviços de saúde (Santos et al, 2011).

Assim, o escore obtido neste estudo a partir da SATIS-BR indicou um nível de satisfação global intermediário, com média de 3,55 . Os outros fatores como a qualidade da assistência prestada ao usuário, a sua participação no serviço e as condições de trabalho, também obtiveram escores intermediários de satisfação. Esses 
resultados corroboram com os dados obtidos por Pitta (1996), Ishara (2007), De Marco et al (2008), Ishara, Bandeira e Zuardi (2008), Rebouças et al (2008), Santos et al (2011), Leal, Bandeira e Azevedo (2012), Barbosa (2013) e Pinho (2014).

A análise dos resultados obtidos com os fatores da escala SATIS-BR, permitiu identificar o fator "Relacionamento no Serviço" e como o maior escore obtido (3.90). Este fator avalia a satisfação do profissional a respeito do seu relacionamento com os colegas de trabalho e com seus superiores, além de avaliar sua satisfação quanto ao grau de autonomia em relação as outras pessoas no serviço.

O resultado encontrado neste estudo para o fator acima descrito corrobora com os achados nos estudos de Ishara (2007), Ishara, Bandeira e Zuardi (2008), Camilo et al (2012), Rebouças, Legay e Abelha (2007), Reid et al (1999) e Resende, Bandeira e Oliveira (2016) que também encontraram na relação com os colegas, e na autonomia que possuíam no serviço como a maior fonte de satisfação.

O fator "Participação da Equipe no Serviço" obteve o segundo maior escore $(3,67)$, o qual avalia a satisfação da equipe com relação aos seguintes aspectos: participação nas decisões tomadas no serviço, na implantação dos tratamentos e na avaliação do serviço, assim como na expressão de suas opiniões sobre o serviço, participação em discussões profissionais com os colegas, expectativa de ser promovido e seu grau de responsabilidade no serviço. Acredita-se que tal resultado possa estar associado à falta de coordenação direta no CAPSad Macapá (detentor de maior número de profissionais na amostra do estudo), o que implicava em uma coordenação conjunta, entre os trabalhadores do serviço.

Em contrapartida, o fator que avaliava a satisfação com as "Condições de Trabalho" obteve o menor escore $(3,33)$. Este fator avalia a satisfação da equipe de acordo com os seguintes aspectos: as condições gerais das instalações, os salários e benefícios recebidos, conforto e aparência do serviço, as medidas de segurança e confidencialidade em vigor no serviço, bem como o clima do ambiente no trabalho.

$O$ resultado encontrado neste estudo para o fator acima descrito, corrobora com os achados nos estudos de Camilo et al (2012), De Marco et al (2008), Ishara, Bandeira e Zuardi (2008), Rebouças, Legay e Abelha (2007), Ishara (2007) e Resende, Bandeira e Oliveira (2016), os quais também obtiveram o menor escore para o fator "Condições de Trabalho". Entretanto, contrasta com os estudos de Leal, Bandeira e Azevedo (2012) e Pinho (2014), os quais obtiveram os maiores escores para este fator. 
A satisfação com a "Qualidade do Serviço" oferecido obteve o segundo pior escore $(3,65)$. Este fator avalia os seguintes aspectos: o tratamento e os cuidados oferecidos aos pacientes, a maneira da equipe lidar com os pacientes, o grau de adequação dos serviços, a quantidade de informação dada ao paciente sobre sua doença e sobre o tratamento, o grau de competência profissional da equipe, a compreensão da equipe sobre os problemas e expectativas dos pacientes.

Para uma instituição atingir seus objetivos de excelência no atendimento e qualidade nos serviços prestados, é necessário ter profissionais satisfeitos e que gozem de boa qualidade de vida (De Marco et al, 2008).

A estrutura e as condições de trabalho são itens determinantes para a satisfação profissional. Quando ocorre de um trabalhador sentir-se insatisfeito, o mesmo pode afetar todo o clima organizacional do serviço, induzindo assim outros trabalhadores a adotarem uma postura semelhante, o que consequentemente ocasiona reflexos na assistência, com prejuízo na qualidade do serviço prestado.

As variáveis de atitudes frente ao álcool, alcoolismo e alcoolista também foram analisadas, a partir da EAFAAA. Apesar desta escala ter sido inicialmente elaborada e aplicada a estudantes e profissionais de enfermagem (Vargas, 2011b; Vargas e Luis, 2008; Vargas e Bittencourt, 2013; Vargas, Labate, 2006; Vargas, 2010), a mesma também já foi aplicada a estudantes de psicologia (Merces, 2013) e demais profissionais de saúde (Vargas, 2014).

Desta forma, constatou-se uma tendência de atitude positiva para o fator 1, o qual é atribuído à perspectiva "o trabalhar e o relacionar-se com o alcoolista" que teve a maior média $(3,72)$ entre os outros fatores. De acordo com Vargas (2005), este fator verifica a percepção, opiniões e sentimentos frente ao indivíduo alcoolista, bem como o trabalhar e o relacionar-se com o paciente. Estes dados contrapõem-se aos de Vargas (2011b) e Vargas e Bittencourt (2013), os quais encontraram atitudes negativas em seus estudos para este fator e corroboram com os de Barbosa (2013) e Prantes (2016) que encontraram atitudes positivas em seus estudos.

O fator 2 também obteve tendência de atitude positiva, sendo atribuído "as atitudes frente ao alcoolista", descrito por Vargas (2005), como o que está relacionado com o envolvimento de opiniões, sentimentos e percepções frente ao indivíduo alcoolista, destacando principalmente suas características físicas e psíquicas, bem como comportamentos e atitudes atribuídas a esse usuário. Os dados encontrados 
em estudo realizado com estudante de enfermagem divergem dos achados deste, pois se constatou que os estudantes tinham atitudes negativas ao se relacionar com alcoolistas, além de relatarem medo do comportamento agressivo e o não saber conduzirem o atendimento a um usuário de álcool (Vargas, 2011b). Já os estudos de Barbosa (2013) e Prantes (2016) obtiveram os mesmo resultados, com tendências positivas para este fator.

Atitude positiva frente ao fator acima descrito pode contribuir para que profissional que presta assistência em serviços de saúde reconheça no alcoolista alguém que está doente e precisa de ajuda e na internação em hospital geral um momento de crise e passível da intervenção, o que pode favorecer o estabelecimento do relacionamento entre profissional e paciente alcoolista (Vargas; Luiz 2008).

O fator 3 teve o pior escore no resultado desta pesquisa, com média de 2,67, tendendo a atitude negativa frente ao álcool, alcoolista e alcoolismo. Este fator referese à "atitude frente ao alcoolismo e a etiologia" (Vargas, 2005). As atitudes negativas quanto a etiologia pode comprometer o manejo com esses usuários, e isto pode estar associado a falta de preparo, reforçando o que os pesquisadores têm criticado quanto a ausência de qualificação e capacitação, tanto para os estudantes quanto para os profissionais da área da saúde (Vargas, 2011b; Merces, 2013; Vargas e Bittencourt, 2013). Os dados encontrados neste estudo foram semelhantes aos encontrados nos estudos de Merces (2013), Barbosa (2013) e Prantes (2016), que também obtiveram o menor escore para este fator.

O fator 4, "atitudes frente ao uso do álcool" que diz respeito às opiniões, aos sentimentos e às predisposições do profissional de saúde quanto aos custos psíquicos e sociais acarretados pelo uso/abuso do álcool envolvendo o indivíduo, a família e outras esferas de relacionamento pessoal, como o trabalho, amigos e outros obteve uma média intermediária, com tendência positiva, sendo o escore médio de 3,19.

Entretanto, o estudo de Vargas e Labarte (2006) revelou que enfermeiros de um hospital geral consideram o álcool como perigoso e nocivo, mesmo que usado socialmente. Além disso, concluíram que os profissionais veem o seu uso como moralmente incorreto, e isto pode atribuir ao indivíduo às causas e consequências de sua doença, uma vez que podem conceber que o paciente conhece os riscos oferecidos pelo uso do álcool. 
De uma forma global, os dados deste estudo tiveram como resultado um escore intermediário com uma média de 3,38, o que caracteriza uma tendência positiva em relação às atitudes frente ao álcool, alcoolismo e alcoolista, resultados semelhantes aos encontrados por Prantes (2016) e Barbosa (2013). Esta tendência positiva pode estar relacionada ao fato dos profissionais trabalharem em serviços especializados no cuidado de pessoas que fazem uso/abuso de álcool e outras drogas.

Resultados semelhantes foram encontrados por Pinikahana, Happell e Carta (2002), que revelaram atitudes positivas dos profissionais de saúde mental da cidade de Victória (Austrália), frente aos pacientes adictos. Os profissionais demonstraram reconhecer que a dependência de drogas e álcool são doenças tratáveis. Uma atitude positiva e mais otimista em relação às intervenções terapêuticas permite que os profissionais de saúde, prestem os cuidados necessários às pessoas que necessitam desse tipo de assistência.

Assim, de acordo com Soares, Vargas e Oliveira (2011), profissionais que possuem contato com pacientes alcoolistas, tendem, consequentemente, a apresentar mais habilidades do que aqueles que tiveram pouco ou nenhum contato com esse tipo de paciente, além de mostrarem atitudes mais positivas e melhor conhecimento sobre a temática.

\section{USUÁRIOS}

Os usuários dos CAPSad são predominantemente homens (83,3\%), pardos (65\%), solteiros (43,3\%) e com idades entre 31 a 40 anos $(38,3 \%)$.

Essa predominância de homens, solteiros e adultos (acima de 30 anos) foi encontrada em outros estudos que descreveram o perfil sociodemografico de usuários de AOD (Ferreira Filho et al, 2003; Passos e Camacho, 1998; Faria e Schneider, 2009; Monteiro et al, 2011; Capistrano et al, 2013; Oliveira, 2012; Peixoto et al, 2010, Guimarães et al, 2008, Barbosa et al, 2015). Entretanto, os dados deste estudo contrastaram com outros que evidenciaram a maioria de indivíduos brancos (Passos e Camacho, 1998; Ferreira Filho et al, 2003, Guimarães et al, 2008).

O predomínio do sexo masculino pode estar relacionado ao fato de que os homens são os mais atingidos pelo problema da dependência de AOD, o que consequentemente, os leva a procura por tratamento. Além disso, questões culturais, 
baseadas em preconceitos, fazem com que as mulheres procurem menos os serviços de atendimento a usuários de AOD, por razões como o estigma social em relação ao seu papel na sociedade e por conta do próprio perfil de usuário da mulher ser diferente do homem (Faria e Schneider, 2009; Elbreder et al, 2008; Oliveira, 2013).

Entretanto, em outros serviços de saúde mental, há a predominância do sexo feminino, uma vez que as mulheres sentem vergonha da doença, o que resulta no seu afastamento do tratamento (Peliosi e Moreira, 2005; Kantorski et al 2009, Monteiro et al, 2011).

Os adultos maduros na faixa etária de 31 a 40 anos, e média de idade de 41,9 anos, constituíram a maioria deste estudo, resultados semelhantes ao de Pereira et al (2012), Oliveira (2013) e Barbosa et al (2015). Este resultado demonstra que apesar de a tendência do uso de drogas ser cada vez mais precoce, a procura por tratamento para a reabilitação é característica de indivíduos com idades mais avançadas. Tal fato é consequência do intenso sofrimento que eles passam por utilizarem drogas há muito tempo (Capistrano et al, 2013; Guimarães et al, 2008; Peixoto et al, 2010).

A baixa escolaridade e a falta de renda fixa foram questões encontradas na maioria dos usuários. O ensino médio não foi concluído por $60 \%$ deles, e $31,7 \%$ não possuem nem o ensino fundamental completo. Além disso, $60 \%$ não possuem renda fixa, por não trabalharem (30\%) ou por trabalharem eventualmente (30\%), resultados semelhantes aos encontrados por Ferreira Filho et al (2003), Capistrano et al (2013), Oliveira (2013) e Peixoto et al (2010).

Os dados sobre adesão ao tratamento mostram que $58,3 \%$ estão pela primeira vez no serviço. Percebe-se ainda que $68,3 \%$ estão frequentando a mais de um ano, destes, $46,7 \%$ estão entre 1 a 2 anos e $21,6 \%$ entre 3 a 5 anos.

Adesão ou aderência ao tratamento pode ser entendida como o grau em que 0 paciente segue as recomendações médicas, ou de outro profissional de saúde, e é entendida como o retorno e a manutenção do tratamento indicado (Monteiro et al, 2011).

Com o propósito de ofertar um novo cuidado que será articulado pelo referente, garantindo a continuidade do tratamento com a inclusão dos aspectos subjetivo, social, familiar e laboral, o MS indica que cada usuário possua um técnico de referência no serviço. Este é definido como aquele que tem como responsabilidade o monitoramento do usuário, o projeto terapêutico individual, o contato com a família e 
a avaliação das metas traçadas no projeto (Brasil, 2004b). Estudos mostram a importância desse profissional como um importante dispositivo do arranjo organizacional da saúde mental (Silva e Costa, 2010).

Entretanto, 43,3\% dos usuários dos CAPSad do Amapá, desconhecem esse profissional que deveria estar atuando conjuntamente com ele durante seu tratamento. Este dado deve ser levado em consideração, uma vez que o técnico de referência constitui uma aproximação entre o profissional ou equipe a certo número de usuários, ocasionando uma assistência de modo singular por meio de um projeto terapêutico individual (Furtado; Miranda, 2006).

Observa-se que $80 \%$ dos usuários não participam do processo de avaliação das atividades ofertada pelos serviços, apesar de estarem de acordo com a importância de sua participação. A respeito disso, Wetzel e Kantorski (2004) afirmam que esse processo de avaliação das atividades proporciona a identificação de como eles percebem o serviço, bem como o compromisso que eles têm com a proposta do tratamento, o que é fator fundamental para a boa qualidade da assistência prestada e consequentemente a satisfação com o serviço.

Além disso, outros fatores estão relacionados com a satisfação dos pacientes como: adesão ao tratamento, características do atendimento, variáveis sociodemográficas e clínicas dos pacientes, tipos de intervenção, redução da sintomatologia, competência da equipe, qualidade da relação entre terapeuta e cliente, acessibilidade aos serviços, qualidade das instalações, continuidade dos cuidados e também a informação recebida (Silva et al, 2012).

De acordo com os dados obtidos, os usuários dos CAPSad do Amapá possuem um bom grau de satisfação global, com escore médio de 3,98 (dv 0,20). Estudos obtiveram resultados semelhantes com relação ao nível de satisfação, entretanto os escores globais foram acima de 4 (Heckert; Teixeira; Trindade, 2006; Kantorski et al, 2009; Jaegger et al, 2009; Camilo et al, 2012; Silva et al, 2012; Camilo et al, Barbosa et al, 2015; Pinho, 2014).

Os fatores relacionados a "competência e compreensão da equipe" e "apoio recebido e acolhida da equipe" receberam as melhores avaliações, com escore médio de 4,14 cada, e o fator relacionado à "condição física e conforto" dos CAPSAad, obteve o pior escore, 3,14, corroborando com os estudos de Kantorski et al (2009), 
Resende, Bandeira e Oliveira, (2016) e Pinho (2014), apesar desses ainda receberem nota acima de 4.

Embora o serviço tenha recebido boa avaliação, 88,3\% dos usuários relataram que os CAPSad podem ser melhorados, e entre as melhoras indicadas por eles, a estrutura física foi a mais apontada. Este fato justifica a satisfação com o serviço relacionado a "condição física e conforto" ter recebido o menor escore.

O resultado desta boa avaliação do serviço recebida pelos usuários pode ser expresso pelo receio em perder o direito ao serviço, mesmo que este seja de baixa qualidade, fazendo do usuário do sistema público uma espécie de usuário cativo. Além disso, pode ocorrer uma relutância em expressar opiniões negativas, conhecido como viés de gratidão (Esperidiao; Trad, 2005).

Apesar da satisfação do paciente ser um dos pontos mais utilizados, outro fator tem tido destaque na avaliação dos serviços na perspectiva do usuário: a percepção de mudanças em função do tratamento recebido.

A Escala de Mudança Percebida visa avaliar quais foram às mudanças percebidas pelos próprios pacientes como resultado do tratamento por eles em serviços de saúde mental, sendo divididos e 3 subsecalas que avaliam a "atividade física e saúde", "aspectos psicológicos e sono" e o "relacionamento e estabilidade emocional".

Nessa perspectiva, o escore global da EMP (média de 2,68), indica que no geral os usuários dos CAPSad do Amapá se consideram melhores do que antes de iniciar o tratamento. Ao compararmos com outros estudos que também avaliaram a mudança percebida em serviços de saúde mental, podemos perceber similiaridades nos resultados (Perreault et al, 2010; Lima, 2013, Costa et al, 2011; Barbosa, 2013, Pinho, 2014).

O maior índice de melhora percebida foi encontrado na subescala relacionada aos "aspectos psicológicos e sono" $(2,70)$ que avalia as mudanças percebidas em relação à sua confiança em si própria, seu humor, seus problemas pessoais, seu sentimento de interesse pela vida, sua capacidade de suportar situações difíceis e a qualidade do seu sono.

O menor índice de melhora percebida foi encontrado na subescala "relacionamento e estabilidade emocional" $(2,66)$ que avalia avaliam as mudanças percebidas pelo paciente em relação a sua convivência com os amigos, a estabilidade 
de suas emoções, a sua convivência com a família e a convivência com outras pessoas.

De forma geral, $78,3 \%$ dos usuários sentiram melhora na sua vida desde o início do tratamento. Essa melhora pode estar relacionada ao fato do usuário se sentir acolhido no serviço, além de encontrar apoio tanto dos profissionais como de outros usuários que estão passando pelos mesmos problemas.

\section{FAMILIARES}

Os familiares dos usuários dos CAPSad caracterizam-se por ser em sua maioria do sexo feminino $(85,7 \%)$, sendo as mães o vínculo mais encontrado $(42,8 \%)$, seguido dos cônjuges (32,1\%).

Em relação a idade, houve o predomínio de pessoas acima dos 50 anos $(67,9 \%)$, com a raça/cor autodeclarados de pardos $(71,45 \%)$, casados ou com companheiros $(78,7 \%)$, com o ensino médio completo $(28,6 \%)$.

Estes resultados corroboram com outros que avaliaram o perfil dos cuidadores de pacientes em sofrimento mental (Costa et al, 2011; Bandeira et al, 2011; Barbosa, 2013; Pinho, 2014; Miranda; Souza; Ferreira, 2014; Iseselo, Kajula e Yahya-Malima, 2016; Jardim et al, 2013) ao apresentarem que as mães constituem na maioria dos casos os principais cuidadores. Estudos demonstram que o cuidar ainda se constitui culturalmente como função do sexo feminino, em especial das mães, sendo elas as que mais sentem a sobrecarga comparada aos demais familiares (Barroso; Bandeira; Nascimento, 2007).

Em relação aos cuidados dispensados ao usuário do serviço, 57,1\% dos familiares afirmam serem os únicos que cuidam do seu familiar, o que demonstra que geralmente nas situações de uso e abuso de AOD, a família faz-se representar por um único membro da família que assume a condição de cuidador, ocasionando desta forma, uma sobrecarga advinda do processo de cuidar (Miranda et al, 2006).

Neste sentido, deve-se ressaltar que os cuidadores de dependentes de AOD possuem características diferenciadas, uma vez que no geral, o cuidado com esses pacientes não interfere diretamente nas atividades de vida diária do cuidador, por demandar menos cuidados físicos, comparadas a outros problemas como demência, doenças renais, deficiências motoras, entre outras. Além disso, muitos desses 
usuários nem chegam a ser considerados por si mesmos e nem pelos familiares como doentes, apesar de causarem problemas (Santos; Martin, 2009).

A respeito da sobrecarga que este cuidador vem a sofrer em decorrência do problema que seu familiar enfrenta, constatou-se neste estudo que $67.6 \%$ dos familiares se sentem sobrecarregados com os cuidados demandados. Dentre as situações que eles sentem mais a questão da sobrecarga, foi apontado o momento em que o usuário está sob efeito do álcool e/ ou droga.

Nos últimos anos, o papel de cuidador tem sido tema de estudos, por este ser considerado indispensável no processo de reabilitação do paciente em sofrimento psíquico (Bandeira; Barroso, 2005; Saunders, 2003).

Entretanto, observa-se que a doença mental atinge não só o paciente, mas toda a sua família, que parece não estar superando as exigências e as dificuldades resultantes do papel de cuidador. Essa situação, além de poder ter reflexos negativos no cuidado prestado ao próprio paciente, tem o potencial, para criar um novo cliente para os serviços de saúde mental: o próprio familiar cuidador (Albuquerque; Cintra; Bandeira, 2010).

A satisfação de familiares dos usuários vem ganhando a cada ano mais relevância para a avaliação de serviços de saúde mental, pois são eles que acompanham a rotina do paciente de forma mais próxima, podendo avaliar as mudanças que ocorrem (Bandeira et al, 2011).

O grau de satisfação global dos familiares deste estudo, obteve um escore médio de 4,0 (dp 0,57) o que demonstra um alto nível de satisfação com o serviço.

O fator que apesentou maior escore de satisfação foi o fator 1, referente aos "resultados do tratamento" com a média de 4,04 (dp 0,81). Este fator avalia se, na opinião do familiar, o paciente se beneficiou do tratamento recebido no serviço, se este tratamento foi efetivo em ajudá-lo a lidar com os seus problemas e se o paciente recebeu o tratamento que o familiar achava que ele necessitava.

O fator 2, referente a "acolhida e competência da equipe" avalia o grau de satisfação do familiar com relação à competência e a capacidade da equipe de compreender o problema do paciente e o tipo de ajuda que ele necessitava. Este fator obteve o escore médio de 4,0 (dp 0,52).

O fator 3 referente a "privacidade e confidencialidade", recebeu a pior avaliação, com escore médio de 3,96 (dp 0,57). Este fator avalia a satisfação do 
familiar em relação às medidas tomadas no serviço para garantir a privacidade e confidencialidade sobre o problema do paciente, no decorrer do tratamento.

Apesar de estes dados informarem um bom nível de satisfação com relação aos serviços, outros estudos (Bandeira et al, 2011; Barbosa, 2013; Pinho, 2014; Miranda; Souza; Ferreira, 2014; Camilo, 2011) que também foram avaliados positivamente pelos familiares, obtiveram escores mais altos dos que foram encontrados neste estudo.

A percepção do familiar quanto às mudanças nos diversos aspectos da vida do usuário é outro fator levado em consideração durante a avaliação de serviços de saúde mental, e para avaliar essa percepção, este estudo utilizou a Escala de Mudança Percebida - Familiares.

O escore global encontrado neste estudo identificou uma melhora na vida do usuário, segundo a percepção do familiar, com a média de 2,63, resultado semelhante a outros estudos (Costa, 2009; Cesari, 2010, Barbosa, 2013; Pinho, 2014), sendo a sub-escala "dimensão psicológica" a que recebeu a maior média $(2,68)$, fato igualmente encontrados nos estudos citados.

Importante ressaltar que a dimensão relacionada aos aspectos psicológicos e sono foi a que obteve o melhor resultado, tanto dos usuários, quanto dos familiares.

A sub-escala que obteve a pior nota foi a dimensão "Saúde Física" com a média de 2,57, resultado este diferente aos encontrados nos estudos de Costa (2009); Cesari (2010), Barbosa (2013); Pinho (2014), que encontraram na dimensão "Ocupação" o pior escore.

Uma possível explicação para a dimensão "saúde física" ter recebido o pior resultado, seria a presença de efeitos colaterais dos psicofármacos, que podem afetar estas áreas da vida do paciente (Costa et al, 2011).

De forma geral, foram percebidas melhorias na vida dos usuários por $82,1 \%$ dos familiares. Este resultado demonstra que os CAPSad estão ajudando de alguma forma na reabilitação dos usuários, na perspectiva dos familiares. 


\section{LIMITAÇÕES DO ESTUDO}

O presente estudo foi realizado nos CAPSad do Estado do Amapá, compreendendo os dois únicos serviços ofertados, um no município de Macapá e outro no município de Santana. Seus resultados podem, portanto, ser generalizados apenas para o contexto do cuidado de usuários de álcool e outras drogas do Estado.

Uma limitação encontrada no presente estudo, diz respeito ao contato com os usuários, tanto no serviço, quanto telefônico e visitas domiciliares. Alguns dos usuários sorteados inicialmente já haviam abandonado o tratamento, e seus prontuários não possuíam informações de contato, ou estas estavam desatualizadas. Desta forma, muitos deles não puderam ser contatados, o que nos obrigou a fazer novos sorteios para a obtenção de uma amostra considerável. É de se esperar que indivíduos com menos contatos nos registros dos prontuários, bem como aqueles que estavam afastados das atividades, encontrem-se em uma situação mais vulnerável, com maiores agravos à sua saúde mental e física, o que modificaria os resultados da pesquisa, caso tivesse sido possível contatar a todos.

Outra limitação encontrada, diz respeito às perdas de trabalhadores e principalmente dos familiares. Houve uma perda de 4 trabalhadores $(11,1 \%)$, por motivos de recusa, sendo as mesmas justificadas por falta de disponibilidade de horários para responder as perguntas. Quanto aos familiares, houve uma perda maior, de $53,3 \%$, sendo estas justificadas pelo fato de muitos usuários não indicarem um familiar e/ou amigos para participarem do estudo, além do fato de não conseguirmos contato com este grupo, após cinco tentativas, tanto por via telefônica, quanto por visita domiciliar. A visão do familiar frente aos resultados do tratamento ofertado nos serviços é considerada uma importante ferramenta a ser analisada, e com essa perda considerável, pode atestar que alguns resultados poderiam ser diferentes caso pudéssemos ter acesso a totalidade deste grupo. 


\section{CONCLUSÃO}

O presente estudo teve como objetivo descrever e analisar os Centros de Atenção Psicossocial de Álcool e outras Drogas do estado do Amapá a partir da visão dos trabalhadores, usuários e familiares. Entender a relação existente entre os sujeitos do estudo e o serviço torna-se relevante para a melhoria do serviço prestado, e consequentemente, melhorias na vida do usuário.

Pode-se constatar que os CAPSad do Amapá seguem a maioria das normativas exigidas pelo MS. Entretanto, o CAPSad de Santana ainda precisa ajustar alguns itens, como o número mínimo de profissionais exigidos, além da oferta de alimentação para os usuários, o que acaba por influenciar na oferta de mais oficinas e grupos terapêuticos.

Apesar disso, os CAPSad do Amapá foram avaliados positivamente por todos os sujeitos envolvidos no estudo, sendo os trabalhadores, o grupo que teve o menor índice de satisfação global com o serviço. Para os trabalhadores, as condições de trabalho foram apontadas como o principal fator que necessita de melhorias, sendo a falta de ferramentas adequadas e a estrutura física dos prédios os principais itens apontados como desfavoráveis para realização de atividades terapêuticas com os usuários.

Ainda na visão dos trabalhadores, as características organizacionais no que se refere ao apoio e a supervisão por parte das Secretarias de Saúde e Coordenações de Saúde Mental, foram avaliadas negativamente. Este é um dado preocupante, uma vez que o trabalhador precisa ter suporte destas instancias, além do que, são eles que estabelecem diretrizes políticas na área de álcool e outras drogas, e isto pode dificultar a obtenção de qualidade no serviço ofertado aos usuários.

A maioria das atividades dos CAPSad são realizadas em grupo, o que pode ser considerada favorável, pois este tipo de atividade preparam o indivíduo para a sua ressocialização, além de trabalhar o altruísmo, a compreensão de si mesmo e a importância da família e da sociedade no tratamento. No entanto, foi constatado que - CAPSad de Santana necessita de melhorias urgentes, pois o mesmo vem ofertando cada vez menos oficinas e grupos terapêuticos, servindo apenas para psicoterapias individuais e atendimentos ambulatoriais. 
Além disso, pode-se perceber a carência de atividades comunitárias, bem como de geração de renda, resultado da falta de parcerias com outras instituições que propiciem esta relação. Ressalta-se que a inexistência dessas ações dificulta a reinserção do usuário na sociedade.

Deve-se considerar a importância dos profissionais do CAPSad como articuladores para a reinserção dos usuários na sociedade. Para isto, conhecer o território bem como toda a estrutura da RAPS é essencial para efetivar essa articulação. Investimentos em cursos de atualização por parte do governo, além de melhorar a estruturação da RAPS no Estado, são necessários para construir e desenvolver a verdadeira Rede de Atenção Psicossocial.

A satisfação dos usuários com o serviço foi considerada boa, em especial ao fato relacionado a competência e compreensão da equipe, além da ajuda recebida no serviço. Entretanto, novamente o item relacionado à estrutura física foi considerado como o pior item do serviço. Essa satisfação corrobora com os achados da mudança percebida relatada pelos usuários, que afirmam estarem melhores do que antes de iniciar o tratamento.

Os familiares também avaliaram positivamente os CAPSad, apesar de termos constatados que poucos frequentam o serviço, consequentemente, poucos o conhecem. Desta forma, a satisfação positiva esta pode estar relacionada as mudanças percebidas em seus familiares, além de poderem dividir a sobrecarga do cuidado com os profissionais do serviço.

Esses resultados podem indicar que os CAPSad apesar de algumas fragilidades, cumprem com o seu papel, através do estabelecimento de vínculos, da construção de uma perspectiva ampliada da clínica, transformando os serviços em locais de acolhimento e enfrentamento coletivo de situações ligadas ao problema do álcool e de outras drogas.

Além disso, fortalecer a política de educação e do cuidado em saúde e em detrimento à política da repreensão de quem faz o consumo de álcool e outras drogas poderá trazer melhores resultados ao tratamento, uma vez que a comunidade precisa ser informada e conscientizada sobre o assunto, com o intuito de diminuir o preconceito existente sobre essa temática e consequentemente ser sujeito participativo no tratamento dos usuários. 


\section{REFERENCIAS}

Adami, NP, Maranhão, AMSA. Qualidade dos serviços de saúde: conceitos e métodos avaliativos. Rev. Acta Paulista Enfermagem. 1995; 8, (4): 47-55.

Albuquerque EPT, Cintra AMO, Bandeira M. Sobrecarga de familiares de pacientes psiquiátricos: comparação entre diferentes tipos de cuidadores. J Bras Psiquiatr. 2010; 59(4):308-316

Almeida PF, Escorel S. Da avaliação em saúde à avaliação em Saúde Mental: gênese, aproximações teóricas e questões atuais. Saúde Debate 2001; 25(58):35-47.

Amarantes, $\mathrm{P}$ (org). Loucos pela vida: a trajetória da reforma psiquiátrica no Brasil. Rio de Janeiro: SDE/ENSP; 1995

Amarante P. Saúde mental e atenção psicossocial. Rio de janeiro: Fiocruz, 2007

Antunes B, et al. Visita domiciliar no cuidado a usuários em um centro de atenção psicossocial: relato de experiencia. Cien Cuid Saude. 2012, jul/set; 11(3): 600-604.

Azevedo JMR, Barbosa MA. Triagem nos serviços de saúde. Rev Enferm UERJ. 2007; 15(1):33-9.

Bandeira M, et al. Escala de Avaliação da Satisfação dos Familiares com Serviços de Saúde Mental: SATIS-Br. J Bras Psiquiatr. 2002;51(3):153-66

Bandeira M, et al. Satisfação de familiares de pacientes psiquiátricos com os serviços de saúde mental e seus fatores associados. J Bras Psiquiatr. 2011; 60(4):284-93.

Bandeira M, et al. Percepção dos pacientes sobre o tratamento em serviços de saúde mental: validação da Escala de Mudança Percebida. Psicologia: Reflexão e Crítica. 2011b;24(2):236-44.

Bandeira M, Felicio CM, Cesari L. Validation of the Perception of Change Scale Family Version (EMP-F) as a treatment outcome measure in mental health services. Revista Brasileira de Psiquiatria. 2010;32(3):283-7.

Bandeira M, Ishara S, Zuardi AW. Satisfação e sobrecarga de profissionais de saúde mental: validade de construto das escalas SATIS-BR e IMPACTO-BR. J Bras Psiquiatr. 2007; 56(4): 280-86

Bandeira M, Pitta AMF, Mercier C. Escalas brasileiras de avaliação de satisfação (SATIS-BR) e da sobrecarga (IMPACTO-BR) da equipe técnica em serviços de saúde mental. Jornal Brasileiro de Psiquiatria. 2000; 49(4):105-15. Disponível em http://www.ufsj.edu.br/portal2- 
repositorio/File/lapsam/Artigos\%20digitalizados/Escalas\%20brasileiras\%20de\%20av aliacao\%20da\%20satisfacao\%20(SATIS-

BR)\%20e\%20da\%20sobrecarga\%20(IMPACTO-

BR)\%20da\%20equipe\%20tecnica\%20em\%20servicos\%20de\%20saude $\% 20$ mental. PDF

Bandeira, M, Barroso SM. Sobrecarga das famílias de pacientes psiquiátricos. J Bras Psiquiatria. 2005; 54(1): 34-46.

Barbosa G, et al. Satisfação de usuários num centro de atenção psicossocial em álcool e outras drogas. Revista Portuguesa de Enfermagem de Saúde Mental. 2015; 14.

Barbosa GC. Avaliação dos Centros de Atenção Psicossocial em Álcool e outras drogas do Município de São Paulo. [tese]. São Paulo: Escola de Enfermagem, Universidade de São Paulo; 2013

Barroso SM, Bandeira M, Nascimento E. Sobrecarga de familiares de pacientes psiquiátricos atendidos na rede pública. Rev. Psiq. Clin. 2007; 34(6):270-277.

Bastos, Fl, Bertoni N (org.) Pesquisa Nacional sobre o uso de crack: quem são os usuários de crack e/ou similares do Brasil? quantos são nas capitais brasileiras? Rio de Janeiro: Editora ICICT/FIOCRUZ, 2014.

Bichaff, RO. Trabalho nos Centros de Atenção Psicossocial: uma reflexão crítica das práticas e suas contribuições para a consolidação da Reforma Psiquiátrica. [Dissertação]. São Paulo: Escola de Enfermagem da Universidade de São Paulo; 2006

Blankertz LE, Robinson SE. Turnover intentions of community mental health workers in psychosocial rehabilitation services. Community Ment Health J. 1997;33(6):517-29.

Borges LO, et al. A síndrome de Burnout e os valores organizacionais: um estudo comparativo em hospitais universitários. Psicologia: Reflexão e Crítica, 2002, 15(1): p.189-200.

Braga LM, Torres LM, Ferreira VM. Condições de trabalho e fazer em enfermagem. Rev. Enf-UFJF-Juiz de Fora. 2015; 1(1): 55-63

Brasil MS. Decreto 7179 de 20 de maio de 2010. Institui o Plano Integrado de Enfretamento ao Crack e outras Drogas, cria o seu Comitê Gestor, e dá outras providencias. [legislação da internet]. Brasília; 2010. Disponível em http://www.planalto.gov.br/ccivil 03/ Ato2007-2010/2010/Decreto/D7179.htm

Brasil, MS, SVS/CN-DST/AIDS SdAàS. A Política do Ministério da Saúde para a Atenção Integral a Usuários de Álcool e outras Drogas. In: Saúde Md, editor. $2^{\underline{a}}$ ed. Brasília, 2004. 
Brasil, MS. Portaria 130 de 26 de janeiro de 2012. Redefine o Centro de Atenção Psicossocial de Álcool e outras drogas 24h (CAPSad III) e os respectivos incentivos financeiros [legislação da internet] Brasília, 2012.Disponível em

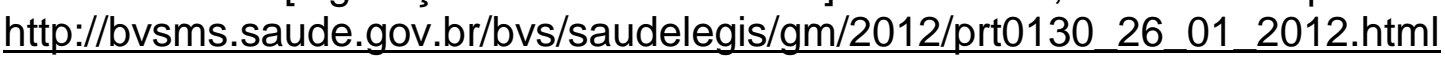

Brasil, MS. Portaria 3088 de 23 de dezembro de 2011. Institui a Rede de Atenção Psicossocial para pessoas com sofrimento ou transtorno mental e com necessidades decorrentes do uso de crack, álcool e outras drogas no ambito do Sistema Único de Saúde. [legislação da internet]. Brasília; 2011. Disponível em http://bvsms.saude.gov.br/bvs/saudelegis/gm/2011/prt3088 23122011 rep.html

Brasil, MS. Portaria 4279 de 30 de dezembro de 2010. Estabelece Diretrizes para a orgaização da Rede de Atenção a saúde no ambito do Sistema Único de Saúde. [legislação da internet]. Brasília; 2010b. Disponível em http://conselho.saude.gov.br/ultimas noticias/2011/img/07 jan portaria4279 301210 .pdf

Brasil, MS. Programa "Crack, é possivel vencer". Brasília, 2011c. disponivel em: http://www.pmf.sc.gov.br/arquivos/arquivos/pdf/27 122012 14.21.49.508c1d19b25 7034560dd1ae6320731c8.pdf. Acessado em 29/12/2016 às 11:10. Brasília, 2011c.

Brasil, MS. Redes de Atenção Psicossocial. Disponível em http://www.saude.pr.gov.br/arquivos/File/RAPS.pdf. Acessado em 29/12/2016 às 10:33. Brasília, 2011b

Brasil, MS. Secretaria Nacional de Programas Especiais de Saúde. I Conferencia Nacional de Saúde Mental: relatório final. Brasília: Centro de Documentação do Ministério da Saúde, 1988

Brasil, MS. Coordenação Geral de Saúde Mental, Álcool e Outras Drogas. Saúde Mental em Dados -12. Ano 10, n.12. Brasilia, 2015.

Brasil, MS. Portaria n. 0 1.190/GM, de 04 de junho de 2009. Institui o Plano Emergencial de ampliação do acesso ao tratamento e prevenção em álcool e outras drogas no SUS (PEAD 2009-2010) e define as suas diretrizes gerais. Brasilia, 2009.

Brasil, MS. Portaria n. ${ }^{\circ}$ 1174/GM, de 07 de julho de 2005. Destina incentivo financeiro emergencial para o Programa de Qualificação dos Centros de Atenção Psicossocial CAPS. Brasília, 2005. In:__ Secretaria de Atenção à Saúde. Legislação em Saúde Mental - 2004 a 2010. Brasília, 20. 257p.

Brasil, MS. Portaria n.ํ 336/GM, de 19 de fevereiro de 2002. Dispõe sobre os Centros de Atenção Psicossocial. 2002.

Brasil, MS. Secretaria de Atenção à Saúde. Departamento de Ações Programáticas Estratégicas. Saúde Mental no SUS: os centros de atenção psicossocial. Brasília, 2004b 
Brasil, MS. Secretaria de Atenção à Saúde. Departamento de Ações Programáticas Estratégicas. Manual de Estrutura Física dos Centros de Atenção Psicossocial e Unidades de Acolhimento: Orientações para elaboração de projetos de construção de CAPS e de UA como lugares de atenção psicossocial nos territórios. Brasilia: Ministério da Saúde, 2013

Brasil, MS. Secretaria de Atenção à Saúde. Relatório de Gestão 2003-2006: saúde mental no SUS: acesso ao tratamento e mudança do modelo de atenção. Brasília, 2007.

Camilo CA, et al . Avaliação da satisfação e sobrecarga em um serviço de saúde mental. Cien. Saúde Colet. 2012; 20 (1): 82-92

Camilo CA. Avaliação de um serviço de saúde mental: perspectivas dos pacientes, familiares e profissionais. [Dissertação]. Universidade Federal de São João Del Rei. 2011

Campos RTO, et al. Avaliação da rede de centros de atenção psicossocial: entre a saúde coletiva e a saúde mental. Rev Saude Publica 2009; 43(Supl. 1):16-22.

Capistrano FC, et al. Perfil sociodemografico e clinico de dependentes químicos em tratamento: análise de prontuário. Esc Anna Nery (impr). 2013; 17(2):234-241

Carlini ES, et al. II Levantamento domiciliar sobre o uso de drogas psicotrópicas no Brasil: estudo envolvendo as 108 maiores cidades do país. São Paulo: Centro Brasileiro de Informações sobre Drogas Psicotrópicas, Departamento de Psicobiologia da Escola Paulista de Medicina; 2006. Available from: http://200.144.91.102/sitenovo/conteudo.aspx?cd=644.

Carvalho CG, Amaral RMS, Magalhães SR. Assistencia de enfermagem ao portador de transtorno psiquico: visita domiciliar. E-scientia, Belo Horizonte. 2011; 4(1): 31-38

Cesari L. Percepção de mudança e qualidade de vida em pacientes com esquizofrenia. [Dissertação]. Universidade Federal de São João Del Rei. 2010

Clementino FS, et al. Avaliação da estrutura organizacional dos Centros de Atenção Psicossocial do Municipio de Campina Grande, Paraíba. Rev bras ci saúde. 2016; 20(4):261-268.

Contandriopoulos AP, et al. A avaliação na área da saúde: conceitos e métodos. In: Hartz ZMA. Avaliação em saúde: dos modelos conceituais à prática na análise da implantação de programas [online]. Rio de Janeiro: Editora Fiocruz, 1997. 132p. ISBN 85-8567636-1. Available from SciELO Books <http://books.scielo.org>.

Contrandriopoulos AP. Avaliando a institucionalização da avaliação. Ciênc. Saúde coletiva, 2006; 11(3): 705-711. 
Costa CS, et al. A percepção de pacientes e familiares sobre os resultados do tratamento em serviços de saúde mental. Cad Saude Publica 2011; 27(5):995-1007.

Costa CS. Percepção de mudança em função do tratamento recebido nos serviços de saúde mental: comparação entre pacientes e familiares. [Dissertação]. Universidade Federal de São João Del Rei. 2009.

Costa PHA, Colugnati FAB, Ronzani TM. Avaliação de serviços de saúde mental no Brasil: revisão sistemática da literatura. Ciência e Saúde Coletiva. 2015; 20(10): 32433253

D'Innocenzo M, Adami NP, Cunha ICKO. O movimento pela qualidade nos serviços de saúde e enfermagem. Rev Bras Enferm. 2006, 59(1):84-8.

De Marco PF, et al. O impacto do trabalho em saúde mental: transtornos psiquiátricos menores, qualidade de vida e satisfação profissional. J Bras Psiquiatr.2008; 57(3): 178-83.

Dias OV, Ramos LH, Costa SM. Avaliação da qualidade dos serviços de saúde na perspectiva da satisfação dos usuários. Revista Pró-univerSUS. 2010; 1(1): 11-26.

Dualibi LB, Ribeiro R, Laranjeira R. Profile of cocaine and crack users in Brasil. Cad. Saúde Pública. 2008; 24 (Sup 4):S545-S557, 2008

Duarte MLC, Kantorski LP. Avaliação da atenção prestada aos familiares em um centro de atenção psicossocial. Rev. bras. enferm. 2011; 64(1):47-52.

Elbreder MF, et al. Perfil de mulheres usuárias de álcool em ambulatório especializado em dependência química. J Bras Psiquiatr. 2008; 57(1):9-15.

Esperidião M, Trad LAB. Avaliação de satisfação de usuário. Ciencia e Saúde Coletiva. 2005; 10(supl):303-312.

Faria JG, Schneider DR. O perfil dos usuários do CAPSad-blumenau e as políticas públicas em saúde mental. Psicologia \& Sociedade. 2009; 21(3):324-33

Ferreira Filho OF, et al. Perfil sóciodemográfico e de padrões de uso entre dependentes de cocaína hospitalizados. Rev. Saúde Públic. 2003; 37(6): 751-9.

Furtado JP, Miranda L. O dispositivo "técnicos de referência" nos equipamentos substitutivos em saúde mental e o uso da psicanálise winnicottiana. Revista Latinoamericana de Psicopatologia Fundamental. São Paulo. 2006; IX (3), 508-524.

Furtado, J.P. Equipes de referência: arranjo institucional para potencializar a colaboração entre disciplinas e profissões. Interface - Comunic., Saúde, Educ.2007; 11(22):239-5. 
Guimarães $\mathrm{CF}$, et al. Perfil do usuário de crack e fatores relacionados à criminalidade em unidade de internação para desintoxicação no Hospital Psiquiátrico São Pedro de Porto Alegre (RS). Rev Psiquiatr RS. 2008; 30(2):101-108.

Heckert, U., Teixeira, L.S. \& Trindade, A.S. Avaliação da satisfação dos usuários do Centro Regional de Referência em Saúde Mental (CRRESAM) da região central de Juiz de Fora, MG. HU revista. 2006; 32(1):15-19.

Iseselo MK, Kajula L, Yahya-Malima KI. The psychosocial problems of families caring for relativies with mental health illness and their coping strategies: a qualitative urban basead study in Dar es Salaam, Tanzania. BMC psychiatric. 2016; 16:146

Ishara S, Bandeira M, Zuardi AW. Public psychiatric services: job satisfaction evolution. Rev. Bras Psiquiatr. 2008; 30(1): 38-41

Ishara S. Equipes de saúde mental: avaliação da satisfação e do impacto do trabalho em hospitalização integral e parcial [tese]. Ribeirão Preto: Universidade de São Paulo, 2007.

Jaegger, RC. et al. A experiência de morar fora: avaliação da satisfação de usuários em um serviço de saúde mental. Cadernos de Saúde Coletiva. 2004; 12(1): 27-39.

Jardim VMR. et al. Perfil do familiar de pacientes crônicos em sofrimento psíquico. Ciencia, Cuidado e Saúde. 2013; 7. ISSN 1984-7513

Kantorski LP, et al. Satisfação dos usuários dos centros de atenção psicossocial da região Sul do Brasil. Rev Saude Publica. 2009b; 43(Supl. 1):29-35

Kantorski LP, Machado AT, Oliveira CA. Centro de Atenção Psicossocial reinventando o cuidado em saúde mental. Texto \& Contexto enferm, 2000; 9(1): 233243

Kantorski LP. CAPSUL - Avaliação dos CAPS da Região Sul do Brasil: relatório. Pelotas: Conselho Nacional de Desenvolvimento Cientifico e Tecnológico (CNPq). Ministério da Saúde, 2007.

Kantorski LP. et al. Contribuições do estudo de avaliação dos centros de atenção psicossocial da região sul do Brasil. Cad. Bras. Saúde Mental. 2009; 1(1)

Kantorski, LP, et al. Avaliação qualitativa de ambiência num Centro de Atenção Psicossocial. Cienc saúde coletiva. 2011; 16(4):2059-66

Leal RMAC, Bandeira MB, Azevedo KRN. Avaliação da qualidade de um serviço de saúde mental na perspectiva do trabalhador: satisfação, sobrecarga e condições de trabalho dos profissionais. Psicologia: teoria e prática. 2012; 14(1):15-25

Lima FC. Avaliação da mudança percebida e satisfação de usuários de CAPS-AD. [Dissertação] Florianópolis: Universidade Federal de Santa Catarina; 2013 
Machado AR, Miranda PSC. Fragmentos da história da atenção à saúde para usuários de álcool e outras drogas no Brasil: da justiça a saúde pública. História, Ciência e Saúde 2007; 14(13):801-821.

Machado LV, Boarini ML. Políticas sobre drogas no Brasil: a estratégia da redução de danos. Psicol.cienc.prof. v.33.n.3.Brasilia, 2013.

Medeiros SM, et al. Condições de trabalho e enfermagem: a transversalidade do sofrimento no cotidiano. Rev. Eletr. Enf. [internet]. 2006; 8(2):233-40. Disponível em https://www.fen.ufg.br/fen revista/revista8 2/v8n2a08.htm. Acesso em janeiro de 2017.

Merces, NP. Atitudes de estudantes de psicologia acerca do álcool, alcoolismo e do alcoolista. [dissertação]. São Paulo: Escola de Enfermagem, Universidade de São Paulo, 2013

Mercier L. et al. Measuring clients perception as outcome measurement. In: Roberts AR, Yeager KRE (ed). Evidence-based pratice manual: Research an outcome measures in health and human services. New York: Oxford University Press, 2004. P.904-909.

Miranda F. et al. The negative impact of the disturb of the use and abuse of the alcohol in the Family coexistence. Rev. Eletr Enf. 2006; 8(2): 222-32

Miranda POM, Souza OF, Ferreira TF. Avaliação da satisfação dos pacientes e familiares em um serviço de saúde mental na cidade de Rio Branco-AC. J Bras Psiquiatr. 2014; 63(4):332-40.

Monteiro CFS, et al. Perfil sociodemográfico e adesão ao tratamento de dependentes em álcool em CAPSad do Piauí. Esc Anna Nery. 2011; 15(1):90-5

Nascimento ADF, Galvanese ATC. Avaliação da estrutura dos Centros de Atenção Psicossocial do município de São Paulo, SP. Revista de Saúde Pública. 2009; 43: 493-504.

Nemes, MIB. Avaliação em Saúde: questões para o programa DST/AIDS no Brasil. Rio de Janeiro: Associação Brasileira Interdisciplinar de AIDS; 2001

Oliveira MAF, et al. Processo de avaliação de serviços de saúde mental: uma revisão integrativa. Saúde Debate. 2014; 38(101): 368-378.

Oliveira VC. Perfil sociodemográfico, clínico e familiar de dependentes químicos em tratamento em um Centro de Atenção Psicossocial -álcool e outras drogas da região metropolitana de Curitiba. [dissertação]. Curitiba: Universidade Federal do Paraná. 2012

Organización Panamericana de la Salud. Epidemiologia del uso de drogas em América Latina y el Caribe: um enfoque de la salud pública. Washigngton, D.C.: 2009 
Passos SRL, Camacho LAB. Características da clientela de um centro de tratamento para dependência de drogas. Rev. Saúde Pública, 1998; 32(1): 64-71.

Paulin, LF, Turato, ER. Antecedentes da reforma psiquiátrica no Brasil: as contradições dos anos 1970. História, Ciências, Saúde- Manguinhos. 2004; 11(2):241-258.

Peixoto C, et al. Impacto do perfil clínico e sociodemográfico na adesão ao tratamento de pacientes de um Centro de Atenção Psicossocial a usuários de álcool e outras drogas (CAPSad). J Bras Psiquiatr. 2010; 59(4): 317-321.

Pelisoli CL, Moreira AK. Caracterização epidemiológica dos usuários do Centro de Atenção Psicossocial Casa Aberta. Rev. Psiquiatr. 2005; 27(3): 270-77

Pereira MO, et al. Perfil dos usuários dos serviços de saúde mental do município de Lorena- São Paulo. Acta Paul Enferm, 2012; 25(1): 48-54.

Perreault M. et al. Relationship between perceived improvement and treatment satisfaction among clients of a methadone maintenance program. Evaluation and program planning. 2010; 33(4): 410-417

Pillon, S, Laranjeira R, Dunn, J. Nurse's atitudes towards alcoholism: factor analysis of three commonly udes scales. São Paulo Medical Journal. 1998; 116(2):1661-1666

Pinho PH. Avaliação dos Centros de Atenção Psicossocial em Álcool e outras drogas do Município de São Paulo. [tese]. São Paulo: Escola de Enfermagem, Universidade de São Paulo; 2014

Pinikahana J, Happell B, Carta B. Mental Health professionals' atitudes to drug and substance abuse. Nursing \& health sciences. 2002; 4(3):57-62

Pitta AMF. Qualidade de serviços de saúde mental: desafios para a epidemiologia. J Bras Psiquiatr. 1996; 45(6): 313-21.

Pitta AMF. Um balanço da reforma psiquiátrica no Brasil: instituições, atores e políticas. Ciencia e Saúde Coletivo. 2011; 16(12): 4589-4589.

Prates, JG. Avaliação das atitudes dos profissionais de Centros de Atenção Psicossocial em Álcool e outras Drogas do município de São Paulo [tese]. São Paulo: Escola de Enfermagem, Universidade de São Paulo; 2016

Rebouças D, et al. O trabalho em saúde mental: um estudo de satisfação. Cad. Saúde Publica, 2008; 24(3): 624-632

Rebouças D, Legay LF, Abelha L. Satisfação com o trabalho e impacto causado nos profissionais de serviços de saúde mental. Rev. Saúde Pública. 2007; 41(2):244-50 
Reid $\mathrm{Y}$, et al. Explanations for stress and satsfaction in mental health professionals: a qualitative study. Social psychiatry and psychiatry epidemiology, v.34, n.6, p.301-308, 1999. ISSN 0933-7954.

Resende KIDS, Bandeira, Oliveira DCR. Assessment of Patient, Family and Staff Satisfaction in a Mental Health Service. Paideia. 2016; 26(64): 245-253

Rocha, RM. Enfermagem em saúde mental. 2.ed.atual. e ampl. Rio de Janeiro: Ed. Senac Nacional, 2005

Rodrigues, LR. Saúde Mental e Profissionais do Programa Saúde da Família: uma proposta de educação permanente. [Tese].

Santos AFO. Familiares cuidadores de usuários de serviço de saúde mental: sobrecarga e satisfação com o serviço. [Dissertação]. Faculdade de Filosofia, Ciências e Letras de Ribeirão Preto. Universidade de São Paulo,2010.

Santos AM, et al. Análise dos níveis de satisfação de trabalhadores de saúde mental de um Hospital público de referência psiquiátrica em Belém (PA). Rev Baiana Saúde Pública. 2011; 35(4):813-25

Santos ECV, Martin D. Cuidadoras de pacientes alcoolistas no município de SantoS, SP, Brasil. Rev Bras Enferm. 2009; 62(2):194-9.

Saunders JC. Families living with severe mental illness: a literature review. Issues in Mental Health Nursing. 2003; 24:175-198

Schimidt MB, Figueiredo AC. Acesso, acolhimento e acompanhamento: três desafios para o cotidiano da clínica em saúde mental. Rev Latinoam. Psicopat. Fund. 2009; 12(1): 130-40.

Schneider JF. et al. Utilização da avaliação de quarta geração em um centro de atenção psicossocial. Rev Gaúcha Enferm. Porto Alegre (RS). 2009;30(1):131-5.

Severo AKS, L'abbate S, Campos RTO. A supervisão clínico-institucional como dispositivo de mudanças na gestão do trabalho em saúde mental. Interface (Botucatu) [online]. 2014, vol.18, n.50, pp.545-556.

Silva EA, Costa II. O profissional de referência em saúde mental: das responsabilizações ao sofrimento psíquico. Revista Latinoamericana de Psicopatologia Fundamental. São Paulo. 2010; 13(4):635-647.

Silva MA, et al. Satisfação dos pacientes com os serviços de saúde mental: a percepção de mudanças como preditora. J Bras Psiquiatr. 2012; 61(2); 64-71

Siqueira MM, Gomide Junior S. Suporte no trabalho. In: (Org.) Medidas do comportamento organizacional: ferramentas de diagnóstico e de gestão. Porto Alegre: Artmed, 2008. p.283-294. 
Soares J, Vargas D, Oliveira MAF. Atitudes e conhecimentos de profissionais de saúde diante do álcool, alcoolismo e do alcoolista: levantamento da produção científica nos últimos 50 anos. SMDA Revista eletrônica saúde mental, álcool e drogas. $2011 ; 7(1): 45-52$.

Stancato K, Zilli PT. Fatores geradores da rotatividade dos profissionais de saúde: uma revisão da literatura. Rev. Adm. Saúde. 2010. 12(47):87-99.

Surjus LTLS, Campos RO. A avaliação dos usuários sobre os Centros de Atenção Psicossocial (CAPS) de Campinas, SP. Rev. latinoam. psicopatol. fundam. 2011; 14(1):122-133.

Tavares CMDM, Sobral VRS, Avaliação das práticas de cuidar envolvendo arte no âmbito do Centro de Atenção Psicossocial (CAPS). Revista Mineira de Enfermagem. 2005; 9(2): 121-125

Tomasi E, et al. Efetividade dos centros de atenção psicossocial no cuidado a portadores de sofrimento psíquico em cidade de porte médio do Sul do Brasil: uma análise estratificada. Cad Saude Publica 2010; 26(4):807-815.

United Nations Office on Drugs and Crime, World Drug Report 2016 (United Nations publication, Sales No. E.16.XI.7).

Vargas D, Bittencourt MN. Álcool e alcoolismo: atitudes de estudantes de enfermagem. Rev. Bras Enferm. 2013; 66(1):84-9.

Vargas D, Labate RC. Atitudes de enfermeiros de hospital geral frente ao uso do ao álcool, alcoolismo e alcoolista. Rev. Bras Enferm. 2006; 59(1):47-51

Vargas D, Luis MAV. Construção e validação de uma escala de atitudes frente ao álcool e alcoolismo. Rev. Bras Enferm. 2008; 16(5):101-8

Vargas D. A construção de uma escala de atitudes frente ao álcool, ao alcoolismo e ao alcoolista: um estudo psicométrico.[tese] Ribeirão Preto: Universidade de São Paulo; 2005

Vargas D. Atitudes de enfermeiro frente as habilidades de identificação para ajudar o paciente alcoolista. Rev. Bras Enferm. 2010; 63(2):190-5

Vargas D. Atitudes de enfermeiros de hospital geral frente às características pessoais do paciente alcoolista. Rev. Bras Enferm. 2010b. 63(6): 1028-34.

Vargas D. Versão reduzida da escala de atitudes frente ao álcool, alcoolismo e ao alcoolista: resultados preliminares. Rev Esc Enferm USP. 2011; 45(4):918-25

Vargas D. Atitudes de estudantes de enfermagem frente questões relacionadas ao álcool, alcoolismo e e alcoolista. Acta Paul Enferm 2011b; 24(5):638-44 
Vargas D. Construct validation of the scale of attitudes toward alcohol, alcoholism and individuals with alcohol use disorders. Rev psiquiatr. clin. 2014; 41(4):105-10

Vargens RW, Cruz MS, Santos MAd. Comparação entre usuários de crack e de outras drogas em serviço ambulatorial especializado de hospital universitário. Revista LatinoAmericana de Enfermagem. 2011;19(spe):804-12.

Wachs, F. Educação Física e saúde mental: uma prática de cuidados emergente em Centros de Atenção Psicossocial (CAPS). [Dissertação]. Porto Alegre: Universidade Federal do Rio Grande do Sul; 2008.

Wetzel C, Kantorski LP. Avaliação dos serviços em saúde mental no contexto da reforma psiquiátrica. Texto Contexto Enferm. 2004; 13 (4):593-8.

World Health Organization. Global status Report on alcohol and health. Geneva: WHO, 2014. XII, 286 p.p

Wykes T, Stevens W, Everitt B. Stress in community care teams: will it affect the sustainability of community care? Soc Psychiatry Psychiatry Epidemiol. 1997; 32:398407 


\section{APÊNDICES}

APÊNDICE 1 - Pedido de autorização institucional

Macapá, de

de 2014.

Prezado(a) Sr.(a),

Venho por meio desta, solicitar autorização para que eu Ronédia Monteiro Bosque, doutoranda do programa de Pós - Graduação em Cuidado da Saúde da Escola de Enfermagem da Universidade de São Paulo possa realizar a pesquisa intitulada: "Avaliação dos Centros de Atenção Psicossocial em Álcool e outras Drogas do Estado do Amapá", sob a Coordenação da Prof. ${ }^{a}$ Dr. . Márcia Aparecida Ferreira de Oliveira.

$\mathrm{Na}$ oportunidade, esclareço que a pesquisa será realizada nos CAPSad do Estado do Amapá, com os coordenadores, membros das equipes técnicas, usuários e familiares. A pesquisa tem por finalidade avaliar a qualidade de atenção em saúde oferecida nos CAPSad.

O objetivo geral da pesquisa é avaliar a qualidade das práticas assistenciais por meio da estrutura, processo e resultado da atenção aos usuários de álcool e outras drogas desenvolvidas pelos CAPSad do Estado do Amapá junto aos coordenadores, profissionais, usuários e familiares destes serviços.

Agradeço antecipadamente, e me coloco à disposição para quaisquer esclarecimentos que se fizerem necessários.

Ronédia Monteiro Bosque

Doutoranda do Programa de Pós - Graduação em Cuidado da Saúde da Escola de Enfermagem da Universidade de São Paulo,

Fone: 55(96) 81115494 
APÊNDICE 2 - Termo de consentimento livre e esclarecido - Coordenador e técnicos do CAPSad

(RESOLUÇÃO 466/12 DO MINISTÉRIO DA SAÚDE)

Nome do entrevistado

Pesquisadora: Ronédia Monteiro Bosque - doutoranda fone: 55 (96) 81115494 e-mail ronedia@usp.br programa de Pós Graduação da escola de enfermagem da Universidade de São Paulo.

Coordenadora do Projeto - Prof..$^{a}$ Dr. ${ }^{a}$ Márcia Aparecida Ferreira de Oliveira - Professora Associada do Departamento de Enfermagem Materno Infantil e Psiquiátrica da Escola de Enfermagem da Universidade de São Paulo e-mail: marciaap@usp.br

Estamos apresentando o Sr. (a) o presente termo de consentimento livre e informado caso queira e concorde em participar de nossa pesquisa, intitulada "Avaliação dos Centros de Atenção Psicossocial em Álcool e outras Drogas do Estado do Amapá", autorizando a minha observação durante o seu trabalho no CAPSad, a aplicação de formulários referentes às etapas de coleta de dados do estudo e a consulta aos prontuários.

Esclarecemos que o referido estudo tem como objetivo: avaliar a qualidade das práticas assistenciais por meio da estrutura, processo e o resultado da atenção aos usuários de álcool e outras drogas desenvolvida pelos CAPSad do Estado do Amapá, junto aos coordenadores, profissionais, usuários e familiares destes serviços.

Garantimos o sigilo e o anonimato dos sujeitos desse estudo, o livre acesso aos dados, bem como a opção de não participação em qualquer uma das fases do processo. Caso você tenha disponibilidade e interesse em participar como sujeito deste estudo, autorize e assine o consentimento abaixo:

Pelo presente consentimento livre e informado, declaro que fui informado (a) de forma clara, dos objetivos, da justificativa, dos instrumentos utilizados na presente pesquisa.

Declaro que aceito voluntariamente participar do estudo e autorizo o uso do gravador nos momentos em que se fizer necessário.

Fui igualmente informado (a) da garantia de: solicitar resposta a qualquer momento às informações sobre riscos e benefícios relacionados à pesquisa; da liberdade de retirar meu consentimento em qualquer momento do estudo sem que isto me traga qualquer prejuízo do meu atendimento; do sigilo e anonimato; e de que não sofrerei qualquer prejuízo, caso me negue a participar do estudo ou interrompa minha participação.

Enfim, foi garantido que todas as determinações ético-legais serão cumpridas antes, durante e após o término desta pesquisa. 
Local/Data:

Assinatura do participante:

Em caso de dúvida ou denúncias sobre irregularidades éticas, entrar em contato com o comitê de ética em pesquisa da Escola de Enfermagem da Universidade de São Paulo por meio do telefone: 55 (11) 30617548 ou e-mail edipesq@usp.br. Endereço: Av. Dr. Enéias de Carvalho Aguiar, 419 - CEP 05403-000-São Paulo - SP. 
APÊNDICE 3 - Carta convite do responsável legal dos participantes da pesquisa.

MACAPÁ de de 2014.

Prezado(a ) Sr.(a).

O convidamos a participar, bem como autorizar a participação de seu familiar, usuário do CAPSad, de uma pesquisa que Eu Ronédia Monteiro Bosque - doutoranda, vinculada ao Programa de Pós - Graduação em Enfermagem da Escola de Enfermagem da Universidade de São Paulo (EEUSP), intitulada como: “Avaliação dos Centros de Atenção Psicossocial em Álcool e outras Drogas do Estado do Amapá”, sob coordenação da Prof. ${ }^{a}$ Márcia Aparecida Ferreira de Oliveira".

A pesquisa tem por finalidade: Avaliar a qualidade das práticas assistenciais por meio de estrutura, o processo e o resultado da atenção aos usuários de álcool e outas drogas desenvolvida pelo CAPSad da Grande São Paulo junto aos coordenadores, profissionais, usuários e familiares destes serviços.

Você e seu familiar, que é usuário do CAPSad, são livres para expressarem suas ideias e poderão fazer questionamentos sobre o estudo e sobre a participação de vocês nele. Se tiverem alguma dúvida procuraremos esclarecê-la em qualquer fase da pesquisa.

A sua participação e de seu familiar usuário do serviço é voluntária, sendo assim vocês não são obrigados (as) a participarem do estudo. Vocês têm o direito de abandonar a pesquisa em qualquer etapa, e em momento algum isto lhe trará prejuízos ou constrangimentos.

Se vocês se negarem a participar da pesquisa ou interrompê-la, não sofrerão nenhum prejuízo.

A sua participação na pesquisa, bem como de seu familiar, usuário do CAPSad, não oferece a vocês nenhum risco e o benefício que a pesquisa trará a você, ao seu familiar e aos trabalhadores do serviço está relacionado às melhorias do atendimento e tratamento do CAPSad, uma vez que os resultados do estudo ajudarão a melhorar o trabalho que é realizado no serviço, no sentido de melhorar a qualidade de vida de todos os envolvidos.

Os dados da presente pesquisa serão registrados e analisados; posteriormente, no momento em que forem publicados, seus nomes não serão constaram nos registros.

Assim, a identidade de vocês não será revelada em nenhum momento, nem mesmo na fase de publicação do estudo.

Agradecemos antecipadamente, e nos colocamos a disposição para quaisquer esclarecimentos que fizerem necessários. 
Ronédia Monteiro Bosque

Doutoranda do Programa de Pós - Graduação em Enfermagem da (EEUSP)

Em caso de dúvidas ou denúncias sobre irregularidades éticas, entrar em contato com o comitê de Ética em pesquisa da Escola de Enfermagem da Universidade de São Paulo por meio do Tel.: 55 (11) 30617548 ou e-mail: edpesq@usp.br, end. Rua Enéias de Carvalho de Aguiar, no 419 - CEP 05403-000 - São Paulo - SP. 
APÊNDICE 4 - Termo de consentimento livre e esclarecido - Do participante ou do representante legal do participante (RESOLUÇÃO 466/12 DO MINISTÉRIO DA SAÚDE)

Nome do entrevistado

Pesquisadora: Ronédia Monteiro Bosque - doutoranda fone: 55 (96) 81115494 e-mail ronedia@usp.br no programa de Pós Graduação da escola de enfermagem da Universidade de São Paulo.

Coordenadora do Projeto - Prof. ${ }^{\text {a }}$ Dr. ${ }^{-}$Márcia Aparecida Ferreira de Oliveira

Professora Associada do Departamento de Enfermagem Materno Infantil e Psiquiátrica da Escola de Enfermagem da Universidade de São Paulo e-mail: marciaap@usp.br.

Estamos apresentando ao Sr.(a) o presente termo de consentimento livre e informado caso queira e concorde em participar de nossa pesquisa, intitulada "Avaliação dos Centros de Atenção Psicossocial em Álcool e outras drogas do Estado do Amapá”, autorizando a minha observação durante a sua permanência no CAPSad, a realização de uma entrevista por meio da aplicação de formulários às etapas de coleta de dados do estudo e a consulta aos prontuários. Esclarecemos que o referido estudo tem como objetivo: avaliar a qualidade das práticas assistenciais por meio da estrutura, o processo e o resultado da atenção aos usuários de álcool e outras drogas desenvolvida pelos CAPSad do Estado do Amapá junto aos coordenadores, profissionais, usuários e familiares destes serviços.

Garantimos o sigilo e anonimato dos sujeitos desse estudo, o livre acesso aos dados, bem como a opção de não participação em qualquer uma das fases do processo. Caso você tenha disponibilidade e interesse em participar como sujeito desse estudo, autorize e assine o consentimento abaixo:

Pelo presente consentimento livre e informado, declaro que fui informado (a) de forma clara, dos objetivos, da justificativa, dos instrumentos utilizados na presente pesquisa. Declaro que aceito voluntariamente participar do estudo e autorizo o uso do gravador dos momentos em que se fizer necessário.

Fui igualmente informado (a) da garantia de: solicitar resposta a qualquer dúvida com relação aos procedimentos; do acesso em qualquer momento às informações sobre procedimentos, riscos e benefícios relacionados à pesquisa; da liberdade de retirar meu consentimento em qualquer momento do estudo sem que isso me traga qualquer prejuízo do meu atendimento; do sigilo e anonimato; e de que não sofrerei qualquer prejuízo, caso me negue a participar do estudo ou interrompa a minha participação.

Enfim, fui garantido que todas as determinações ético-legais serão cumpridas antes, durante e após o término desta pesquisa. 
Local/Data:

Assinatura do Participante:

Em caso de dúvidas ou denúncias sobre irregularidades éticas, entrar em contato com o comitê de Ética em pesquisa da Escola de Enfermagem da Universidade de São Paulo por meio do Tel.: 55 (11) 3061-7548 ou e-mail: edpesq@usp.br, end.: Rua Enéias de Carvalho de Aguiar, no 419 - CEP 05403-000 - São Paulo - SP.. 


\section{ANEXOS}

ANEXO 1 - Parecer do Comitê de Ética em Pesquisa.

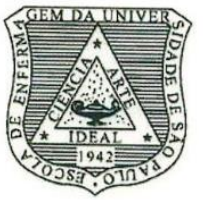

UNIVERSIDADE DE SÃO PAULO

ESCOLA DE ENFERMAGEM

Av. Dr. Enéas de Carvalho Aguiar, 419 - CEP 05403-000

Tel.: (011) 3061-7548/8858 - Fax: (011) 3061-7548 -

Săo Paulo - SP - Brasil

São Paulo, 24 de maio de 2011.

Ilm. ${ }^{a}$ Sr. ${ }^{a}$

Maria Odete Pereira

Ref.: Processo nº 1001/2011/CEP-EEUSP - - SISNEP - CAAE: 0005.0.196.000-11

Prezada Senhora,

Em atenção à solicitação referente à análise do projeto "Metodologias de avaliação e medidas políticas de impacto para ações em álcool e outras drogas", a ser desenvolvido no Departamento de Enfermagem Materno-Infantil e Psiquiátrico desta Instituição, sob a responsabilidade da Professora Doutora Márcia Aparecida Ferreira de Oliveira, foi considerado aprovado pelo Comitê de Ética em Pesquisa da Escola de Enfermagem da Universidade de São Paulo (CEP/EEUSP).

Analisado sob o aspecto ético-legal, atende às exigências da Resolução $n^{\circ}$ 196/96 do Conselho Nacional de Saúde.

Esclarecemos que após o término da pesquisa, os resultados obtidos deverão ser encaminhados ao CEP/EEUSP, para serem anexados ao processo.

Atenciosamente,

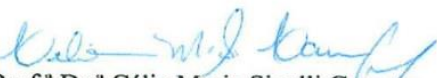

Prof. ${ }^{a}$ Dr. ${ }^{a}$ Célia Maria Sivalli Campos

Coordenadora do Comitê de Ética em Pesquisa da

Escola de Enfermagem da Universidade de São Paulo 
ANEXO 2 - Instrumento para o coordenador do serviço.

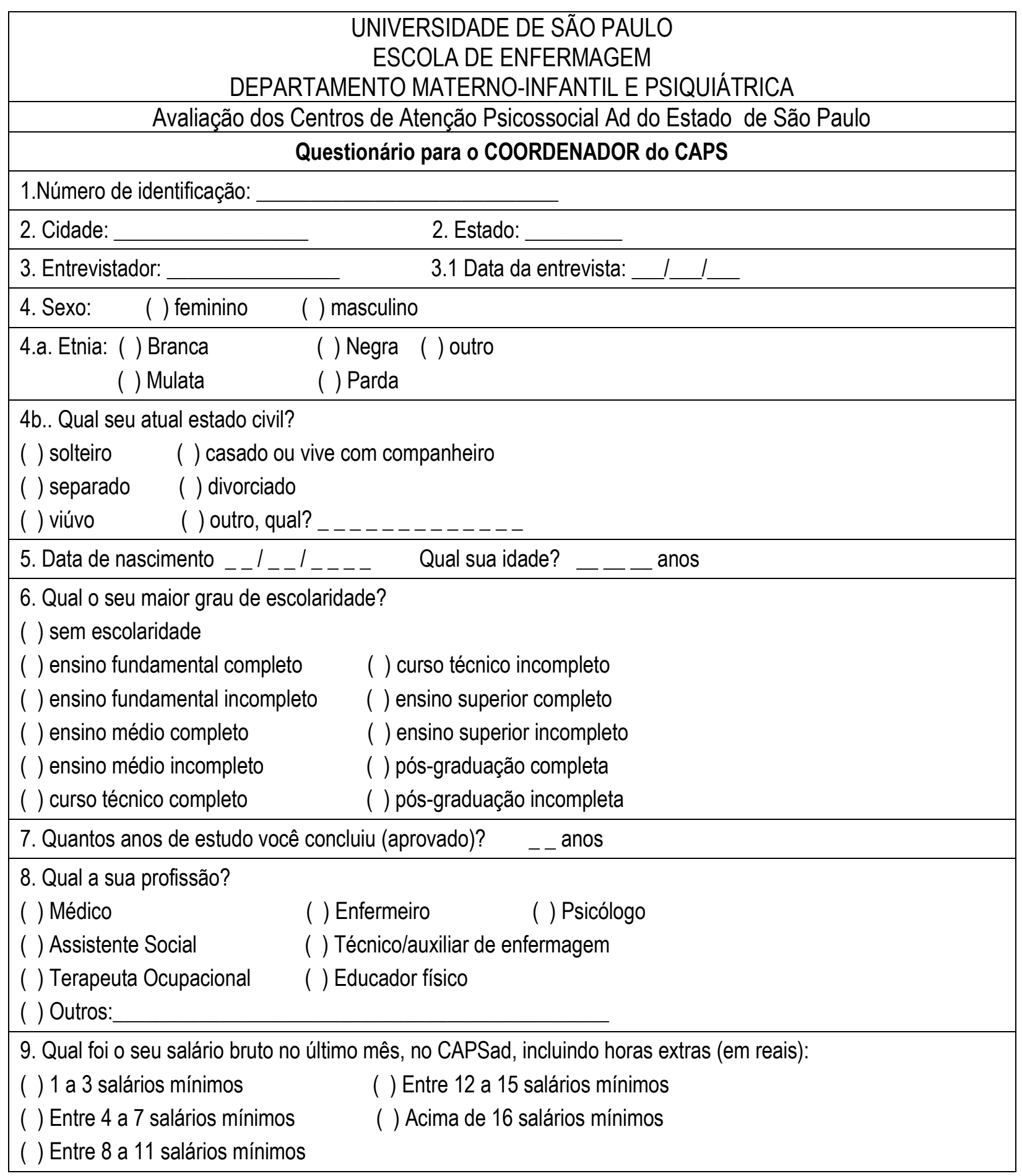




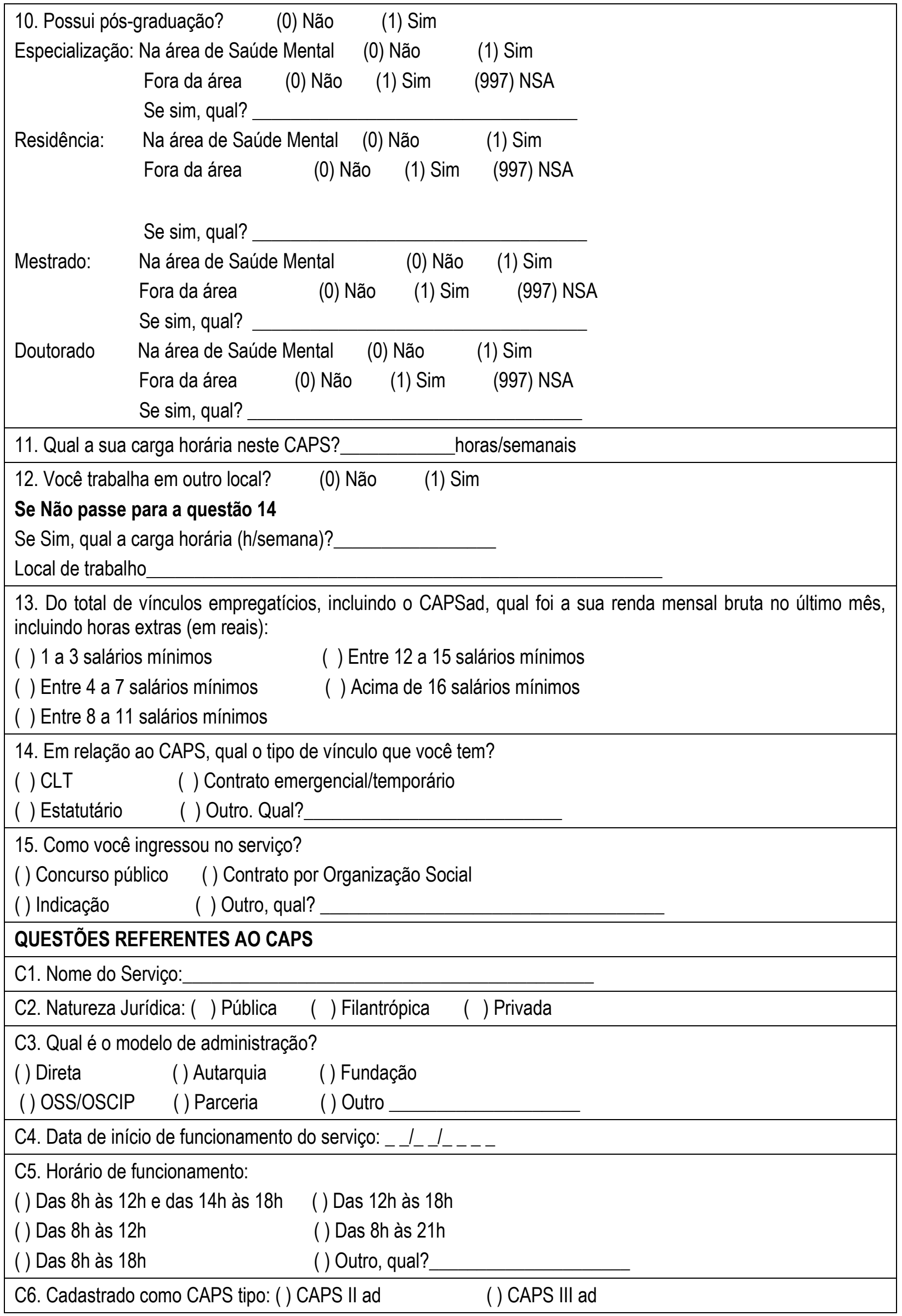




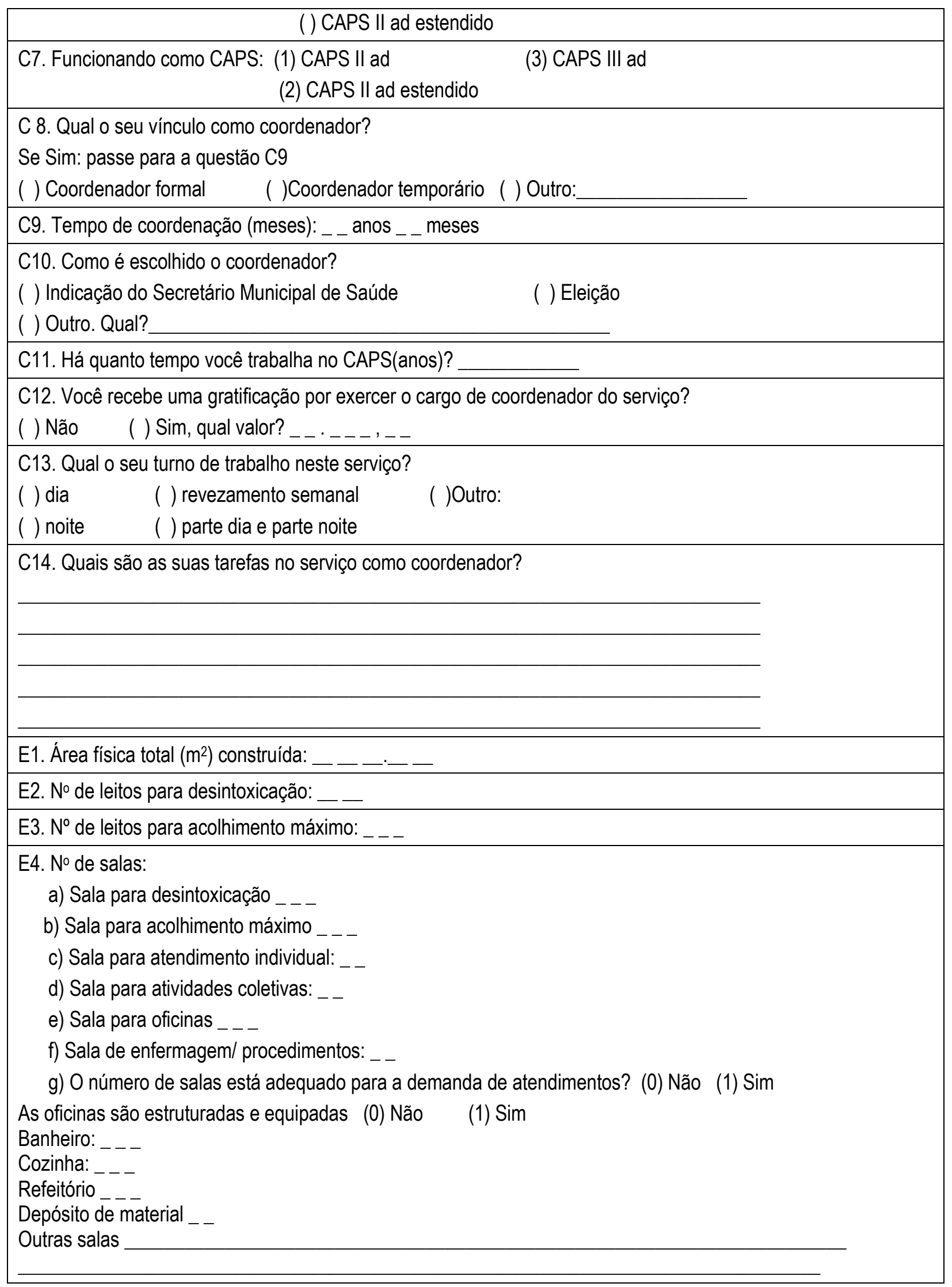




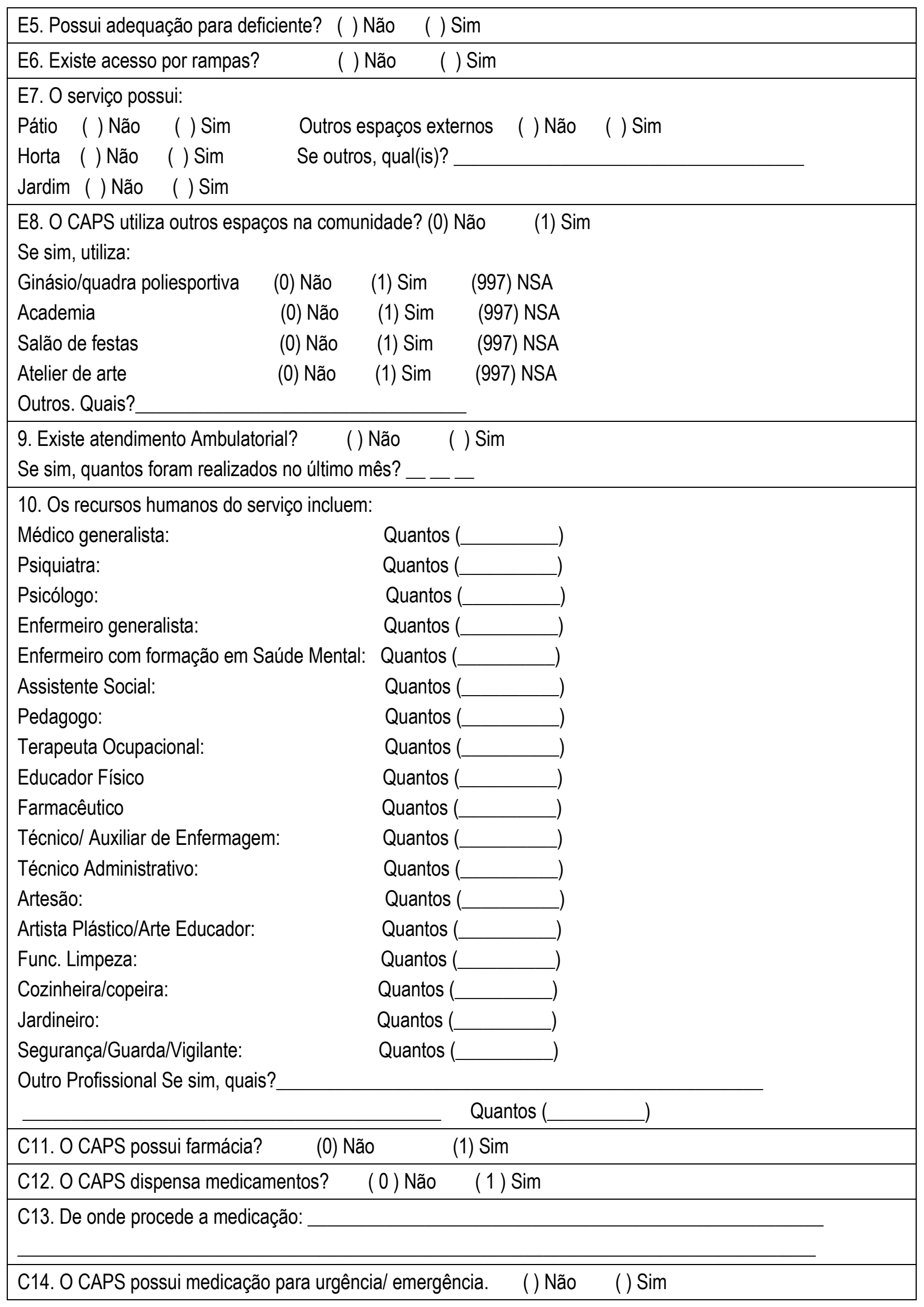




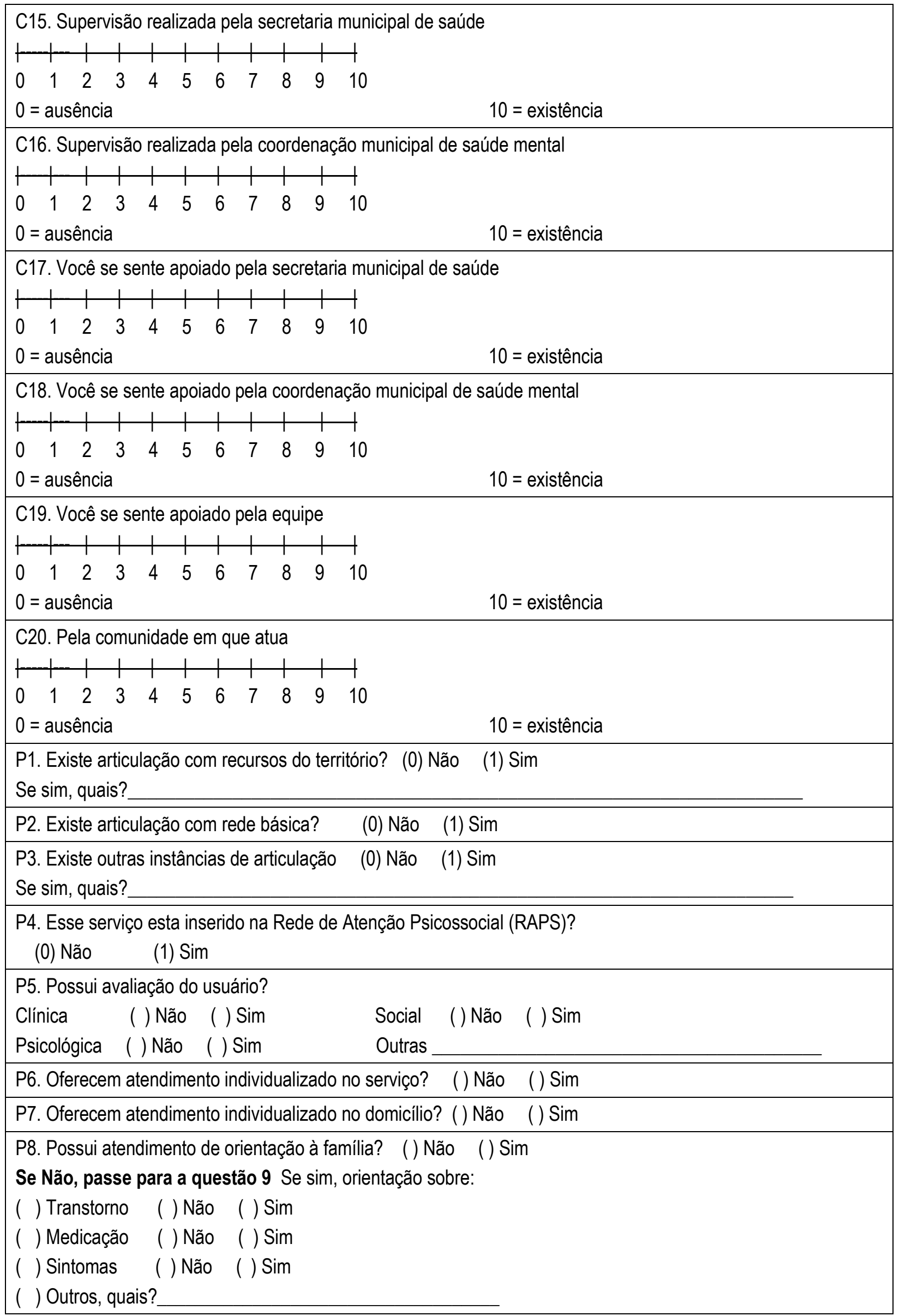




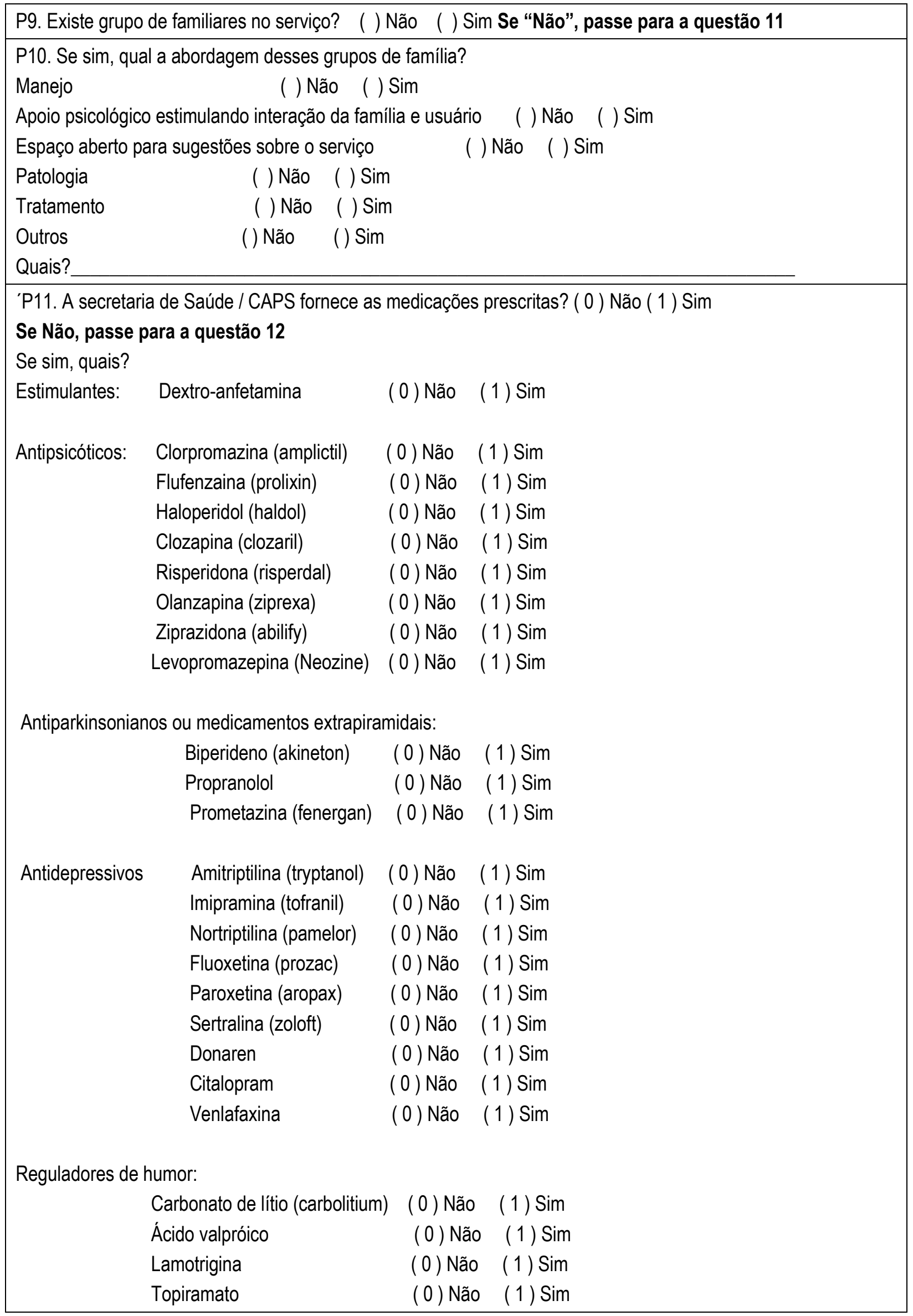




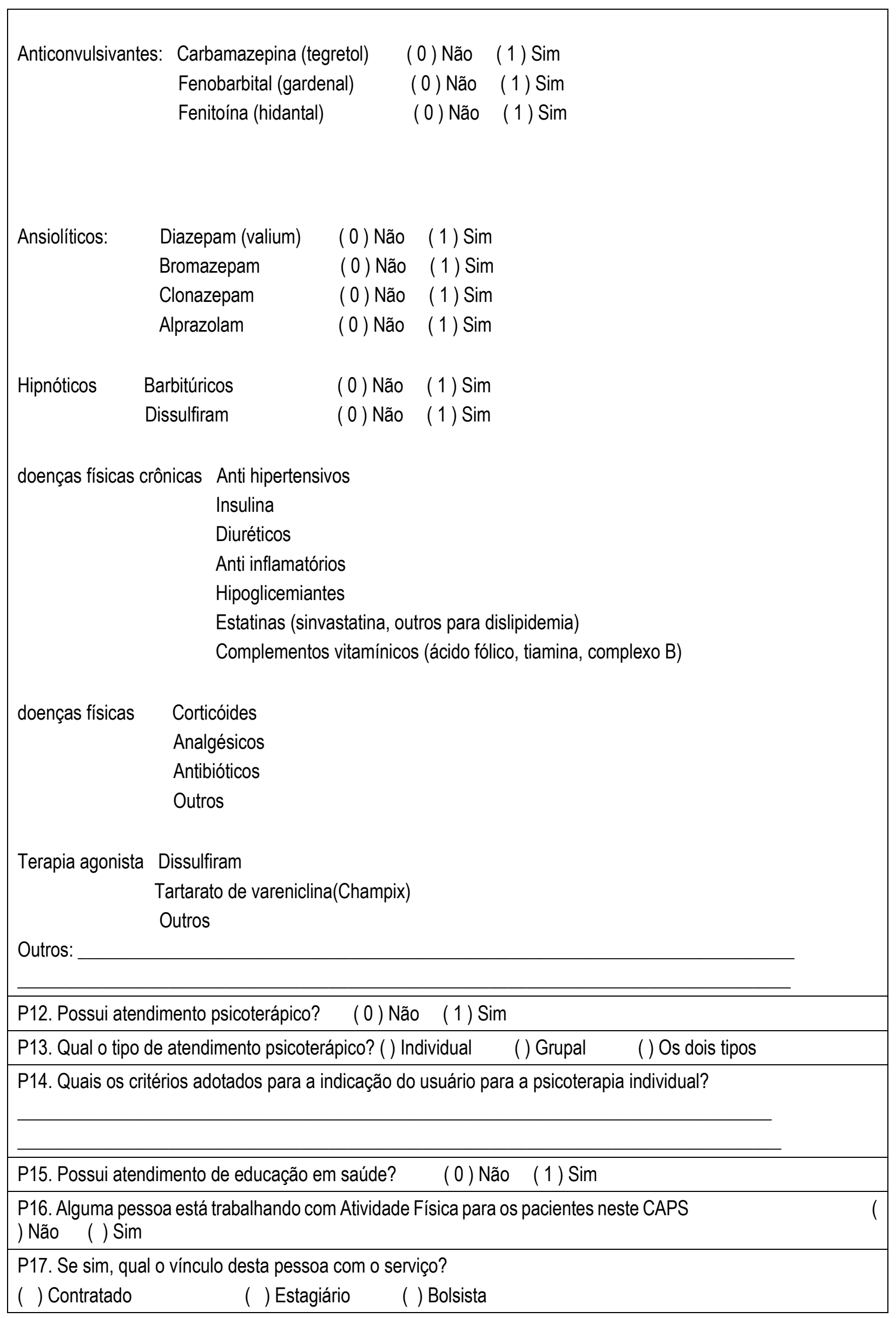




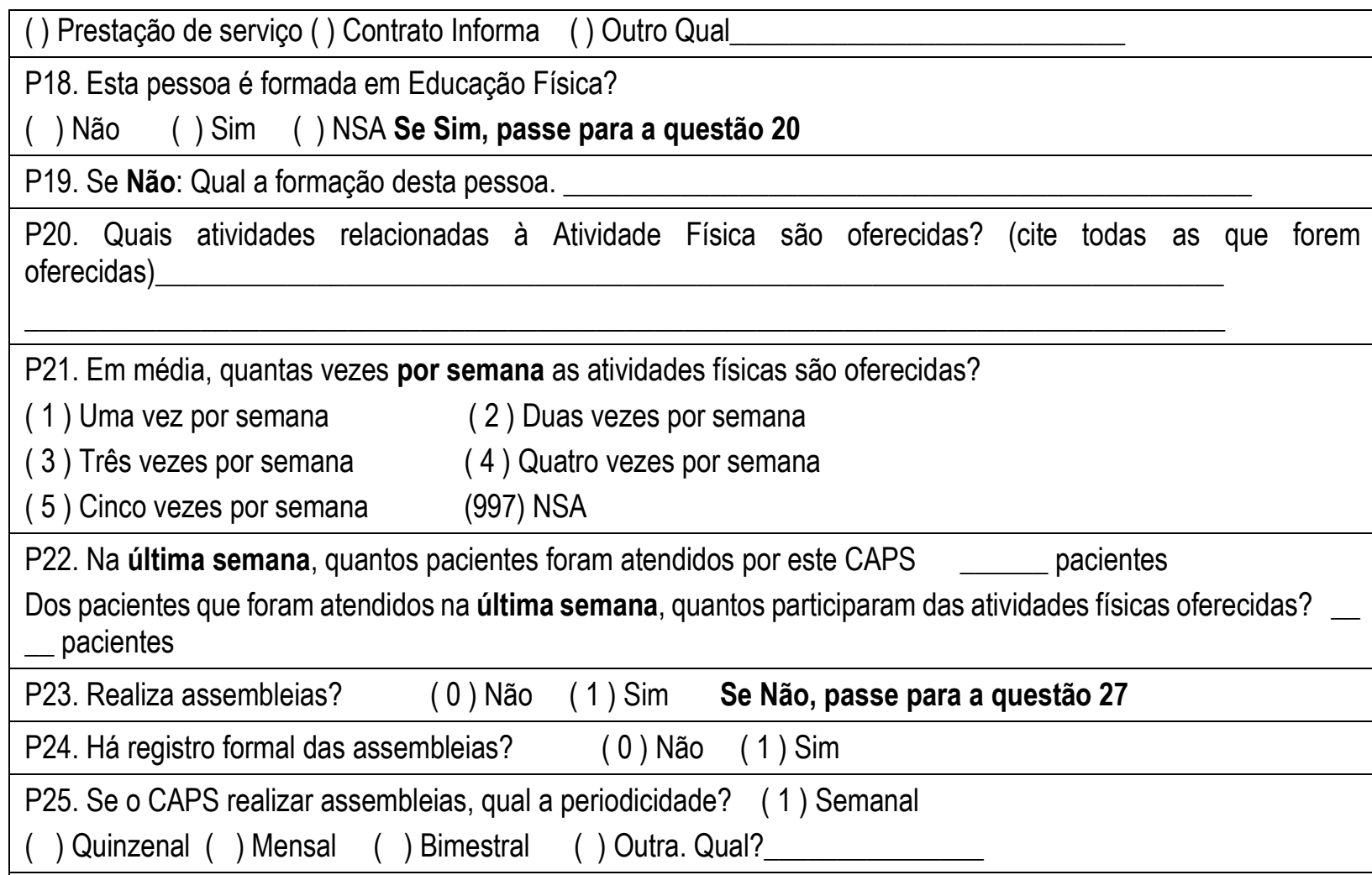

P26. Quem participa das assembleias?
( 1 ) Usuário
( 0 ) Não (1) Sim
(2) Familiares
( 0 ) Não (1) Sim
(3) Equipe
( 0 ) Não (1) Sim
( 4 ) Comunidade
( 0 ) Não (1) Sim
(999) Outros
( 0 ) Não (1) Sim Quais?

P27. O serviço realiza projetos de geração de renda? ( )Não

Se Não, porque?

P28. Qual é a regulamentação dessa atividade ( )Cooperativas ( ) ONGS ( ) Outro

P29. Possui abordagem interdisciplinar? ( 0 ) Não (1) Sim

P30. O serviço possui algum mecanismo para evitar internações em situações de crise ( ) Não ( ) Sim

Se SIM, quais mecanismos? Cite pelo menos 3

Se NÃO, para onde encaminha? () Pronto Socorro

( ) Emergência Psiquiátrica ( ) Internação em Hospital Geral

( ) Internação em Hospital Psiquiátrico ( ) Outro
P31. Como são indicadas as internações. ( )Em reunião de equipe
(2) Pelo médico

() Outros, quais? 
P32. Excluindo as situações de emergências clínicas e psquiátricas, quais são os critério para internação em AOD neste caps?

() A voluntariedade do usuário

( ) $O$ esgotamento todas as possibilidades de tratamento no CAPS

(3) Outro, quais?

P33. Para onde são encaminhadas as internações em AOD?

Enfermaria especializada em AOD em hospital geral ( ) Não ( ) Sim

Comunidade terapêutica () Não () Sim

Hospital Psiquiátrico () Não () Sim

Outros, quais?

P34. Cite as 3 principais dificuldades em relação ao fluxo de internação neste CAPS?

P35. Quanto tempo se espera pela vaga fornecida pela central de vagas?
() Até 3 dias
() Até 1 semana
( ) Até 2 semanas
( ) Mais que 2 semanas
() outros,

36. Há outra via de acesso, não citada, para a obtenção de vaga de internação () Não （） Sim Se SIM, quais

37. Quem participa das reuniões de equipe?
Médico:
( 0 ) Não (1) Sim
Psiquiatra:
( 0 ) Não (1) Sim
Psicólogo:
( 0 ) Não (1) Sim
Enfermeiro:
( 0 ) Não (1) Sim
Assistente Social:
( 0 ) Não (1) Sim
Terapeuta ocupacional:
( 0 ) Não (1) Sim
Técnico ou Auxiliar de Enfermagem:
( 0 ) Não (1) Sim
Técnico Administrativo:
( 0 ) Não (1) Sim
Artista Plástico:
( 0 ) Não (1) Sim

Se existir outro profissional, liste-os

P38. Qual a periodicidade das reuniões de equipe?
(1) Semanal
( 2 ) Quinzenal
( 3 ) Mensal
( 4 ) Bimestral
(5) Conforme a necessidade
(6) Não realiza

P39. Qual a duração dessas reuniões? (tempo médio em minutos)

\section{P40. Abordam questões administrativas? \\ ( 0 ) Não (1) Sim}

Se Não, passe para a questão 42

P41. Se sim com que frequência?
(1) Semanal
(2) Quinzenal
( 3 ) Mensal
(4) Bimestral
(999) Outro (especificar): 
P42. Abordam questões técnicas (discussões de Projetos Terapêuticos Singulares (PTS) discussões de casos, discussões sobre medicações)?

( 0 ) Não (1) Sim (997) NSA

\section{Se Não, passe para a questão 44}

P43. Com qual frequência?
(1) Semanal
( 2 ) Quinzenal
( 3 ) Mensal
( 4 ) Bimestral
(999) Outro (997) NSA

P44. Possui sistema de referência para outros serviços?

Atendimento especializado () Não ( ) Sim

Se sim: ( 2 ) Formal $\quad(3)$ Informal

Emergência Psiquiátrica $\quad$ ( 0 ) Não $\quad$ (1) Sim

Se sim: ( 2 ) Formal (3) Informal

Hospital Geral (internação psiquiátrica) ( 0 ) Não (1) Sim

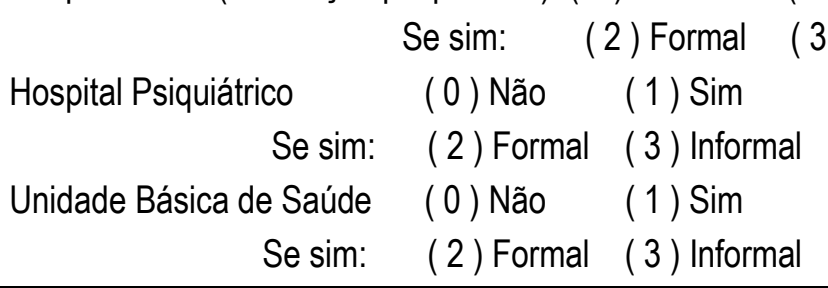

P45. Possui sistema de contra referência?

\begin{tabular}{|c|c|c|}
\hline Atendimento especializado & ( 0 ) Não & (1) Sim \\
\hline Se sim: & ( 2 ) Formal & ( 3 ) Informal \\
\hline Emergência Psiquiátrica & ( 0 ) Não & (1) Sim \\
\hline Se sim: & ( 2 ) Formal & ( 3 ) Informal \\
\hline Hospital Geral & ( 0 ) Não & (1) Sim \\
\hline Se sim: & ( 2 ) Formal & ( 3 ) Informal \\
\hline Hospital Psiquiátrico & ( 0 ) Não & (1) Sim \\
\hline Se sim: & ( 2 ) Formal & ( 3 ) Informal \\
\hline Unidade Básica de Saúde & ( 0 ) Não & (1) Sim \\
\hline Se sim: & ( 2 ) Formal & ( 3 ) Informal \\
\hline
\end{tabular}

P46. Na sua opinião, o fluxo de referência e contra referência é organizado ( 0 ) Não (1) Sim

P47. O serviço referencia internação psiquiátrica. ( ) Não ( ) Sim Se Não, passe para a questão 49

P48. Se sim, onde os pacientes são internados?

Hospital geral (0) Não (1) Sim

Se Sim: qual o local/ cidade?

Hospital psiquiátrico ( 0 ) Não (1) Sim

Se Sim: qual o local/ cidade?

P49. Conta com associação de usuários? ( 0 ) Não (1) Sim

P50. Possui projeto terapêutico institucional? ( 0 ) Não (1) Sim

P51. Os usuários possuem plano terapêutico singular? ( 0 ) Não ( 1 ) Sim

P52. O serviço conta com Conselho Gestor Local? ( ) Não ( ) SimSe Não, passe para a questão 54

P53. Se Sim, qual a periodicidade das reuniões?

(1) Quinzenal (2) Mensal (3) Anual (999) Outros 
P54. O usuário possui algum técnico de referência? () Não ( ) Sim Se Não, passe para a questão 55

Se sim, qual categoria profissional entra como técnico de referência?

$\begin{array}{lll}\text { Médico: } & \text { ( } 0 \text { ) Não } & \text { ( } 1 \text { ) Sim } \\ \text { Psicólogo: } & \text { ( } 0 \text { ) Não } & \text { (1) Sim } \\ \text { Enfermeiro: } & \text { ( } 0 \text { ) Não } & \text { ( } 1 \text { ) Sim } \\ \text { Assistente Social: } & \text { ( } 0 \text { ) Não } & \text { (1) Sim } \\ \text { Terapeuta ocupacional: } & \text { ( } 0 \text { ) Não }\end{array}$

Técnico ou Auxiliar de Enfermagem:

(1) Sim

Outro Profissional: ( ) Não ( ) Sim Se sim, qual?

P55. Existem programas de estágios / extensão? ( ) Não ( ) Sim Se Não, passe para questão 56 Se sim, qual o caráter dos estágios?
(1) Voluntário
( 0 ) Não
(1) $\operatorname{Sim}$
( 2 ) Curricular
( 0 ) Não (1) Sim
(3) Curso técnico
( 0 ) Não
(1) $\operatorname{Sim}$
( ) Outro Qual?
Quais áreas realizou estágios?

$\begin{array}{lll}\text { Medicina } & \text { ( ) Não } & \text { ( ) Sim } \\ \text { Enfermagem } & \text { ( ) Não } & \text { ( ) Sim } \\ \text { Psicologia } & \text { ( ) Não } & \text { ( ) Sim } \\ \text { Serviço Social } & \text { ( ) Não } & \text { ( ) Sim } \\ \text { Terapia Ocupacional } & \text { ( ) Não } & \text { ( ) Sim } \\ \text { Artes } & \text { ( ) Não } & \text { ( ) Sim }\end{array}$
( ) Outra. Qual?

\section{O CAPS contempla:}

P56. Acolhimento diurno?

$\begin{array}{ll}\text { ( } 0 \text { ) Não } & (1) \text { Sim } \\ \text { ( } 0 \text { ) Não } & \text { ( } 1 \text { ) Sim }\end{array}$

P57. Acolhimento noturno?

( 0 ) Não (1) Sim

P58. Acesso livre dos usuários?

P59. Acesso com hora marcada dos usuários? ( 0 ) Não (1) Sim

P60. Que profissional realiza o acolhimento?

Técnico de Enfermagem (0) Não (1) Sim

Enfermeiro ( 0 ) Não (1) Sim

Técnico Administrativo (0) Não (1) Sim

Psicólogo ( 0 ) Não (1) Sim

Médico Psiquiatra (0) Não (1) Sim

Assistente Social ( 0 ) Não (1) Sim

Artista Plástico (0) Não (1) Sim

Outro Profissional ( 0 ) Não (1) Sim, qual?

P61. É realizada triagem no serviço? ( 0 ) Não (1) Sim

P62. O serviço realiza manejo do usuário em situação de crise como surto, agitação psicomotora, risco de agressão a outros ou a si mesmo?

( ) Não ( ) Sim

P63. O serviço atende pessoas com risco de suicídio? ( ) Não ( ) Sim

P64. O serviço tem estrutura para atender pessoas em risco de suicídio ( ) Não ( ) Sim 


\begin{tabular}{|c|}
\hline P65. O serviço realiza acolhimento por tentativa de suicídio? \\
\hline P66. O serviço solicita exames laboratoriais? \\
\hline 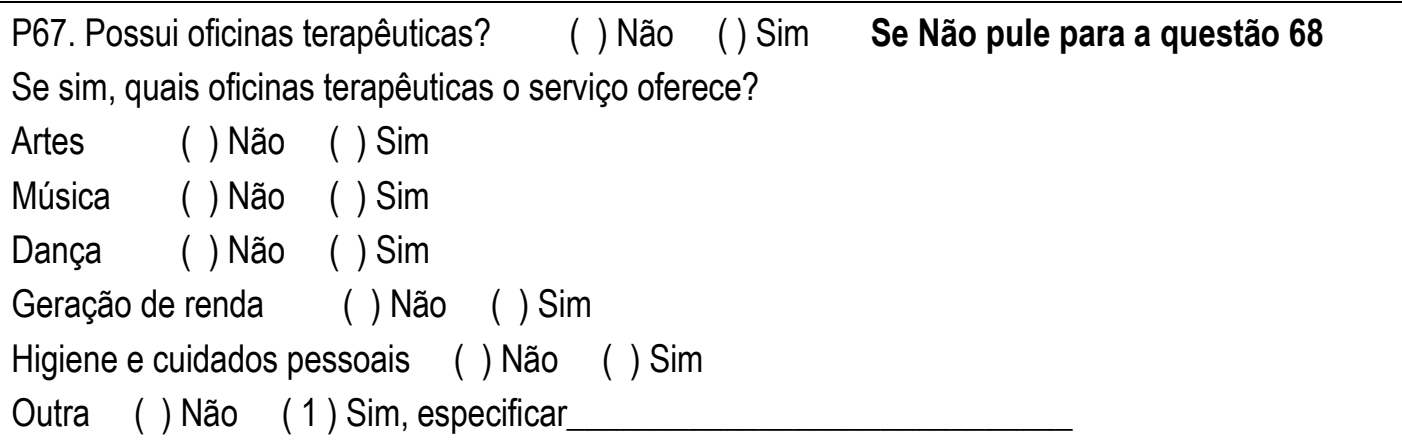 \\
\hline $\begin{array}{l}\text { P68. Possui atividades grupais ( ) Não ( ) Sim Se Não pule para a questão } 69 \\
\text { Se sim as atividades grupais tem caráter: } \\
\text { Operativo } \quad \text { ( ) Não } \quad \text { ( ) Sim } \\
\text { Psicoterapia ( ) Não } \quad \text { ( ) Sim } \\
\text { Psico-educação ( ) Não ( ) Sim } \\
\text { Prevenção de recaída } \quad \text { ( ) Não ( ) Sim } \\
\text { Outro ( ) Não ( ) Sim, especificar }\end{array}$ \\
\hline $\begin{array}{l}\text { P69. Realiza visitas domiciliares? } \\
\text { Se sim, qual o objetivo da visita? }\end{array}$ \\
\hline 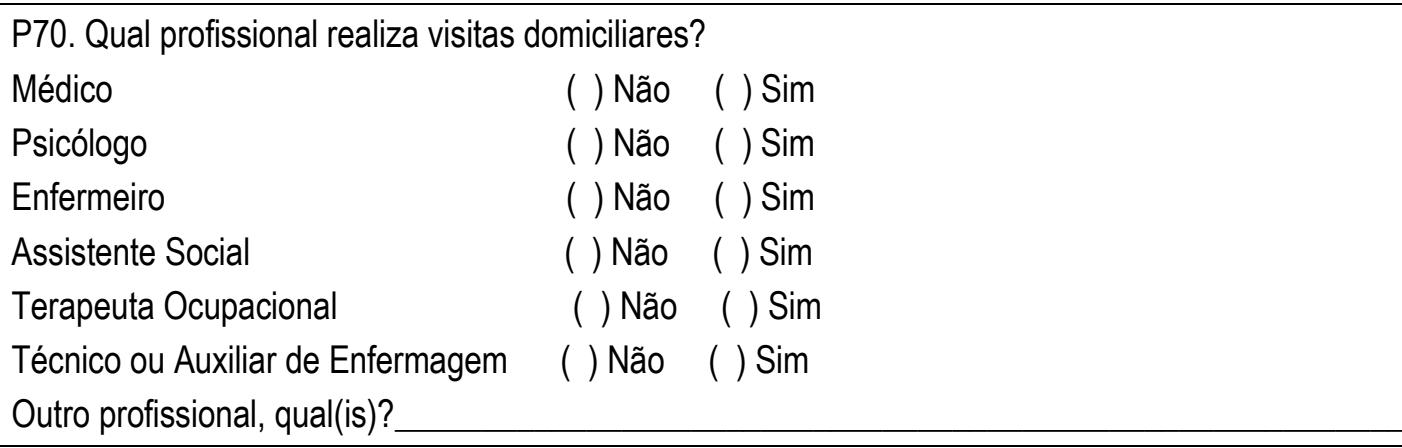 \\
\hline $\begin{array}{l}\text { P71. Com que frequência são realizadas? } \\
\begin{array}{llll}\text { ( ) Semanal } \quad \text { ( ) Quinzenal } & \text { ( ) Mensal } & \text { ( ) Bimestral } \\
\text { ( ) Conforme a necessidade } & \text { ( ) Outro. Qual? } & \end{array}\end{array}$ \\
\hline $\begin{array}{l}\text { P72. O serviço possui transporte para a realização das visitas domiciliares. } \\
\text { Se sim: com que frequência o transporte está disponível para uso do serviço? } \\
\begin{array}{lll}\text { ( ) Todos os dias } & \text { ( ) Duas vezes por semana } & \text { ( ) Três vezes por semana } \\
\text { () Outro Qual? } & & \end{array}\end{array}$ \\
\hline $\begin{array}{llll}\text { P73. Quais os dispositivos que o serviço dispõe para garantia dos direitos de cidadania do usuário? } \\
\begin{array}{llll}\text { Promotoria Pública } & \text { ( ) Não } & \text { ( ) Sim } \\
\text { Ouvidoria } & \text { ( ) Não } & \text { ( ) } \operatorname{Sim} \\
\text { Suporte Jurídico } & \text { ( ) Não } & \text { ( ) Sim } & \\
\text { Orientação e encaminhamento de benefícios } & \text { ( ) Não } & \text { ( ) Sim }\end{array}\end{array}$ \\
\hline
\end{tabular}




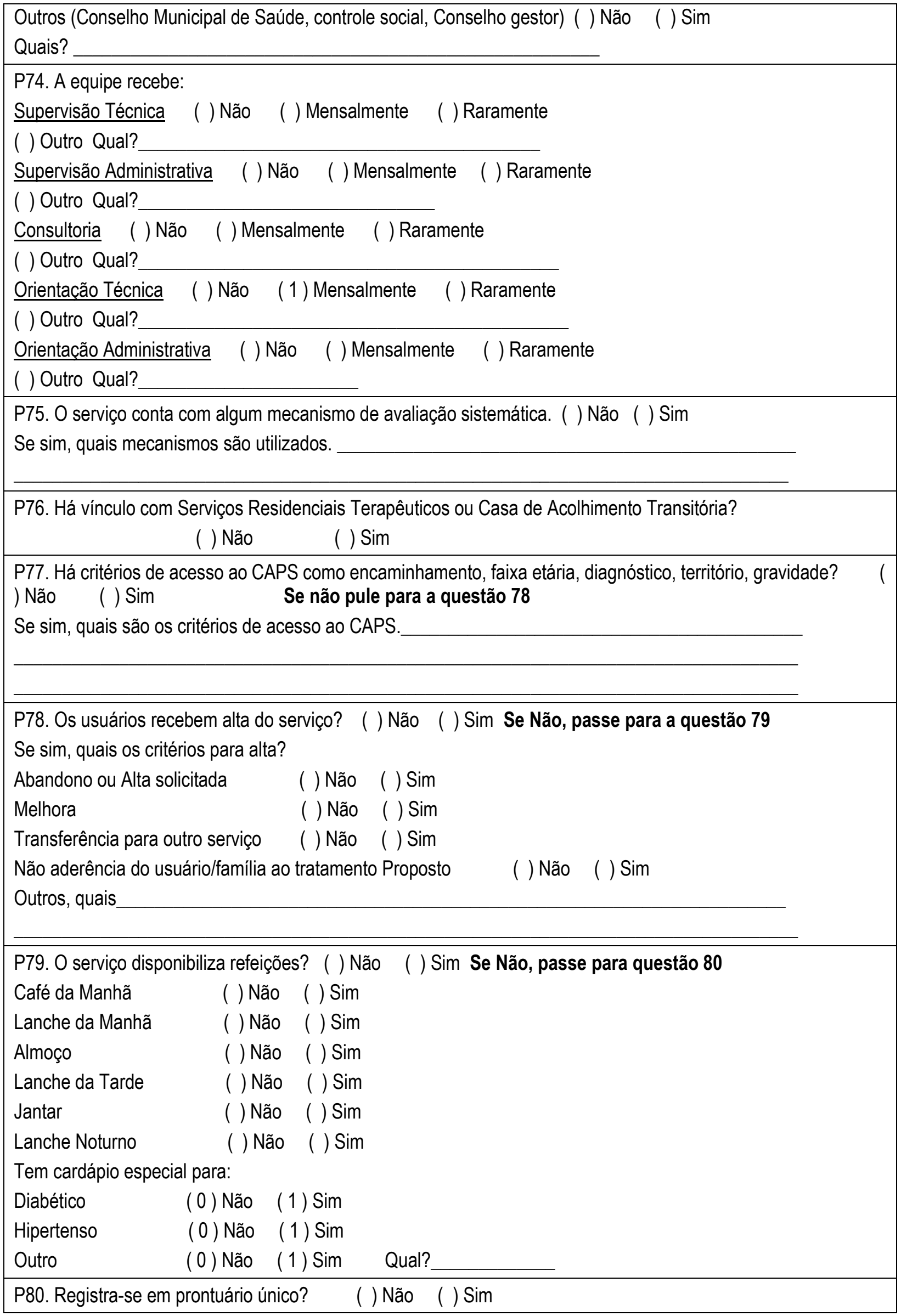




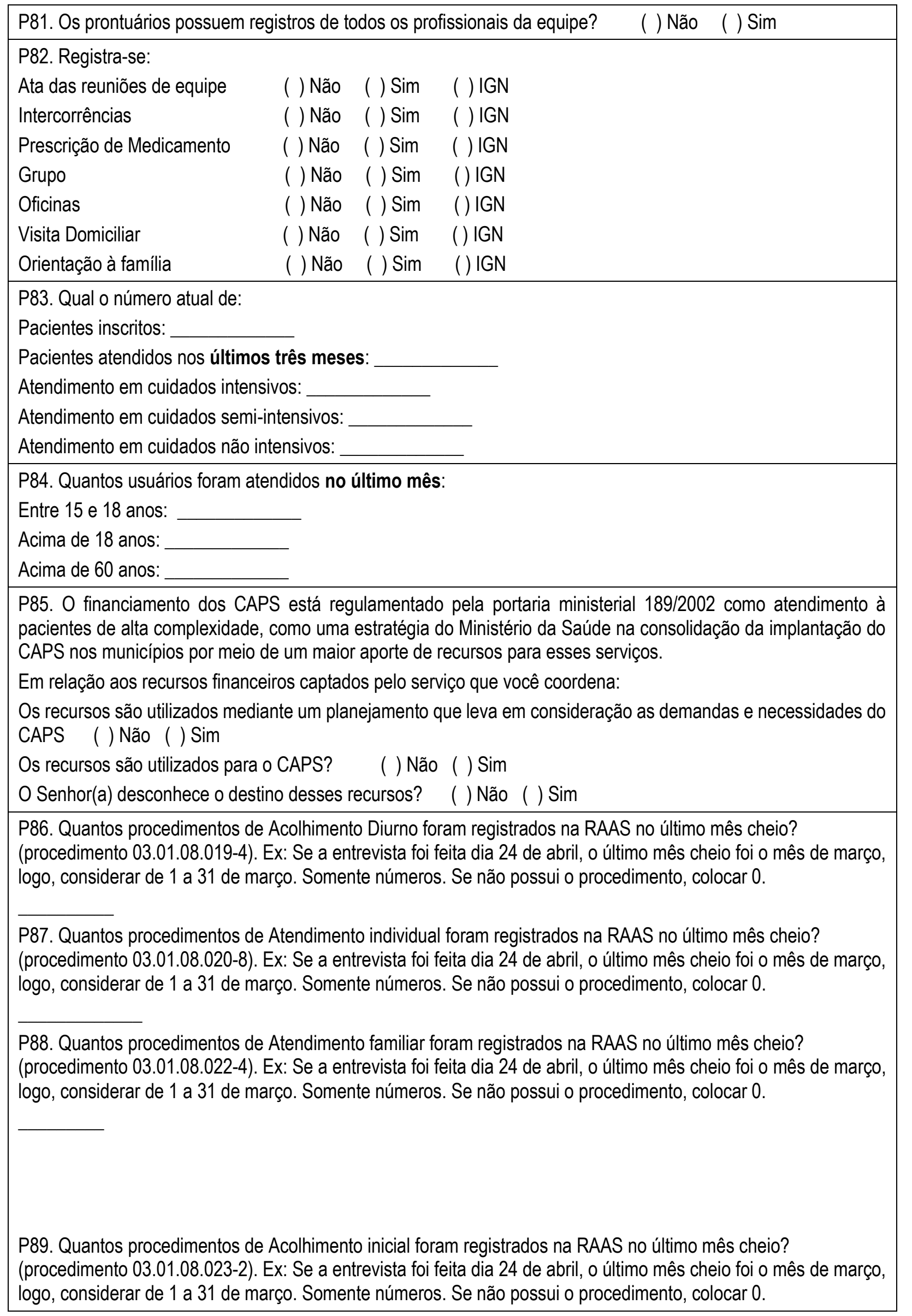


P90. Quantos procedimentos de Atendimento domiciliar foram registrados na RAAS no último mês cheio? (procedimento 03.01.08.024-0). Ex: Se a entrevista foi feita dia 24 de abril, o último mês cheio foi o mês de março, logo, considerar de 1 a 31 de março. Somente números. Se não possui o procedimento, colocar 0.

P91. Quantos procedimentos de Ações de articulação foram registrados na RAAS no último mês cheio? (procedimento 03.01.08.025-9). Ex: Se a entrevista foi feita dia 24 de abril, o último mês cheio foi o mês de março, logo, considerar de 1 a 31 de março. Somente números. Se não possui o procedimento, colocar 0.

P92. Quantos procedimentos de fortalecimento do protagonismo foram registrados na RAAS no último mês cheio? (procedimento 03.01.08.026-7). Ex: Se a entrevista foi feita dia 24 de abril, o último mês cheio foi o mês de março, logo, considerar de 1 a 31 de março. Somente números. Se não possui o procedimento, colocar 0.

P93. Quantos procedimentos de atenção a situações de crise foram registrados na RAAS no último mês cheio? (procedimento 03.01.08.029-1). Ex: Se a entrevista foi feita dia 24 de abril, o último mês cheio foi o mês de março, logo, considerar de 1 a 31 de março. Somente números. Se não possui o procedimento, colocar 0.

P94. Quantos procedimentos de matriciamento de equipe de saúde básica foram registrados na RAAS no último mês cheio? (procedimento 03.01.08.030-5). Ex: Se a entrevista foi feita dia 24 de abril, o último mês cheio foi 0 mês de março, logo, considerar de 1 a 31 de março. Somente números. Se não possui o procedimento, colocar 0 .

P95. Quantos procedimentos de matriciamento de equipe de urgência foram registrados na RAAS no último mês cheio? (procedimento 03.01.08.039-9). Ex: Se a entrevista foi feita dia 24 de abril, o último mês cheio foi o mês de março, logo, considerar de 1 a 31 de março. Somente números. Se não possui o procedimento, colocar 0.

P96. Quantos procedimentos de ações de redução de danos foram registrados na RAAS no último mês cheio? (procedimento 03.01.08.031-3). Ex: Se a entrevista foi feita dia 24 de abril, o último mês cheio foi o mês de março, logo, considerar de 1 a 31 de março. Somente números. Se não possui o procedimento, colocar 0.

P97. Quantos procedimentos de acompanhamento de serviço residencial terapêutico foram registrados na RAAS no último mês cheio? (procedimento 03.01.08.032-1). Ex: Se a entrevista foi feita dia 24 de abril, o último mês cheio foi o mês de março, logo, considerar de 1 a 31 de março. Somente números. Se não possui 0 procedimento, colocar 0 .

P98. Quantos procedimentos de apoio à serviço residencial transitório foram registrados na RAAS no último mês cheio? (procedimento 03.01.08.033-0). Ex: Se a entrevista foi feita dia 24 de abril, o último mês cheio foi o mês de março, logo, considerar de 1 a 31 de março. Somente números. Se não possui o procedimento, colocar 0.

P99. Quantos procedimentos de ações de reabilitação psicossocial foram registrados na RAAS no último mês cheio? (procedimento 03.01.08.034-8). Ex: Se a entrevista foi feita dia 24 de abril, o último mês cheio foi o mês de março, logo, considerar de 1 a 31 de março. Somente números. Se não possui o procedimento, colocar 0.

P100. Quantos procedimentos de promoção da contratualidade foram registrados na RAAS no último mês cheio? (procedimento 03.01.08.035-6). Ex: Se a entrevista foi feita dia 24 de abril, o último mês cheio foi o mês de março, logo, considerar de 1 a 31 de março. Somente números. Se não possui o procedimento, colocar 0. 
P101. Quantos procedimentos de acolhimento noturno foram registrados na RAAS no último mês cheio? (procedimento 03.01.08.002-0). Ex: Se a entrevista foi feita dia 24 de abril, o último mês cheio foi o mês de março, logo, considerar de 1 a 31 de março. Somente números. Se não possui o procedimento, colocar 0.

P102. Quantos procedimentos de acolhimento em terceiro turno foram registrados na RAAS no último mês cheio? (procedimento 03.01.08.003-8). Ex: Se a entrevista foi feita dia 24 de abril, o último mês cheio foi o mês de março, logo, considerar de 1 a 31 de março. Somente números. Se não possui o procedimento, colocar 0 .

Por favor, responda, para cada uma das frases:

(1) para discordo totalmente,

(2) para discordo em parte,

(3) para estou em dúvida,

(4) para concordo em parte,

(5) para concordo totalmente

Fator 1

\begin{tabular}{|l|l|l|l|l|l|}
\hline A equipe precisa de treinamento para trabalhar com o alcoolista & 1 & 2 & 3 & 4 & 5 \\
\hline E preciso tomar cuidado ao trabalhar com o paciente alcoolista & 1 & 2 & 3 & 4 & 5 \\
\hline Não se deve confiar em alcoolistas & 1 & 2 & 3 & 4 & 5 \\
\hline O paciente alcoolista acaba sempre voltando ao serviço com o mesmo problema. & 1 & 2 & 3 & 4 & 5 \\
\hline Considero paciente alcoolista o mais difícil de lidar. & 1 & 2 & 3 & 4 & 5 \\
\hline O alcoolista é um paciente que nunca dá retorno do cuidado. & 1 & 2 & 3 & 4 & 5 \\
\hline O alcoolista é uma pessoa de difícil contato. & 1 & 2 & 3 & 4 & 5 \\
\hline Eu tenho medo de abordar o problema do alcoolismo com o paciente. & 1 & 2 & 3 & 4 & 5 \\
\hline Eu tenho medo da agressividade do alcoolista. & 1 & 2 & 3 & 4 & 5 \\
\hline Sinto-me frustrado quando trabalho com alcoolistas. & 1 & 2 & 3 & 4 & 5 \\
\hline Quando o paciente não quer colaborar, o melhor é desistir de ajudar. & 1 & 2 & 3 & 4 & 5 \\
\hline Quando trabalho com o alcoolista, não sei como conduzir a situação. & 1 & 2 & 3 & 4 & 5 \\
\hline Para atender o alcoolista, é preciso contê-lo. & 1 & 2 & 3 & 4 & 5 \\
\hline Penso que alcoolistas dão muito trabalho para a equipe de saúde. & 1 & 2 & 3 & 4 & 5 \\
\hline Devo cuidar do alcoolista, mesmo que ele não queira. & 1 & 2 & 3 & 4 & 5 \\
\hline Mesmo consciente o alcoolista desrespeita a equipe. & 1 & 2 & 3 & 4 & 5 \\
\hline Sinto raiva ao trabalhar com alcoolistas. & 1 & 2 & 3 & 4 & 5 \\
\hline O paciente alcoolista não aceita o que eu falo. & 1 & 2 & 3 & 4 & 5 \\
\hline Alcoolistas são pacientes dificeis porque não colaboram com o tratamento. & 1 & 2 & 3 & 4 & 5 \\
\hline Eu prefiro trabalhar com pacientes alcoolistas a trabalhar com outros pacientes. & 1 & 2 & 3 & 4 & 5 \\
\hline
\end{tabular}

Fator 2

\begin{tabular}{|l|l|l|l|l|l|}
\hline Alcoolistas são revoltados. & 1 & 2 & 3 & 4 & 5 \\
\hline O alcoolista é um doente. & 1 & 2 & 3 & 4 & 5 \\
\hline Alcoolistas não têm bom senso. & 1 & 2 & 3 & 4 & 5 \\
\hline O alcoolista é agressivo e mal educado. & 1 & 2 & 3 & 4 & 5 \\
\hline O alcoolista é um irresponsável. & 1 & 2 & 3 & 4 & 5 \\
\hline
\end{tabular}




\begin{tabular}{|l|l|l|l|l|l|}
\hline Os alcoolistas são pacientes violentos. & 1 & 2 & 3 & 4 & 5 \\
\hline Penso que pessoas que desenvolvem o alcoolismo são fracas. & 1 & 2 & 3 & 4 & 5 \\
\hline O alcoolista não quer se cuidar. & 1 & 2 & 3 & 4 & 5 \\
\hline Penso que o alcoolista é culpado por seus problemas de saúde. & 1 & 2 & 3 & 4 & 5 \\
\hline O alcoolista não leva o tratamento a sério. & 1 & 2 & 3 & 4 & 5 \\
\hline
\end{tabular}

Fator 3

\begin{tabular}{|l|l|l|l|l|l|}
\hline Percebo que o alcoolista tem baixa auto-estima. & 1 & 2 & 3 & 4 & 5 \\
\hline Penso que passar por um desajuste familiar leva ao alcoolismo. & 1 & 2 & 3 & 4 & 5 \\
\hline O alcoolista é um individuo que não consegue controlar sua ingestão alcoólica. & 1 & 2 & 3 & 4 & 5 \\
\hline O álcool é usado como fuga. & 1 & 2 & 3 & 4 & 5 \\
\hline Penso que todo o alcoolista tem algo mal resolvido. & 1 & 2 & 3 & 4 & 5 \\
\hline A falta de autocontrole leva ao alcoolismo. & 1 & 2 & 3 & 4 & 5 \\
\hline Penso que a depressão leva ao alcoolismo. & 1 & 2 & 3 & 4 & 5 \\
\hline O alcoolismo está relacionado ao nível de instrução do individuo. & 1 & 2 & 3 & 4 & 5 \\
\hline O alcoolista bebe para fugir da realidade. & 1 & 2 & 3 & 4 & 5 \\
\hline O que falta no alcoolista é força de vontade. & 1 & 2 & 3 & 4 & 5 \\
\hline As questões sociais levam o individuo a beber. & 1 & 2 & 3 & 4 & 5 \\
\hline
\end{tabular}

Fator4

\begin{tabular}{|l|l|l|l|l|l|}
\hline Penso que as pessoas têm o direito de beber se elas quiserem. & 1 & 2 & 3 & 4 & 5 \\
\hline A bebida alcoólica é agradável e traz bem-estar. & 1 & 2 & 3 & 4 & 5 \\
\hline O uso de bebida alcoólica é um comportamento normal. & 1 & 2 & 3 & 4 & 5 \\
\hline Beber com moderação não é prejudicial. & 1 & 2 & 3 & 4 & 5 \\
\hline Eu sou contra o uso de álcool em qualquer momento. & 1 & 2 & 3 & 4 & 5 \\
\hline O álcool em quantidades reduzidas é benéfico. & 1 & 2 & 3 & 4 & 5 \\
\hline Eu sou a favor do beber moderado. & 1 & 2 & 3 & 4 & 5 \\
\hline Doses pequenas de álcool são capazes de causar dependência. & 1 & 2 & 3 & 4 & 5 \\
\hline As pessoas podem beber desde que saibam se controlar. & 1 & 2 & 3 & 4 & 5 \\
\hline
\end{tabular}


ANEXO 3 - Instrumento para os trabalhadores do serviço.

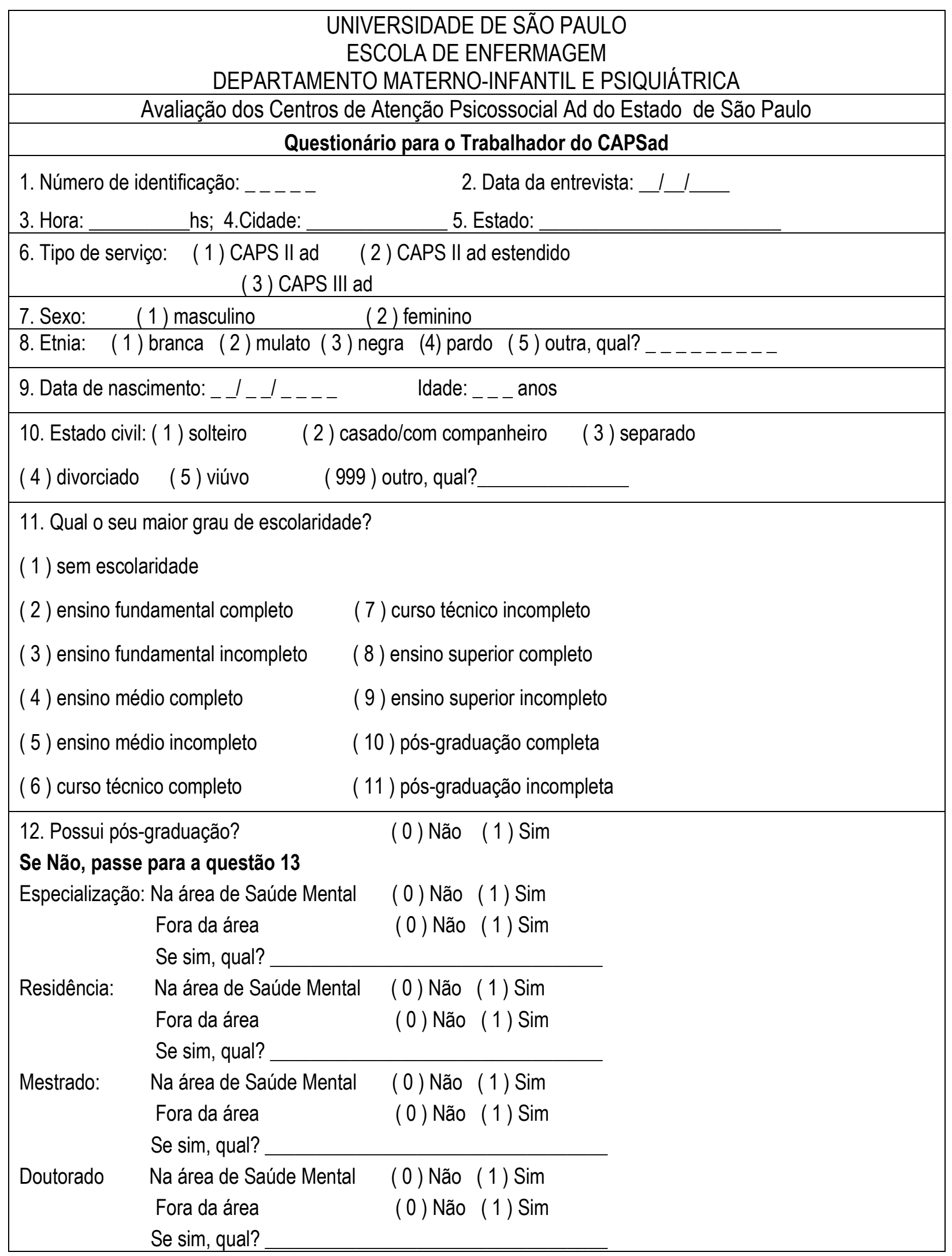



13. Há quanto tempo trabalha em CAPSad?
(1) 1 ano
(2) Entre 2 e 4 anos
(3) Entre 5 e 7 anos
(4) Entre 8 e 10 anos
(5) Mais que 10 anos

14. Há quanto tempo você trabalha neste CAPSad?
(1) 1 ano
(2) Entre 2 e 4 anos
(3) Entre 5 e 7 anos
(4) Entre 8 e 10 anos
(5) Mais que 10 anos

15. Qual a sua profissão?
( 1 ) Médico
( 2 ) Enfermeiro
( 3 ) Psicólogo
( 4 ) Assistente Social
( 5 ) Técnico/auxiliar de enfermagem
(6) Educador físico
( 7 ) Terapeuta Ocupacional
(8) Farmacêutico () Outros:

16. Qual foi o seu salário bruto no último mês, no CAPSad, incluindo horas extras (em reais):
(1) 1 a 3 salários mínimos
(2) 4 a 7 salários mínimos
(3) 8 a 11 salários mínimos
(4) 12 a 15 salários mínimos
(5) Acima de 16 salários mínimos

17. Qual a sua carga horária no CAPSad? horas/ semanais

18. Em relação ao CAPSad, qual o tipo de vínculo que você tem?
(1) CLT
( 2 ) Contrato emergencial/ temporário
( 3 ) Estatutário
(999) outros, quais?
19. Você tem outro vínculo empregatício?
( 0 ) Não
(1) $\operatorname{Sim}$

20. Do total de vínculos empregatícios, incluindo o CAPSad, qual foi a sua renda mensal bruta no último mês, incluindo horas extras (em reais):
(1) 1 a 3 salários mínimos
(2) 4 a 7 salários mínimos
(3) 8 a 11 salários mínimos
(4) 12 a 15 salários mínimos
(5) Acima de 16 salários mínimos
21. Você realiza cursos de atualização?
( 0 ) Não
(1) $\operatorname{Sim}$

\section{Se Não, passe para a questão 24}

Se SIM, com que frequência? ( 1 ) Mensalmente (2) Semestralmente (3) Anualmente

$$
\text { ( } 4 \text { ) Eventualmente ( } 5 \text { ) Raramente } \quad \text { (999) Outro: }
$$

22. Quando foi o último curso de atualização que você participou?
(1) Neste mês
( 3 ) Há 6 meses a 1 ano
( 2 ) Há 2 a 6 meses
( 4 ) mais de 1 ano
( 5 ) nunca participou

23. Quando foi o penúltimo curso de atualização que você participou?
(1) Neste mês
( 3 ) Há 6 meses a 1 ano
( 2 ) Há 2 a 6 meses
( 4 ) mais de 1 ano
( 5 ) nunca participou

24. Qual o seu turno de trabalho neste serviço? 


(1) dia (2) noite (3) revezamento semanal

( 4 ) parte de dia e parte de noite (999) outro:

25. Este turno de trabalho traz problemas para você?

( 0 ) Não (1) Sim

Se sim, quais problemas?
(1) fadiga
( 0 ) Não (1) Sim
( 2 ) choque de horário
( 0 ) Não (1) Sim
( 3 ) organização de vida
( 0 ) Não (1) Sim
(4) estresse
( 0 ) Não (1) Sim
(5) Sinais e sintomas físicos
( 0 ) Não (1) Sim
(999) outros
( 0 ) Não
(1) $\mathrm{Sim}$

Outros, se sim, quais?

\section{ESTRUTURA E PROCESSO DAS PRÁTICAS ASSISTÊNCIAIS}

E1. Você considera que o CAPSad é adequado em relação:
a) Ventilação
(0) Não
(1) $\operatorname{Sim}$

Justifique
b) Iluminação
(0) Não
(1) $\mathrm{Sim}$

Justifique
c) Higiene
(0) Não
(1) $\mathrm{Sim}$

Justifique
d) Área física
(0) Não
(1) $\operatorname{Sim}$

Justifique

E2. Você considera que os equipamentos de proteção coletiva estão instalados e funcionando em seu local de trabalho:
(1) exaustores para ventilação
( 0 ) Não (1) Sim
(2) saída de emergência
( 0 ) Não (1) Sim
(3) mangueira $p /$ incêndio
( 0 ) Não (1) Sim
(4) proteção nas máquinas
( 0 ) Não (1) Sim
(5) extintor de incêndio
( 0 ) Não (1) Sim
(6) ar condicionado
( 0 ) Não (1) Sim
(7) ventilador
( 0 ) Não (1) Sim
(999) outros

Considerando o seu último mês de trabalho, responda as questões de número 3 até 8 : 

E3. Você realizou visitas domiciliárias
(0) Não
(1) $\operatorname{Sim}$

Quantas visitas domiciliárias você realizou:

Se Não, porque?
E4. Você realizou atendimentos individuais
(0) Não
(1) $\operatorname{Sim}$

Quantos atendimentos individuais você realizou:

Consulta

Psicoterapia

Orientação

Procedimentos técnicos

Acompanhamento do uso de medicação

Intervenção em crise

Orientação de atividades da vida diária

Intervenção em agitação psicomotora

Orientação quanto a redução de danos

Outras atividades de atendimento individual?

Qual?
( )NÃO ( ) SIM

( )NÃO ( ) SIM

( )NÃO ( ) SIM

( )NÃO ( ) SIM

( )NÃO ( ) SIM

( )NÃO ( ) SIM

( )NÃO ( ) SIM

( )NÃO ( ) SIM

( )NÃO ( ) SIM

( )NÃO ( ) SIM

E5. Você realizou atendimentos grupais

(0) Não

(1) $\operatorname{Sim}$

Quantos atendimentos em grupo você realizou:

Grupos terapêuticos

Atividades esportivas

Atividades de suporte social

Grupo de leitura e debate

Grupo de confecção de jornal

Grupo de orientações gerais

Grupo de orientações para redução de danos

Grupos de família

Outros grupos

Quais?
( )NÃO ( ) SIM

( )NÃO ( ) SIM

( )NÃO ( ) SIM

( )NÃO ( ) SIM

( )NÃO ( ) SIM

( )NÃO ( ) SIM

( )NÃO ( ) SIM

()NÃO () SIM

( )NÃO ( ) SIM 

E6. Você participou de reuniões de equipe
(0) Não
(1) $\operatorname{Sim}$

Quantas reuniões de equipe você participou:

E7. Você participou de atividades comunitárias?

(0) Não

(1) $\operatorname{Sim}$

Quantas atividades comunitárias você participou:

Festas comunitárias

( )NÃO ( ) SIM

Caminhadas com grupos da comunidade

( )NÃO ( ) SIM

Participação em eventos

( )NÃO ( ) SIM

Participação em grupos dos centros comunitários

( )NÃO ( ) SIM

Outras atividades comunitárias

( )NÃO ( ) SIM

QUAIS?
E8. Você realizou alguma outra atividade
(0) Não
(1) $\operatorname{Sim}$

Se sim, quais?

E9. Desde que você entrou neste emprego, as condições de trabalho:
(1) melhoraram muito
( 3 ) não mudaram
(2) pioraram
( 4 ) melhoraram pouco

E10. Em seu trabalho você enfrenta:
(1) falta de ferramenta adequada para o trabalho
( 0 ) Não (1) Sim
(2) falta de segurança
( 0 ) Não (1) Sim
(3) risco permanente de vida
( 0 ) Não (1) Sim
(4) outras situações que incomodam:
( 0 ) Não (1) Sim

Se sim, quais as outras situações que incomodam?

E11. Em seu trabalho você pode:

Escolher individualmente a forma de fazer suas atividades

( 0 ) Não (1) Sim

Escolher de forma coletiva/em equipe a forma de fazer suas atividades

( 0 ) Não (1) Sim

Fazer reuniões

( 0 ) Não (1) Sim

Fazer cursos

( 0 ) Não (1) Sim

Outras atividades de organização

( 0 ) Não (1) Sim

Conversar com os colegas

( 0 ) Não (1) Sim

Usar suas ideias

( 0 ) Não (1) Sim 
E12. Nos últimos 6 (seis) meses você sofreu algum acidente de trabalho? ( 0 ) Não

Quais?

E13. Você faltou ao trabalho nos últimos 6 (seis) meses? ( 0 ) Não (1) Sim

Se Não, passe para a questão 14

Se sim quantos dias? _ _ dias ausentes

Quais os Motivos:
(1) doença
( 0 ) Não
(1) $\operatorname{Sim}$
(2) acidente
( 0 ) Não
(1) Sim
(3) problema familiar
( 0 ) Não
(1) $\operatorname{Sim}$
( 4 ) problema administrativo
( 0 ) Não
(1) $\mathrm{Sim}$
(999) outros
( 0 ) Não
(1) $\mathrm{Sim}$

Justifique:

E14. Qual o principal critério de inclusão no tratamento CAPSad para as pessoas que procuram este serviço?

(1) O consumo de álcool e outras drogas

(2) A gravidade do consumo de álcool e outras drogas

(3) O impacto global na vida relacionado ao consumo prejudicial de álcool e outras drogas

(4) Outros

E15. Qual o modelo de assistência utilizada neste serviço?
( ) Redução de Danos
( ) Abstinência total
() As duas modalidades
() Não sei () Outros

E16. O que é considerado "abandono de tratamento" nesse serviço?

(1) Não comparecimento ao serviço por 30 dias consecutivos, sem justificativa

(2) Não comparecimento ao serviço por 60 dias consecutivos, sem justificativa

(3) Não sei

(4) Outros
E17. É realizada busca ativa nesse serviço?
(0) Não
(1) $\operatorname{Sim}$

Se não, porque?
E18. Se sim, como é realizada:
(1) Contato Telefônico
(2) Visita Domiciliária

(3) Outros 
E19. Ao fazer a busca ativa, o que costuma se constatar em relação ao abandono do tratamento?

(1) Deve-se à desistência do tratamento

(2) Deve-se à melhora do usuário, segundo a sua percepção

(3) Deve-se ao retorno do usuário às suas atividades sociais (trabalho, lazer)

(4) Deve-se à outra modalidade de tratamento (internação)

(5) Deve-se à troca por outro serviço

(6) Outro, QUAL:

E20. Quais são as oficinas/atividades terapêuticas oferecidas nesse CAPSad?
Grupos Terapêuticos

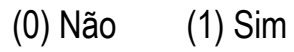
Atividades Esportivas
(0) Não (1) Sim
Atividades de Suporte Social
(0) Não (1) Sim
Grupos de Leitura e Debate
(0) Não (1) Sim
Grupos de Confecção de Jornal
(0) Não
(1) $\mathrm{Sim}$
Grupos de Orientação
(0) Não
(1) $\operatorname{Sim}$
Grupos de Família
(0) Não
(1) $\operatorname{Sim}$

Grupos de orientação de redução de danos (0) Não (1) Sim

Outros

$\begin{array}{lll}\text { Oficinas Terapêuticas } & \text { (0) Não } & \text { (1) Sim } \\ \text { Oficinas Expressivas } & \text { (0) Não } & \text { (1) Sim } \\ \text { Oficinas Geradoras de Renda } & \text { (0) Não } & \text { (1) Sim } \\ \text { Oficinas de Alfabetização } & \text { (0) Não } & \text { (1) Sim } \\ \text { Oficinas Culturais } & \text { (0) Não } & \text { (1) Sim } \\ \text { Oficinas de atividades manuais } & \text { (0) Não } & \text { (1) Sim } \\ \text { Oficinas de Trabalho } & \text { (0) Não } & \text { (1) Sim }\end{array}$

Outros

Atendimento individual

( 0 ) Não (1) Sim

Consulta médica

( 0 ) Não (1) Sim

Psicoterapia

( 0 ) Não (1) Sim

Orientação

( 0 ) Não (1) Sim

Consulta de enfermagem

( 0 ) Não (1) Sim

Consulta com outros técnicos

( 0 ) Não (1) Sim

Procedimentos técnicos

( 0 ) Não (1) Sim

Acompanhamento do uso de medicação
( 0 ) Não
(1) $\operatorname{Sim}$
( 0 ) Não (1) Sim
( 0 ) Não
(1) $\operatorname{Sim}$

Intervenções em crise

Intervenções em agitação psicomotora 


\begin{tabular}{|lll}
\hline Orientação em atividades de vida diária & ( 0 ) Não & ( 1) Sim \\
Orientação em redução de danos & ( 0 ) Não & (1) Sim
\end{tabular}

Outros

Atividades na comunidade

( 0 ) Não ( 1 ) Sim, quais?

Festas comunitárias

( 0 ) Não (1) Sim

Caminhadas com grupos da comunidade

( 0 ) Não ( 1 ) Sim

Participação em eventos e grupos dos centros comunitários

( 0 ) Não ( 1 ) Sim

Outros

$\begin{array}{lll}\text { Outras Atividades referidas } & \text { ( } 0 \text { ) Não } & \text { (1) Sim }\end{array}$

Se sim, quais?

E21. Qual a estrutura organizacional de trabalho adotada pela equipe desse serviço?

( ) Abordagem multiprofissional ( ) Não sei

( ) Abordagem interdisciplinar Outros

E22 0 serviço realiza ações intersetoriais? () Não $\quad$ (1) Sim $\quad$ () Não sei

Se não, Porque?

Se sim, quais são?

E23. Esse serviço tem ações no campo da geração de renda e/ou economia solidária?
(0) Não
(1) $\operatorname{Sim}$

Se não, porque

Se sim, quais são?

E24. Nos atendimentos individuais você utiliza quais abordagens terapêuticas?

$\begin{array}{lll}\text { Entrevista Motivacional } & \text { (0) Não } & \text { (1) Sim } \\ \text { Psicoeducação } & \text { (0) Não } & \text { (1) Sim } \\ \text { Psicoterapias } & \text { (0) Não } & \text { (1) Sim } \\ \text { Comunicação Terapêutica } & \text { (0) Não } & \text { (1) Sim } \\ \text { Aconselhamento } & \text { (0) Não } & \text { (1) Sim } \\ \text { Relacionamento Terapêutico } & \text { (0) Não } & \text { (1) Sim }\end{array}$

Outros, quais?

E25. As intervenções terapêuticas neste serviço visam primordialmente:

(1) Alertar os riscos e perigos do consumo de álcool e outras drogas

(2) Desenvolver consciência crítica acerca dos problemas relacionados para além do consumo de álcool e outras drogas

(3) Afastar as pessoas das drogas 
(4) Evitar lugares e pessoas que incentivam o uso de álcool e outras drogas

(5) Outros

E26. Há retaguarda para urgência psiquiátrica? ( ) Não

() $\operatorname{Sim}$

( ) Não sei

Se sim, liste as principais:

E27. Há retaguarda para urgência clínica? ( ) Não

( ) $\operatorname{Sim}$

( ) Não sei

Se sim, liste as principais:

E28 Como são indicadas as internações para a dependência química dos usuários desse serviço?
(1) Após discussão de caso em reunião de equipe
(2) Pelo médico
(3) A pedido do próprio usuário
(4) A pedido da família
(5) Por via judicial
(6) Outros

E29. Você tem conhecimento dos equipamentos de saúde existentes na área de abrangência do CAPSad?
(0) Não
(1) $\operatorname{Sim}$
(998) Não sei

Se sim, liste os principais:

E30. a) A equipe do serviço, incluindo você, quando necessário encaminha os usuários para esses serviços?
(0) Não
(1) $\operatorname{Sim}$
(998) Não sei

Se, sim liste os mais utilizados:

E30. b) Há algum projeto/atividade em parceria com esses serviços?
(0) Não
(1) $\operatorname{Sim}$
(998) Não sei

Se, sim liste os mais utilizados:

E31 Você tem facilidade de diálogo com os outros equipamentos de saúde da rede, da área de abrangência do CAPSad para o tratamento do usuário?
(0) Não
(1) $\mathrm{Sim}$

Se não, porque?

32. Em relação aos profissionais da rede que encaminham usuários para os CAPSad, você nota que estes conhecem o trabalho desenvolvido pelo CAPSad?
(0) Não
(1) $\mathrm{Sim}$
(998) Não sei

E33. Algum profissional desse CAPSad realiza o matriciamento das equipes de Atenção Básica da área de abrangência dos serviços? (0) Não $\quad$ (1) Sim $\quad$ (998) Não sei 
E34. Qual o principal critério de alta do CAPSad?

(1) A interrupção total do consumo de álcool e outras drogas

(2) A inserção e/ ou reinserção no trabalho formal e informal

(3) A retomada dos laços sociais e familiares

(4) A melhora das condições globais de vida do usuário

Outros, quais?

E35. Que tipo de transporte você usa preferencialmente para chegar a este serviço?
( 1 ) Condução própria
( 4 ) Condução de familiares
( 2 ) Condução de amigos
( 5 ) Transporte público
( 3 ) Caminhada
(999) Outro

E36. Quanto tempo você gasta para vir de sua casa ao CAPSad?

(1) 0-15minutos
( 2 ) 16-30 minutos
( 4 ) 46-60 minutos
( 3 ) 31-45 minutos
( 5 ) mais que 60 minutos

E37. Você acha que os profissionais deste serviço compreendem os problemas dos usuários?
(1) De forma alguma
( 2 ) Não muito
( 4 ) Bem
( 3 ) Mais ou menos
( 5 ) Muito bem

E38. Você acha que os profissionais deste serviço compreendem o tipo de ajuda de que os usuários necessitam?

( 1 ) Não compreendem
( 2 ) Não compreendem muito
( 4 ) Bem
(3) Mais ou menos
( 5 ) Muito bem

E39. Considerando as necessidades globais dos usuários que procuram este serviço para tratamento, até que ponto este serviço é apropriado para recebê-los aqui?
( 1 ) muito inapropriado
( 2 ) inapropriado
( 4 ) apropriado
( 3 ) mais ou menos
( 5 ) muito apropriado

E40. Você acha que existem outros cuidados de que o usuário necessita, mas que não recebe aqui?
(1) Com certeza há
( 4 ) Acho que não há
( 2 ) Acho que há
( 5 ) Não, certamente que não
( 3 ) Talvez

Se você respondeu 1 ou 2 , especifique quais são estes serviços 
E41. Você acha que o CAPSad estimula as famílias a participarem mais ativamente do processo de tratamento de seus familiares?
( 1 ) De forma alguma
( 2 ) Não muito
( 4 ) Muito
( 3 ) Mais ou menos
(5) Extremamente

E42. Você acha a equipe suficientemente competente para lidar com o envolvimento familiar?
( ) Muito incompetente
( ) Competente
() Mais ou menos
( ) Incompetente
( ) Muito competente

E43. Como você classificaria a competência geral da equipe?

( ) muito incompetente
( ) incompetente
( ) competente
( ) Mais ou menos
( ) Muito competente

E44. Para você realizar as atividades assistenciais no CAPSad, você considera que as instalações da unidade são: (1) Péssimas
( 2 ) Ruins
( 4 ) Boas
(3) Regulares
( 5 ) Excelentes

\section{Você...}
(1) nunca
(2) raramente
( 3 ) mais ou menos
( 4 ) frequentemente
(5) sempre

E45. Sente que recebe o apoio de que necessita do seu supervisor

E46. Você participa do processo de tomada de decisões no seu serviço?

E47. Você participa da implementação de programas e/ou atividades novas no serviço?

E48. Você participa do processo de avaliação das atividades e/ou programas do serviço?

E49. Você acha que suas opiniões são levadas em consideração?

E50. Você percebe um bom clima no ambiente de trabalho?

E51 Em geral, como você classificaria o "clima" de amizade no ambiente de trabalho? *
( ) Nada amigável
( ) Amigável
( ) Pouco amigável
( ) Muito amigável
( ) Mais ou menos

E52. Com que frequência você tem reuniões de equipe?
(1) Diária
(2) Mais que uma vez por semana
(3) Uma vez por semana
(4) Entre 1-3 vezes por mês
(5) Menos que uma vez por mês
(6) Nunca 
E53 Se um amigo / familiar estivesse necessitando de ajuda de uma unidade de Saúde Mental, você recomendaria este CAPSad?
(1) Não, com certeza que não
(4) Sim, acho que sim
( 2 ) Não, acho que não
(5) Sim, com certeza
(3) Talvez

Se você respondeu 1 ou 2 (não), por quê?

Se você respondeu 4 ou 5 (sim), por quê?
(1) O CAPSad tem um bom atendimento
( 0 ) Não
(1) $\operatorname{Sim}$
( 2 ) Obtém-se bons resultados no CAPSad
( 0 ) Não
(1) $\operatorname{Sim}$
( 3 ) Outros motivos
( 0 ) Não
(1) Sim, quais?

E54.1 De que você mais gosta neste serviço?
( ) Da minha função
( ) Dos usuários
( ) Do atendimento prestado aos usuários
( ) Nada
( ) Dos colegas de trabalho
() Outros

E54.2 Qual aspecto você menos gosta CAPSad?
( ) Da minha função
( ) Dos usuários
( ) Do atendimento prestado aos usuários
( ) Nada
( ) Dos colegas de trabalho
() Outros

E55. Você acha que o serviço poderia ser melhorado?

( ) Não

( ) $\operatorname{sim}$

Se sim, de que maneira?

E56. Você se sente sobrecarregado no seu serviço?
(1) Nunca
( 4 ) Frequentemente
( 2 ) Raramente
(5) Sempre
(3) As vezes

Se respondeu 4 e 5 (sim), porque?

E57. Em média, qual seria para você a frequência adequada de contato 1/1, entre os membros da equipe e 0 usuário?
(1) Mais que uma vez por dia
(2) Uma vez por dia
(3) $3-6$ vezes por semana
(4) 1 - 2 vezes por semana
(5) 2 - 3 vezes por mês
(6) Aproximadamente uma vez/mês
(7) Menos que uma vez por mês
(8) Nenhuma 


\section{Em cada uma das próximas questões, assinale a alternativa que mais se aproxima do seu sentimento em relação a satisfação. Responda fazendo um círculo em torno do número em cada questão, de acordo com a seguinte escala:}
(1) Muito insatisfeito
(2) Insatisfeito
( 3 ) Indiferente
( 4 ) Satisfeito
(5) Muito satisfeito
58. Você está satisfeito com este serviço?

59. Como você se sente com a expectativa de ser promovido?

60 . Você se sente satisfeito com o grau de responsabilidade que você tem no seu serviço?

61 Você se sente satisfeito no relacionamento com seus colegas?

62. Você se sente satisfeito com a frequência das reuniões de equipe?

63. Você se sente satisfeito com a forma que as reuniões de equipe são realizadas?

64. Até que ponto você se sente satisfeito com a eficácia e utilidade destas reuniões?

65. Você se sente satisfeito com a quantidade de controle exercida por seus superiores?

66. Como você se sente em relação ao grau de autonomia que você tem em seu serviço?

67 . Você se sente satisfeito com a frequência de discussões de trabalho?

68. Você se sente satisfeito com o seu nível de participação nas decisões de trabalho?

69. Você se sente satisfeito com o seu grau de participação na implementação de programas e/ou atividades?

70. Você se sente satisfeito com sua participação no processo de avaliação de atividades e programas do serviço?

71. Você se sente satisfeito com a atenção dada às suas opiniões?

72. Você se sente satisfeito com o clima no ambiente de trabalho?

73. Até que ponto você se sente satisfeito com seu salário?

74. Você está satisfeito com os benefícios que recebe deste trabalho?

75. Você está satisfeito com a atenção e os cuidados que são dados aos pacientes?

76. Você se sente satisfeito com a frequência de contato entre a equipe e os usuários?

77. Como você se sente com o atendimento dado às famílias pela equipe?

78. Você se sente satisfeito com o grau de competência profissional da equipe?

79. Você se sente satisfeito em relação às medidas de segurança ao usuário do CAPSad?

80. Você está satisfeito com o conforto e aparência do CAPSad?

81. Você esta satisfeito com quantidade de informações dadas aos usuários sobre seus problemas de saúde neste serviço?

82. Você esta satisfeito com a quantidade de informações dada aos usuários sobre o tratamento oferecido neste serviço?

83. Em geral, você se sente satisfeito com a forma como os usuários são tratados pela equipe?

84. Você esta satisfeito com o grau de envolvimento dos familiares no processo de tratamento dos usuários no CAPSad?

85. Como você se sente com a quantidade de ajuda que é dada aos usuários pelo CAPSad? 


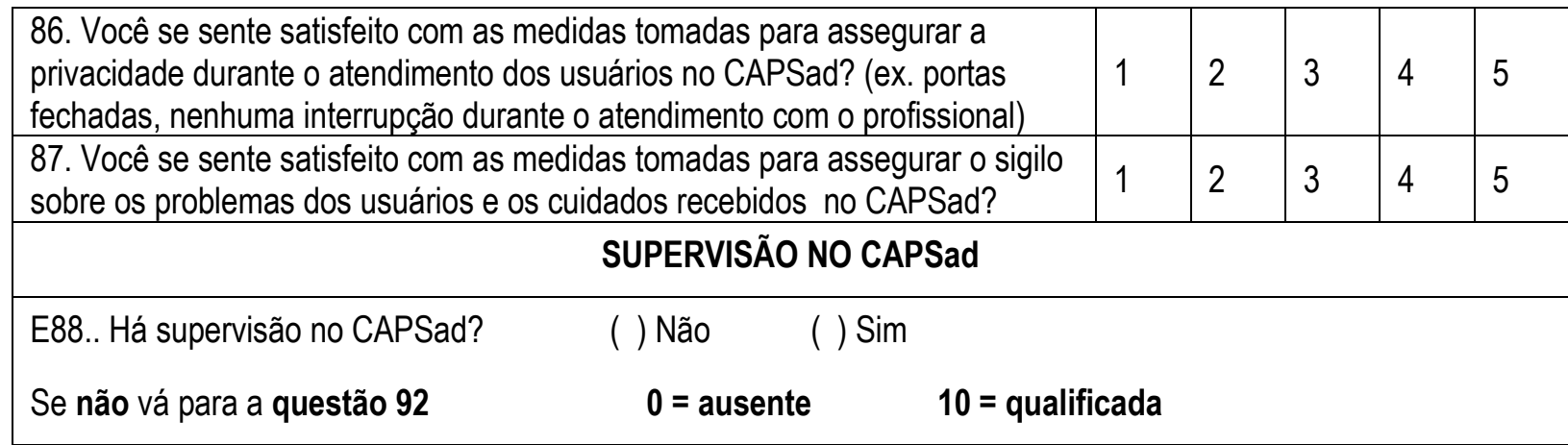

E89. Supervisão pela secretaria municipal de saúde

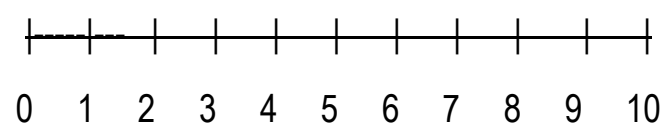

E90 Supervisão pela coordenação municipal de saúde mental

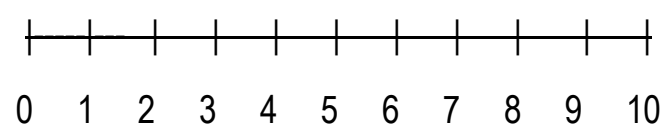

E91. Supervisão entre equipe:

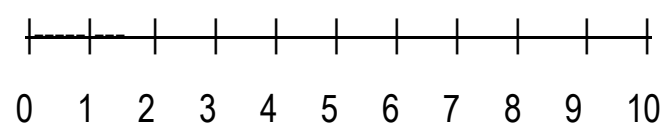

E92. Supervisão pela comunidade em que atua:

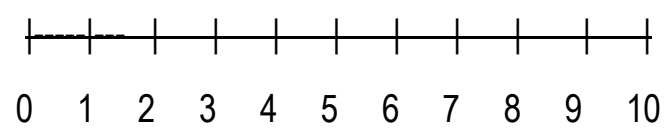

E93. Supervisão pela Organização Social (parceira):

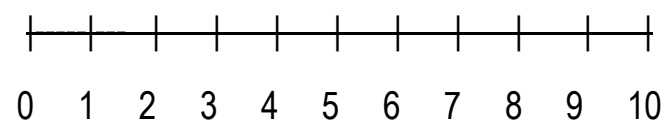

E94. Apoio pela secretaria municipal de saúde

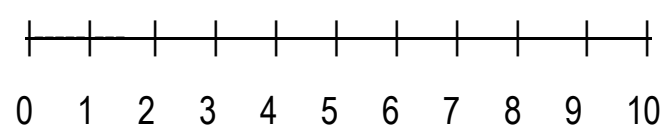

E95. Apoio pela coordenação municipal de saúde mental

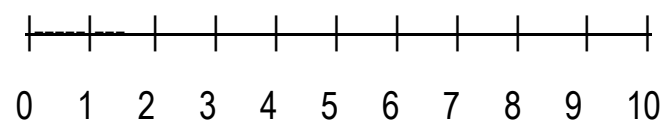

E96. Apoio entre equipe

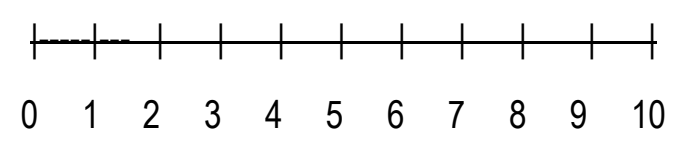


E.97. Apoio pela comunidade em que atua

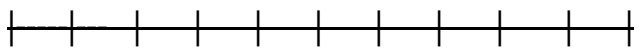

$$
\begin{aligned}
& \begin{array}{lllllllllll}
0 & 1 & 2 & 3 & 4 & 5 & 6 & 7 & 8 & 9 & 10
\end{array}
\end{aligned}
$$

E98. De maneira global, qual a sua avaliação do atendimento prestado pelo CAPSad?

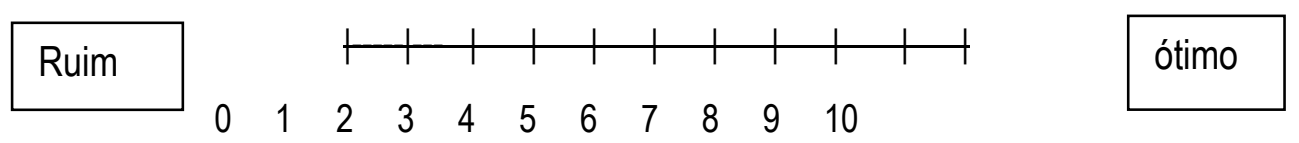

97. Com relação à formação profissional e capacitação para trabalhar com álcool e outras drogas, em sua opinião, quais os temas considerados importantes?

Por favor, responda, para cada uma das frases:

(1) para discordo totalmente,

(2) para discordo em parte,

(3) para estou em dúvida,

(4) para concordo em parte,

(5) para concordo totalmente

Fator 1

\begin{tabular}{|l|l|l|l|l|l|}
\hline A equipe precisa de treinamento para trabalhar com o alcoolista & 1 & 2 & 3 & 4 & 5 \\
\hline E preciso tomar cuidado ao trabalhar com o paciente alcoolista & 1 & 2 & 3 & 4 & 5 \\
\hline Não se deve confiar em alcoolistas & 1 & 2 & 3 & 4 & 5 \\
\hline O paciente alcoolista acaba sempre voltando ao serviço com o mesmo problema. & 1 & 2 & 3 & 4 & 5 \\
\hline Considero paciente alcoolista o mais difícil de lidar. & 1 & 2 & 3 & 4 & 5 \\
\hline O alcoolista é um paciente que nunca dá retorno do cuidado. & 1 & 2 & 3 & 4 & 5 \\
\hline O alcoolista é uma pessoa de difícil contato. & 1 & 2 & 3 & 4 & 5 \\
\hline Eu tenho medo de abordar o problema do alcoolismo com o paciente. & 1 & 2 & 3 & 4 & 5 \\
\hline Eu tenho medo da agressividade do alcoolista. & 1 & 2 & 3 & 4 & 5 \\
\hline Sinto-me frustrado quando trabalho com alcoolistas. & 1 & 2 & 3 & 4 & 5 \\
\hline Quando o paciente não quer colaborar, o melhor é desistir de ajudar. & 1 & 2 & 3 & 4 & 5 \\
\hline Quando trabalho com o alcoolista, não sei como conduzir a situação. & 1 & 2 & 3 & 4 & 5 \\
\hline Para atender o alcoolista, é preciso contê-lo. & 1 & 2 & 3 & 4 & 5 \\
\hline Penso que alcoolistas dão muito trabalho para a equipe de saúde. & 1 & 2 & 3 & 4 & 5 \\
\hline Devo cuidar do alcoolista, mesmo que ele não queira. & 1 & 2 & 3 & 4 & 5 \\
\hline Mesmo consciente o alcoolista desrespeita a equipe. & 1 & 2 & 3 & 4 & 5 \\
\hline Sinto raiva ao trabalhar com alcoolistas. & 1 & 2 & 3 & 4 & 5 \\
\hline O paciente alcoolista não aceita o que eu falo. & 1 & 2 & 3 & 4 & 5 \\
\hline Alcoolistas são pacientes difíceis porque não colaboram com o tratamento. & 1 & 2 & 3 & 4 & 5 \\
\hline Eu prefiro trabalhar com pacientes alcoolistas a trabalhar com outros pacientes. & 1 & 2 & 3 & 4 & 5 \\
\hline
\end{tabular}


Fator 2

\begin{tabular}{|l|l|l|l|l|l|}
\hline Alcoolistas são revoltados. & 1 & 2 & 3 & 4 & 5 \\
\hline O alcoolista é um doente. & 1 & 2 & 3 & 4 & 5 \\
\hline Alcoolistas não têm bom senso. & 1 & 2 & 3 & 4 & 5 \\
\hline O alcoolista é agressivo e mal educado. & 1 & 2 & 3 & 4 & 5 \\
\hline O alcoolista é um irresponsável. & 1 & 2 & 3 & 4 & 5 \\
\hline Os alcoolistas são pacientes violentos. & 1 & 2 & 3 & 4 & 5 \\
\hline Penso que pessoas que desenvolvem o alcoolismo são fracas. & 1 & 2 & 3 & 4 & 5 \\
\hline O alcoolista não quer se cuidar. & 1 & 2 & 3 & 4 & 5 \\
\hline Penso que o alcoolista é culpado por seus problemas de saúde. & 1 & 2 & 3 & 4 & 5 \\
\hline O alcoolista não leva o tratamento a sério. & 1 & 2 & 3 & 4 & 5 \\
\hline
\end{tabular}

\section{Fator 3}

\begin{tabular}{|l|l|l|l|l|l|}
\hline Percebo que o alcoolista tem baixa auto-estima. & 1 & 2 & 3 & 4 & 5 \\
\hline Penso que passar por um desajuste familiar leva ao alcoolismo. & 1 & 2 & 3 & 4 & 5 \\
\hline O alcoolista é um individuo que não consegue controlar sua ingestão alcoólica. & 1 & 2 & 3 & 4 & 5 \\
\hline O álcool é usado como fuga. & 1 & 2 & 3 & 4 & 5 \\
\hline Penso que todo o alcoolista tem algo mal resolvido. & 1 & 2 & 3 & 4 & 5 \\
\hline A falta de autocontrole leva ao alcoolismo. & 1 & 2 & 3 & 4 & 5 \\
\hline Penso que a depressão leva ao alcoolismo. & 1 & 2 & 3 & 4 & 5 \\
\hline O alcoolismo está relacionado ao nível de instrução do individuo. & 1 & 2 & 3 & 4 & 5 \\
\hline O alcoolista bebe para fugir da realidade. & 1 & 2 & 3 & 4 & 5 \\
\hline O que falta no alcoolista é força de vontade. & 1 & 2 & 3 & 4 & 5 \\
\hline As questões sociais levam o individuo a beber. & 1 & 2 & 3 & 4 & 5 \\
\hline
\end{tabular}

Fator4

\begin{tabular}{|l|l|l|l|l|l|}
\hline Penso que as pessoas têm o direito de beber se elas quiserem. & 1 & 2 & 3 & 4 & 5 \\
\hline A bebida alcoólica é agradável e traz bem-estar. & 1 & 2 & 3 & 4 & 5 \\
\hline O uso de bebida alcoólica é um comportamento normal. & 1 & 2 & 3 & 4 & 5 \\
\hline Beber com moderação não é prejudicial. & 1 & 2 & 3 & 4 & 5 \\
\hline Eu sou contra o uso de álcool em qualquer momento. & 1 & 2 & 3 & 4 & 5 \\
\hline O álcool em quantidades reduzidas é benéfico. & 1 & 2 & 3 & 4 & 5 \\
\hline Eu sou a favor do beber moderado. & 1 & 2 & 3 & 4 & 5 \\
\hline Doses pequenas de álcool são capazes de causar dependência. & 1 & 2 & 3 & 4 & 5 \\
\hline As pessoas podem beber desde que saibam se controlar. & 1 & 2 & 3 & 4 & 5 \\
\hline
\end{tabular}


ANEXO 4 - Instrumento para os usuários do serviço.

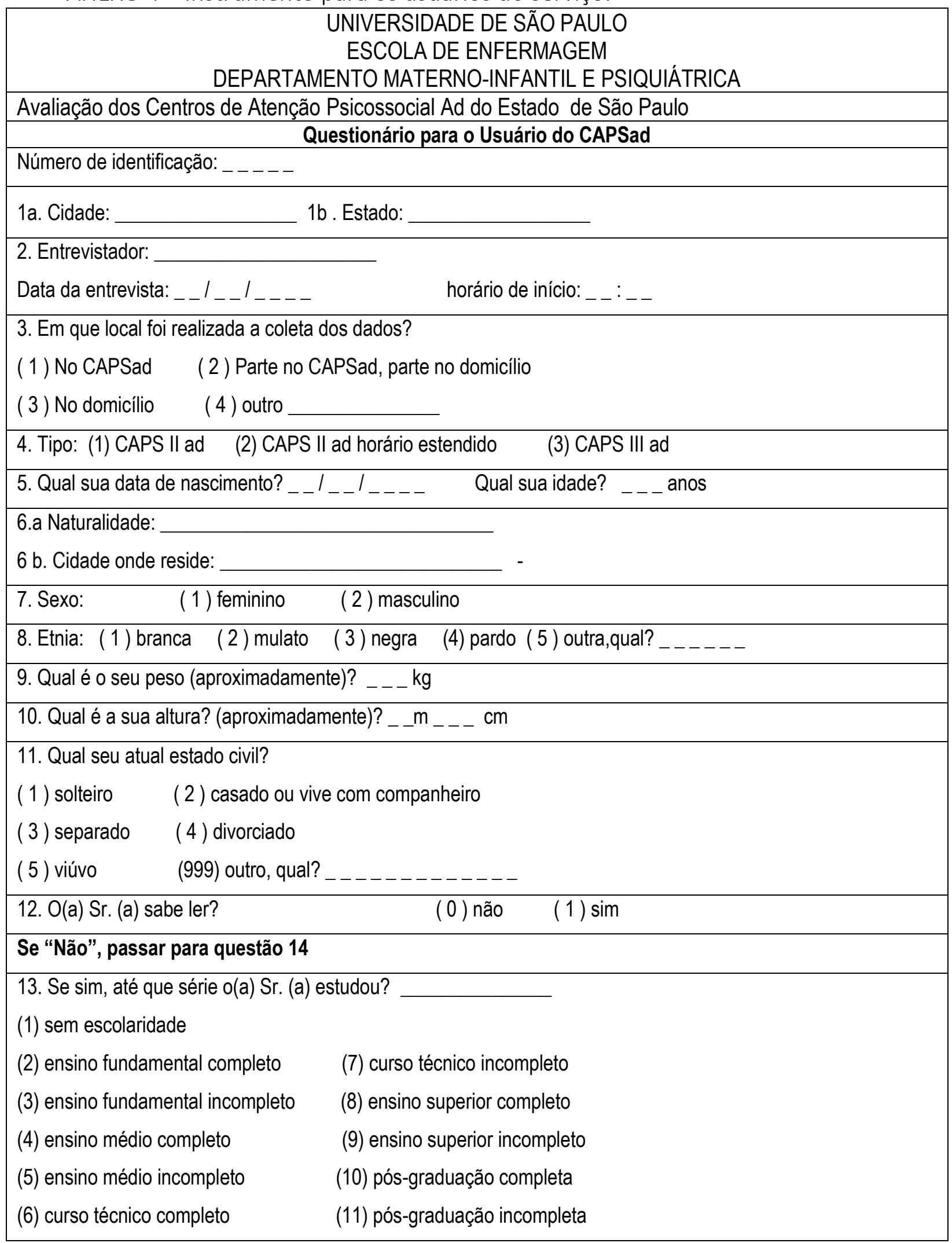



14. Qual sua principal fonte de renda?
(1) emprego
(6) auxílio-doença
(2) seguro-desemprego
(7) pensionista
(3) renda do cônjuge
(8) LOAS
(4) aposentadoria
(9) Não tem renda
(5) renda familiar
(999) outro, qual?

15. Se o(a) Sr. (a) atualmente está trabalhando, explique como é sua jornada de trabalho:

(1) jornada integral remunerada

(2) jornada parcial remunerada

(5) não trabalha

(3) jornada integral não remunerada

(6) trabalho eventual

(4) jornada parcial não remunerada

(999) outro, qual?

16. Qual sua renda no último mês?
(1) Até 2 salários mínimos
(4) Entre 10 a 20 salários mínimos
(2) Entre 2 a 4 salários mínimos
(5) Acima de 20 salários mínimos
(3) Entre 4 a 10 salários mínimos

17. Qual a sua renda familiar no último mês?
(1) Até 2 salários mínimos
(4) Entre 10 a 20 salários mínimos
(2) Entre 2 a 4 salários mínimos
(5) Acima de 20 salários mínimos
(3) Entre 4 a 10 salários mínimos

18. Qual o número de membros/ pessoas na família?

19. Com quem o(a) Sr. (a) vive atualmente?
(1) sozinho (a)
(7) mãe, pai
(2) cônjuge/ companheiro (a)
(8) mãe, pai, irmãos
(3) com filho (a)
(9) amigo (a)
(4) cônjuge/ companheiro (a)/filhos
(999) outro, qual?
(5) outro membro da família
6) mãe, pai, irmãos, filhos e companheiro

20. Com quem o(a) Sr. (a) gostaria de viver?
(1) sozinho (a)
(6) mãe, pai, irmãos, filhos e companheiro
(2) cônjuge/ companheiro (a)
(7) amigo (a)
(3) com filho (a)
(8) mãe, pai
(4) cônjuge/ companheiro (a)/filhos
(9) mãe, pai, irmãos
(5) outro membro da família
(999) outro, qual? 


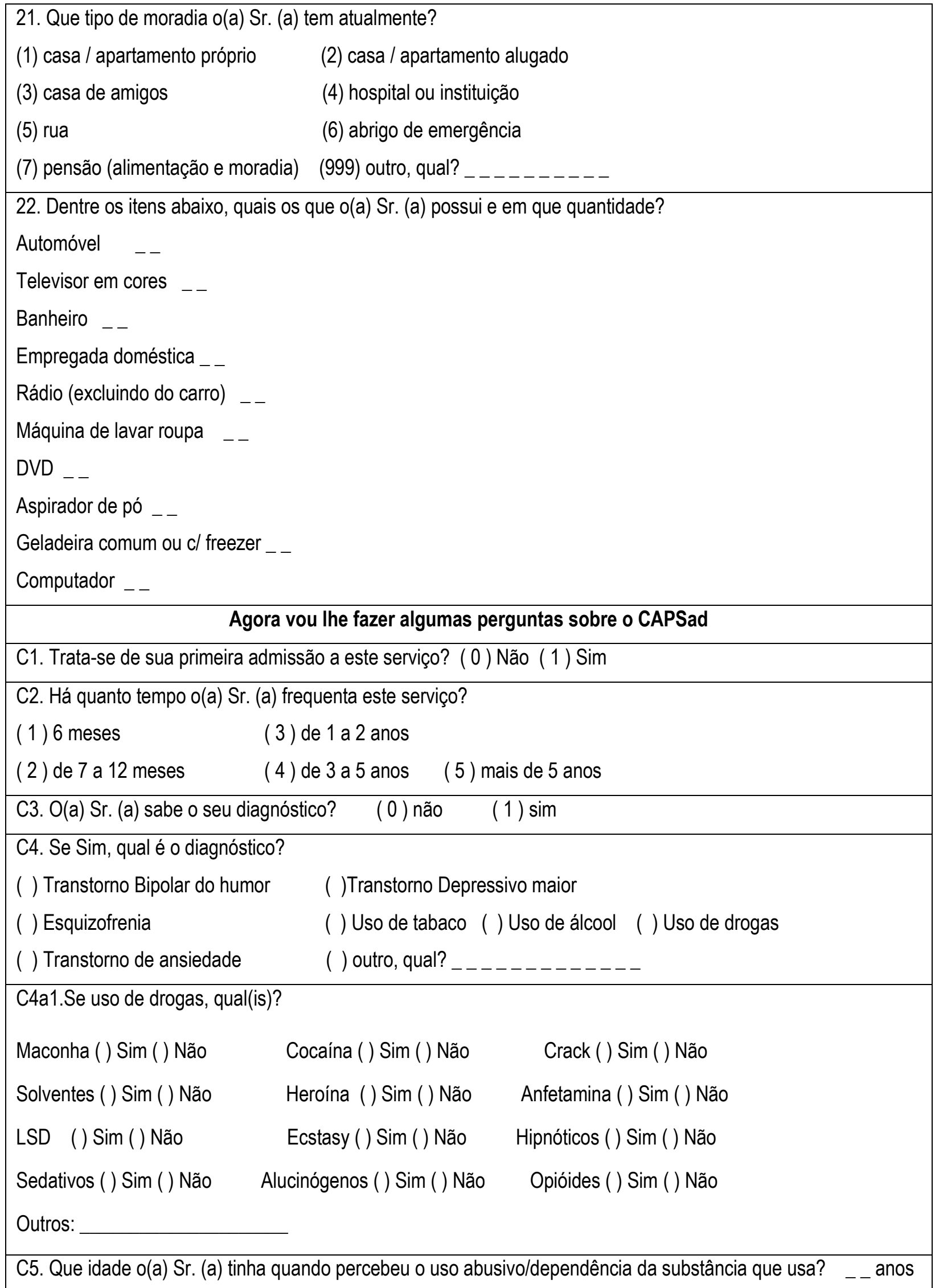


C6. O(a) Sr.(a) já teve alguma internação psiquiátrica ANTES do tratamento no CAPSad?

( 0 ) não (1) sim

Se não, passe para a questão 8

C7. Se sim, quantas e em que local?

Hospital Geral () não () sim Quantas?

Tempo que durou a ultima internação _ _ meses _ _ dias

Hospital psiquiátrico () não () sim Quantas?

Tempo que durou a ultima internação _ _ meses _ _ dias

Comunidade Terap. () não () sim Quantas?

Tempo que durou a ultima internação _ _ meses _ _ dias

Clínica de reabilitação () não () $\operatorname{sim}$ Quantas?

Tempo que durou a ultima internação _ _ meses _ dias

C8. DURANTE o seu tratamento no CAPSad houve necessidade de você ser internado alguma vez?

) não ( ) sim

Onde você foi internado?

$\begin{array}{ll}\text { (1) Hospital Geral } & \text { (3) Hospital psiquiátrico }\end{array}$

(2) Comunidade Terap. $\quad$ (4) CAPSad III

(5) Outro

Quantas vezes?

Data da última internação _ _ _

Tempo de duração da ultima internação _ _-

C9. Você já apresentou desmaios, hipertensão, hiper/hipoglicemia, convulsão, etc, que houve necessidade de urgência nesse CAPSad? ( ) não ( ) sim

Se sim, para onde foi encaminhado?

C10. O(a) Sr. (a) tem algum outro problema de saúde?

( 0 ) Não (1) Sim (998) Não sei

\section{Se "NÃO"passar para questão 18}

C11. Se Sim, qual?

Hipertensão arterial

Diabetes

( 0 ) Não (1) Sim

Obesidade

( 0 ) Não (1) Sim

Problemas oncológicos

( 0 ) Não (1) Sim

DST/ AIDS

( 0 ) Não

(1) $\operatorname{Sim}$

Outro:

( 0 ) Não (1) Sim

C12. Atualmente, o(a) Sr. (a) usa medicação para este problema?

( 0 ) Não (1) Sim

Se "NÃO"passar para questão 14 


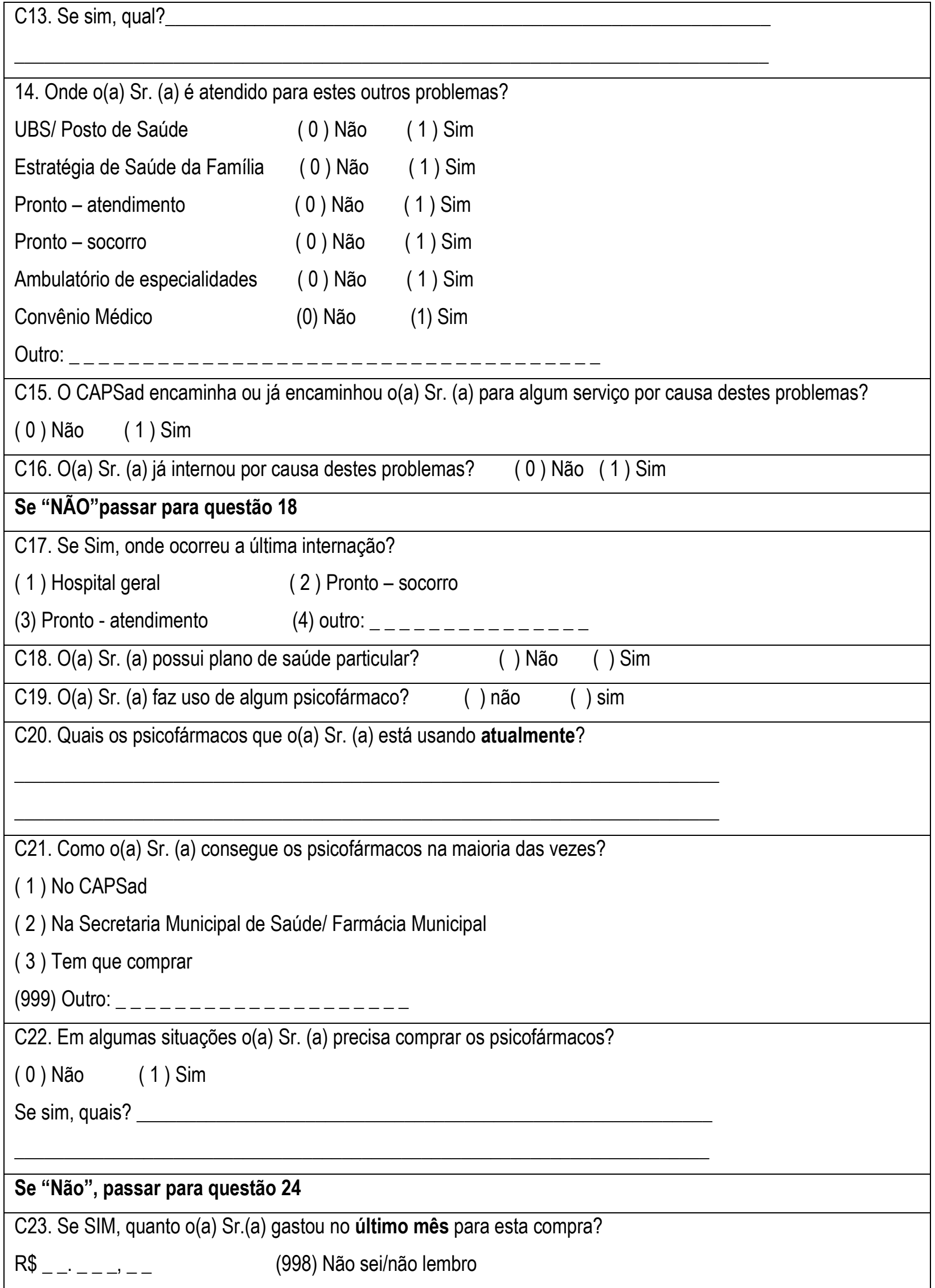


C24. O(a) Sr. (a) segue a prescrição médica?
(1) Nunca
( 2 ) Sempre
(3) Às vezes
( 4 ) De forma irregular
( 5 ) Frequentemente

C25. O(a) Sr. (a) fuma? ( 0 ) Não (1) Sim

C26. Se Sim, há quanto tempo? _ _ anos

C27. Quantos cigarros o(a) Sr. (a) fuma por dia? _ _-

C28. O(a) Sr. (a) consumiu bebida alcoólica nas 4 últimas semanas?

( 0 ) Não (1) Sim

\section{Se "NÃO" passar para questão 34}

C29. Com que frequência durante o último ano o(a) Sr. (a) sentiu culpa ou remorso por beber?

( 0 ) Nunca

(1) Menos que 1 vez ao mês (3) Uma vez por semana

(2) Uma vez ao mês $\quad$ (4) Todos os dias ou quase todos

C30. Com que frequência durante o último ano, o Sr. (a) não conseguiu se lembrar do que aconteceu na noite anterior por causa da bebida?

( 0 ) Nunca

(1) Menos que 1 vez ao mês (3) Uma vez por semana

( 2 ) Uma vez ao mês

( 4 ) Todos os dias ou quase todos

C31. Alguma vez na vida o(a) Sr. (a) ou alguma outra pessoa já se machucou, se prejudicou por causa de o(a) Sr.

(a) ter bebido?

( 0 ) Não (1) Sim, mas não no último ano

( 2 ) Sim, durante o último ano

C32. Alguma vez na vida algum parente, amigo, médico ou outro profissional da saúde já se preocupou com o(a) Sr. (a) por causa da bebida ou the disse para parar de beber?

( 0 ) Não (1) Sim, mas não no último ano

( 2 ) Sim, durante o último ano

C33. O que o(a) Sr. (a) acha do seu consumo de bebida alcoólica?

(1) É um grande problema ( 4 ) Ajuda-lhe um pouco

( 2 ) É um problema pequeno (5) Ajuda-lhe muito

$\begin{array}{ll}\text { ( } 3 \text { ) Não é problema } & \text { (6) Ajuda-lhe, mas é um problema }\end{array}$

C34. O(a) Sr. (a) fez uso de alguma droga ilegal nas últimas 4 semanas?
( 0 ) Não
(1) $\operatorname{Sim}$

Se "NÃO"passar para questão 36 


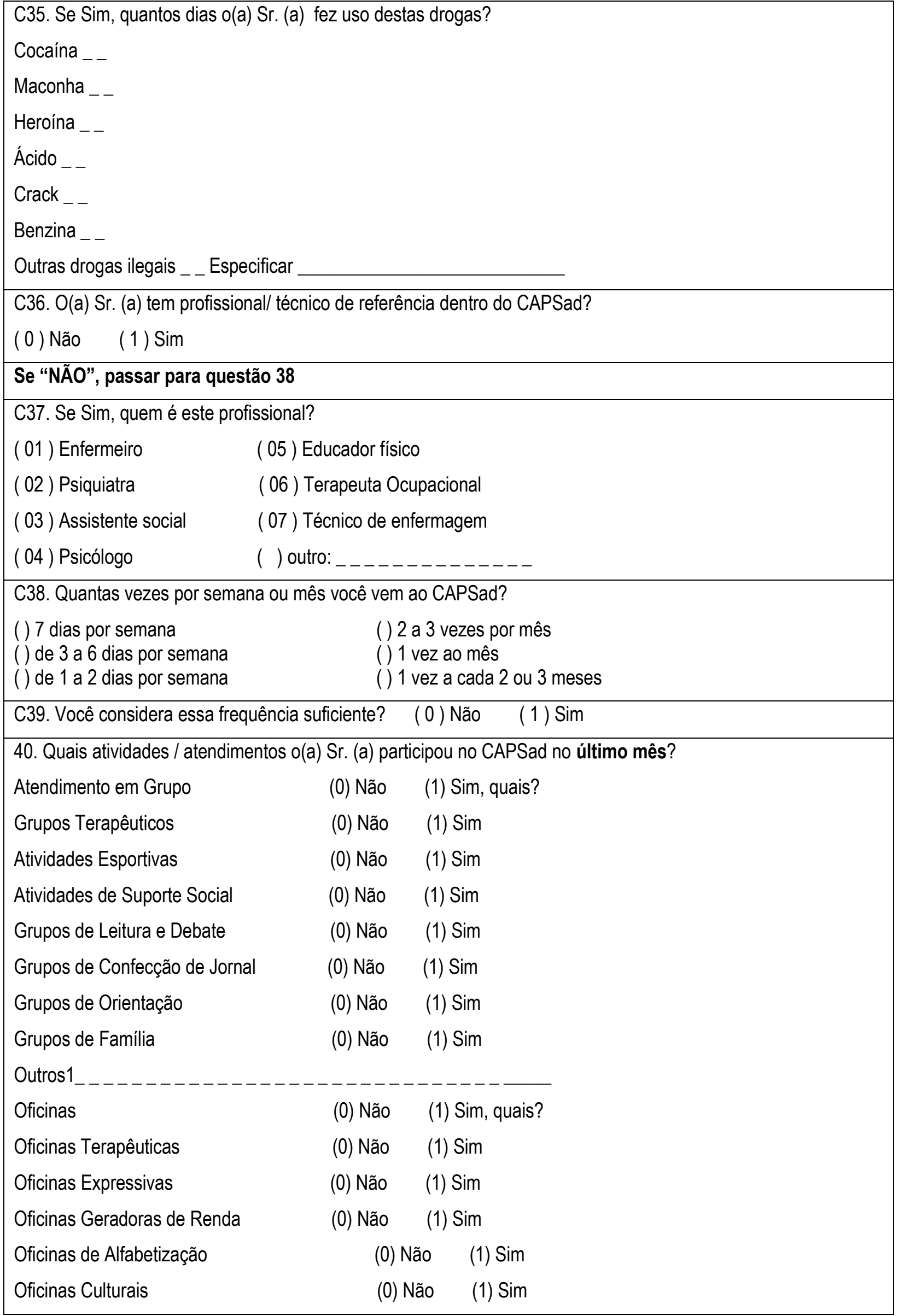




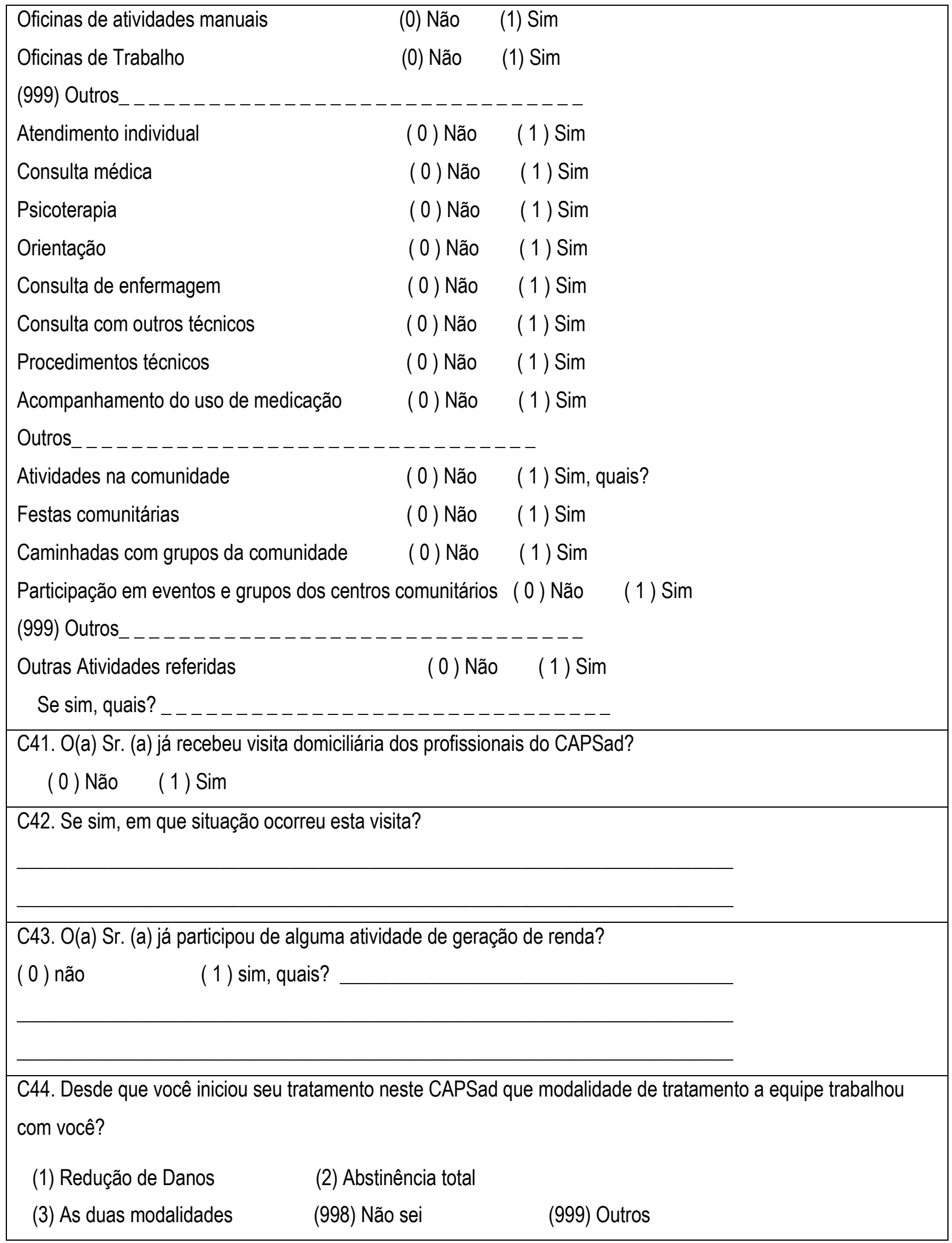


C45. Em outras necessidades, como moradia, educação, lazer, etc, esse serviço Ihe ajuda?
(1) $\operatorname{Sim}$
(2) Não
Se sim, como?

C46. Quem encaminhou o(a) Sr. (a) ao CAPSad?
(1) Minha própria decisão
(5) Um médico/ terapeuta/técnico
(2) Uma pessoa da família
(6) Um serviço de referência
(3) Um amigo
(7) A polícia
(4) Ordem judicial (999) outro

\section{* Nota ao Entrevistador: se foi uma ordem judicial, indicar quem a pediu}

47. Que tipo de transporte o(a) Sr. (a) usa para chegar a este serviço?
(1) Transporte próprio
(4) Transporte público
(2) Transporte da família
(5) Caminhada
(3) Transporte de amigos
(999) Outro

48. Quanto tempo o(a) Sr. (a) gasta para vir de sua casa até o CAPSad?
(1) $0-15 \mathrm{~min}$
( 3 ) $31-45 \mathrm{~min}$
( 2 ) $16-30 \mathrm{~min}$
( 4 ) 46-60 min
( 5 ) mais que $60 \mathrm{~min}$

C49.Como é para o(a) Sr. (a) chegar ao CAPSad?
(1) Muito difícil
( 2 ) Difícil
( 3 ) Mais ou menos
( 4 ) Fácil
( 5 ) Muito fácil

C50. Qual a sua opinião sobre a maneira como o(a) Sr. (a) é tratado, em termos de respeito no CAPSad?
(1) Nunca me senti respeitado
(2) Geralmente não me senti respeitado
(3) Mais ou menos
(4) Geralmente me senti respeitado
(5) Sempre me senti respeitado

C51. Quando o (a) Sr. (a) falou com a pessoa que the admitiu/acolheu no CAPSad, ela Ihe ouviu?

(1) Não ouviu de forma alguma
(2) Não ouviu
(4) Ouviu
(3) Mais ou menos
(5) Ouviu muito

C52. $O$ que o (a) Sr(a) pensava ser o seu problema quando foi admitido/acolhido no CAPSad?
(1) Um problema físico de saúde
(5) Um problema financeiro
(2) Um problema psicológico
(6) Um problema no trabalho
(3) Um problema familiar
(998) Não sei
(4) Um problema social
(999) Outro 
C53. A pessoa que admitiu/acolheu o (a) Sr. (a) no CAPSad pareceu compreender o seu problema?

(1) Não me compreendeu de forma alguma

( 2 ) Não me compreendeu muito (4) Compreendeu bem

( 3 ) Mais ou menos

( 5 ) Compreendeu muito bem

C54. Em geral, como o(a) Sr. (a) acha que a equipe do CAPSad compreendeu a sua necessidade?

(1) Não me compreendeu de forma alguma

( 2 ) Não me compreendeu muito ( 4 ) Compreendeu bem

( 3 ) Mais ou menos

(5) Compreendeu muito bem

C55. A assistência que o(a) Sr. (a) recebe no CAPSad satisfaz suas necessidades?
(1) Muito insatisfatória
( 2 ) Insatisfatória
( 3 ) Mais ou menos
( 4 ) Satisfatórias
( 5 ) Muito satisfatória

C56. Qual a sua opinião sobre o tipo de ajuda dada a você pelo CAPSad?

(1) Parece que eles pioraram as coisas

$\begin{array}{lll}\text { (2) Não obtive nenhuma ajuda } & \text { (3) Não obtive muita ajuda }\end{array}$

$\begin{array}{lll}\text { (4) Senti que obtive alguma ajuda (5) Senti que obtive muita ajuda } & \end{array}$

C57. A assistência que o (a) Sr. (a) recebeu o ajuda a lidar mais eficazmente com seus problemas?
(1) Não, eles parecem piorar as coisas
(4) $\mathrm{Sim}$, eles me ajudam um pouco
(2) Não, eles não ajudam muito
(5) Sim, eles me ajudam muito
(3) Mais ou menos

C58. O(a) Sr. (a) teve alguma dificuldade para obter informações da equipe do CAPSad quando pediu por elas?
(1) Muito frequentemente
(3) Mais ou menos
(5) Nunca
(2) Frequentemente
(4) Raramente
(6) Eu nunca pedi

C59. Se o(a) Sr. (a) teve alguma dificuldade para obter informações da equipe, de que tipo foi?

() Falta de disponibilidade da equipe/profissional () Descaso dos profissionais

() Não sabiam fornecer informações () Outros (especificar)

C60. O(a) Sr. (a) está satisfeito com a discussão feita com o(a) Sr. (a) sobre o seu tratamento no CAPSad?

(1) Muito insatisfeito

$\begin{array}{ll}\text { (2) Insatisfeito } & \text { (4) Satisfeito }\end{array}$

$\begin{array}{ll}\text { (3) Mais ou menos } & \text { (5) Muito satisfeito }\end{array}$

C61. O(a) Sr. (a) obteve no CAPSad o tratamento que o(a) Sr. (a) achava que precisava?

(1) De forma alguma

$\begin{array}{ll}\text { (2) Não muito } & \text { (4) Em geral, sim }\end{array}$

$\begin{array}{ll}\text { (3) Mais ou menos } & \text { (5) Sim, com certeza }\end{array}$ 
C62. O(a) Sr. (a) considera que a equipe do CAPSad esta Ihe ajudando?

(1) Nunca
(2) Raramente
(4) Frequentemente

(3) Mais ou menos

(5) Sempre

C63. Em geral, como o (a) Sr. (a) classificaria a recepção/acolhida dos usuários pelos profissionais do CAPSad?
(1) Nada amigável
(3) Mais ou menos
(5) Muito amigável
(2) Pouco amigável
(4) Amigável

64. Por que o (a) Sr. (a) escolheu o CAPSad? (Marcar até 3 itens)

( ) No passado eu já estive aqui

( ) $O$ serviço foi fortemente recomendado por alguém

( ) Eu conhecia alguém que estava em tratamento aqui

( ) Eu confiei na recomendação de quem me referiu este serviço

( ) A localização é muito conveniente

( ) Estava dentro de minhas possibilidades financeiras

( ) Eu não tive outra escolha

( ) Outro:

C65. O(a) Sr. (a) está de acordo que sua família ou seus parentes sejam envolvidos no seu tratamento?

(1) Discordo totalmente

(2) Discordo

(4) Concordo

(3) Indiferente/Mais ou menos

(5) Concordo totalmente

C66. Na sua opinião, que grau de competência tem a pessoa que the assiste mais de perto (técnico de referência)?
(1) Muito incompetente
(3) Mais ou menos
(5) Muito competente
(2) Incompetente
(4) Competente

C67. Como o(a) Sr. (a) classificaria a competência da equipe do CAPSad?
(1) Muito incompetente
(3) Mais ou menos
(5) Muito competente
(2) Incompetente
(4) Competente

C68. O(a) Sr. (a) participa do processo de avaliação das atividades desenvolvidas no CAPSad?

(0) Não (1) Sim

C69. O que o(a) Sr. (a) acha de participar do processo de avaliação das atividades deste serviço?
(1) Discordo totalmente
(3) Indiferente
(5) Totalmente de acordo
(2) Discordo
(4) De acordo

C70. Como o(a) Sr. (a) classifica a qualidade da assistência que o (a) Sr. (a) recebeu no CAPSad?
() Péssima
() Regular
() Excelente
( ) Ruim
() Boa

C71. Como o (a) Sr. (a) se sente com relação à quantidade de ajuda que recebeu no CAPSad? 


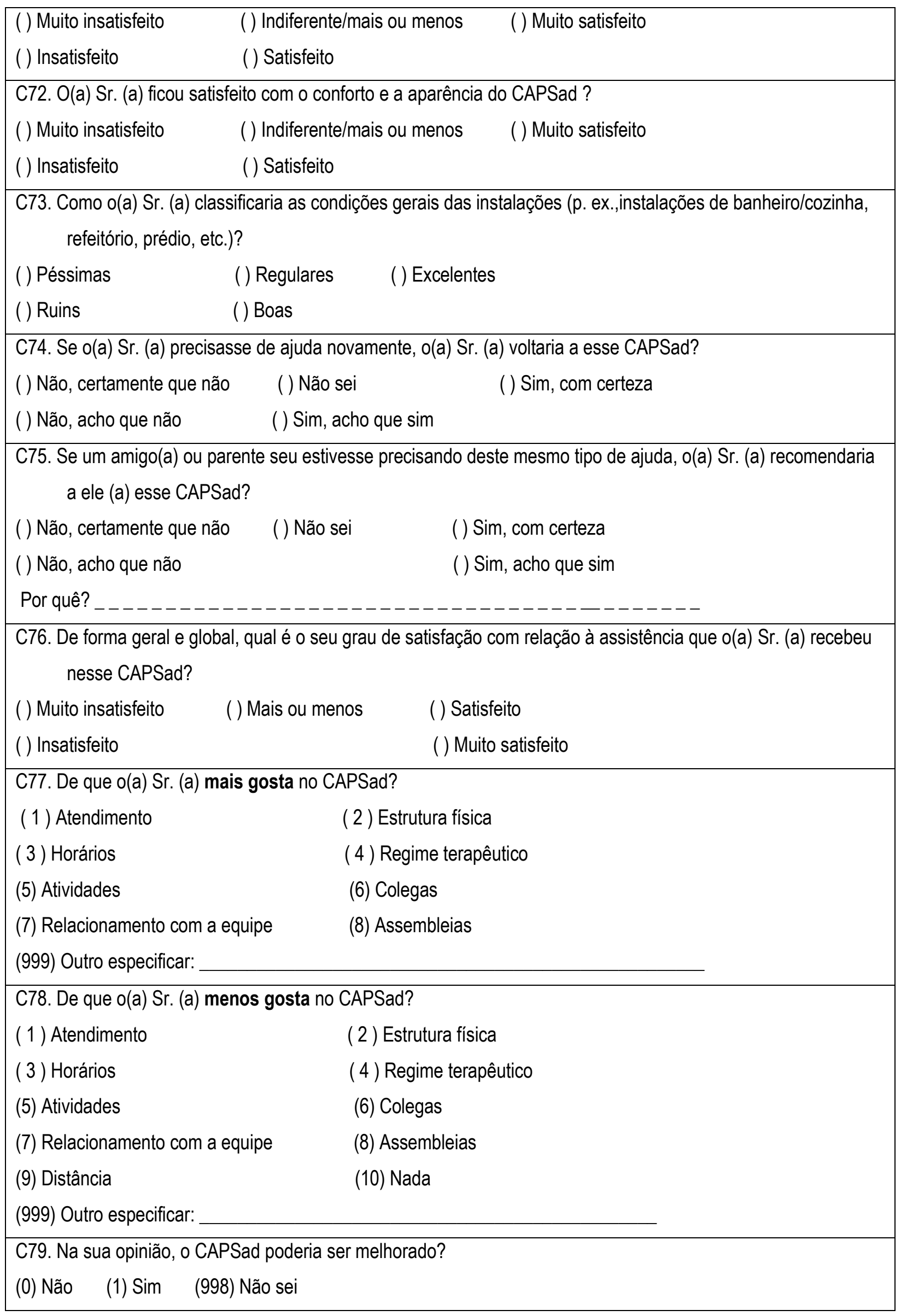


C80. Se Sim, de que maneira?

Agora vou lhe fazer algumas perguntas sobre como você se sente em relação a alguns aspectos de sua vida e você pode responder utilizando as seguintes possibilidades:

$0=$ MUITO INSATISFEITO

$10=$ MUITO SATISFEITO

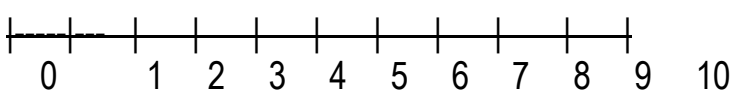

D1. Como o(a) Sr. (a) se sente em relação a maneira com que gasta seu tempo?

Nota:

D2. Como o(a) Sr. (a) se sente quando está sozinho? Nota:

D3. Como o(a) Sr. (a) se sente em relação a sua moradia? Nota:

D4. Como o(a) Sr. (a) se sente em relação à vizinhança do lugar onde o(a) Sr. (a) mora? Nota:

D5. Como o Sr(a). se sente em relação à comida que o(a) Sr. (a) come? Nota:

D6. Como o(a) Sr. (a) se sente em relação à roupa que o(a) Sr. (a) veste? Nota:

D7. Como o(a) Sr. (a) se sente em relação a sua vida afetiva? Nota:

D8. Como o(a) Sr. (a) se sente em relação a sua vida sexual? Nota:

D9. Como o senhor se sente em relação ao seu ciclo de amizades? Nota:

D10. Como o senhor se sente no que se refere ao relacionamento com sua família? Nota:

D11. Como o senhor se sente com relação às pessoas com quem o(a) Sr. (a) mora? Nota:

D12. Como o senhor se sente no que diz respeito ao seu relacionamento com as outras pessoas? Nota:

Agora, eu vou lhe perguntar, para cada aspecto da sua vida, se você acha que você teve mudanças desde que começou a se tratar aqui no CAPSad e se estas mudanças foram para pior ou para melhor.

Nota ao entrevistador: Para os itens abaixo, dizer : "Desde que você começou a se tratar aqui, ....... está(ão).....".

1. Os problemas pessoais

2. O humor

3. A estabilidade das emoções

4. O sentimento de confiança em si próprio

5. O sentimento de interesse pela vida

6. A capacidade de suportar situações difíceis

7. 0 apetite

8. A energia (disposição para fazer as coisas)

9. 0 sono

10. A saúde física (Dores, tremores)

11. A sexualidade (satisfação sexual)

12. A convivência com a família

13. A convivência com os amigos ou amigas

14. A convivência com as outras pessoas

15. $O$ interesse em trabalhar ou se ocupar com alguma coisa

16. As atividades de lazer (as coisas que ele gostava de fazer)

17. As tarefas de casa (ex : cozinhar, fazer compras para a casa,

lavar roupa, arrumar o quarto ou a casa, consertar coisas, etc).

18. A capacidade de cumprir as obrigações e tomar decisões

\begin{tabular}{|c|c|c|}
$\begin{array}{c}\text { Pior do } \\
\text { que antes }\end{array}$ & $\begin{array}{c}\text { Sem } \\
\text { mudanças }\end{array}$ & $\begin{array}{c}\text { Melhor do } \\
\text { que antes }\end{array}$ \\
\hline$(0)$ & $(1)$ & $(2)$ \\
\hline$(0)$ & $(1)$ & $(2)$ \\
\hline$(0)$ & $(1)$ & $(2)$ \\
\hline$(0)$ & $(1)$ & $(2)$ \\
\hline$(0)$ & $(1)$ & $(2)$ \\
\hline$(0)$ & $(1)$ & $(2)$ \\
\hline$(0)$ & $(1)$ & $(2)$ \\
\hline$(0)$ & $(1)$ & $(2)$ \\
\hline$(0)$ & $(1)$ & $(2)$ \\
\hline$(0)$ & $(1)$ & $(2)$ \\
\hline$(0)$ & $(1)$ & $(2)$ \\
\hline$(0)$ & $(1)$ & $(2)$ \\
\hline$(0)$ & $(1)$ & $(2)$ \\
\hline$(0)$ & $(1)$ & $(2)$ \\
\hline$(0)$ & $(1)$ & $(2)$ \\
\hline$(0)$ & $(1)$ & $(2)$ \\
\hline$(0)$ & $(1)$ & $(2)$ \\
\hline$(0)$ & $(1)$ & $(2)$ \\
\hline
\end{tabular}


Impressão geral: Finalizando, eu gostaria de saber se,

19. Desde que você começou a se tratar aqui, em geral, você está

(0)

(1)

(2)

\section{Instrumento para coletar dados em prontuário}

\section{PRONTUÁRIOS}

P1. Número de identificação:

P2..Cidade:

P3..Estado:

P4. Data da coleta:_____/2013

P5.Tipo: ( 1 ) CAPS II ad ( 2 ) CAPS II ad estendido

(3) CAPS III ad

P6. N ${ }^{\circ}$ do prontuário:

P6.Nome do usuário:

P7. Data de ingresso no serviço $1^{\mathrm{a}}$ vez: ${ }_{-} l_{-} I_{\ldots} \ldots$

P8. Data de ingresso no serviço última vez: ___ $I_{-} I_{\ldots} \ldots$

P9. Modalidade de acompanhamento atual:

() Intensivo () Semi-intensivo () Não intensivo

P10. Essa informação foi buscada na Autorização de Procedimentos Ambulatoriais de Alta Complexidade/Custo (APAC)?
( 0 ) Não
(1) $\operatorname{Sim}$

P11. Ingresso na modalidade atual de atendimento: _ _ $I_{-} I_{-} \ldots$

P12. Data do último registro de atendimento: __ $I_{\ldots} I_{\ldots} \ldots$

P13. CID:

P14. Essa informação foi buscada na APAC? ( 0 ) Não $\quad$ (1) Sim

P15. No registro, quem fez acolhimento inicial do usuário?
( 01 ) Enfermeiro
(02) Médico
( 03 ) Psicólogo
( 04 ) Assistente social
(5) Terapeuta Ocupacional
Outro:

P16. Encaminhado por:

Unidade Básica de Saúde

Estratégia de Saúde da Família

Hospital Geral

Emergência

Ambulatório Especializado

Hospital Psiquiátrico

Outro:
( 0 ) Não
(1) $\operatorname{Sim}$
( 0 ) Não
(1) $\mathrm{Sim}$
( 0 ) Não
(1) $\operatorname{Sim}$
( 0 ) Não
(1) Sim
( 0 ) Não
(1) Sim
( 0 ) Não
(1) Sim

P17. Internações psiquiátricas:

( 0 ) Não

(1) $\operatorname{Sim}$

18. Número de internações psiquiátricas anteriores ao ingresso no CAPSad em hospital geral:

19. Número de internações psiquiátricas anteriores ao ingresso no CAPSad no hospital psiquiátrico: _-

20. Número de internações psiquiátricas anteriores ao ingresso no CAPSad em Comunidade Terapêutica: 
21. Número de internações psiquiátricas anteriores ao ingresso no CAPSad em Clínicas de Reabilitação:

22. Número de internações psiquiátricas após o ingresso no CAPSad em hospital geral:

23. Número de internações psiquiátricas após o ingresso no serviço em hospital psiquiátrico:

24. Número de internações psiquiátricas após o ingresso no CAPSad em Comunidade Terapêutica: _ _-

25. Número de internações psiquiátricas após ao ingresso no CAPSad em Clínicas de Reabilitação: _ _ -

26. Data da ultima internação:

27. Tempo que durou a última internação? meses___dias

\section{Verifique a existência de registro dos seguintes itens:}

28. Atendimentos individuais: $\quad$ ( 0 ) Não (1) Sim

Data do último atendimento: _ _ ___ _ _ _ Qual atendimento
29. Atendimento grupal
( 0 ) Não
(1) $\operatorname{Sim}$

Data do último atendimento:

Qual atendimento

30. Projeto Terapêutico Singular - PTS: ( 0 ) Não (1) Sim

Data do último PTS _ _ _ _ _ _- _

31. Intercorrências: $\quad$ ( 0 ) Não $\quad$ (1) Sim

Data da última intercorrência _ _ _ _ _ _ _ Qual intercorrência
32. Visitas domiciliárias:
( 0 ) Não
(1) $\operatorname{Sim}$

Data da última visita domiciliária _ $I_{-} I_{-} \ldots$

33. Atendimento / Orientações aos familiares:

( 0 ) Não (1) Sim Data da última orientação aos familiares _ _ __ _ _ _ _

34. Número de avaliações medicamentosas clínica nos últimos três meses:

Data da última avaliação medicamentosa clínica: _ _ _ _ _ _ _ _

35. Número de avaliações medicamentosas psiquiátrica nos últimos três meses:

Data da última avaliação medicamentosa psiquiátrica: __ ___ ___ _ _

36. Número de visitas domiciliárias no último mês:

(01) Enfermeiro: _ _ Data da última visita: _ _ _ _ _ _ _

(02) Médico: _ _ _ Data da última visita _ _ _ _ _ _ _

(03) Assistente social: __ _ Data da última visita __ $I_{-} I_{-} \ldots$

(04) Psicólogo: _ _ Data da última visita __ _ _ _ _ _

Outro 1:__ Especificar:___ Data da última visita _________ 


\section{Caracterização da última história clínica:}
37. Sinais e sintomas:
( 0 ) Não
(1) $\operatorname{Sim}$
38. Historia familiar:
( 0 ) Não
(1) Sim
39. Uso de medicação:
( 0 ) Não
(1) Sim
40. Avaliação das funções psíquicas:
( 0 ) Não
(1) $\operatorname{Sim}$
41. Apoio familiar:
( 0 ) Não
(1) $\operatorname{Sim}$
42. Adesão às atividades propostas
( 0 ) Não
(1) $\operatorname{Sim}$
43. Perfil sócio econômico
( 0 ) Não
(1) Sim

\section{Caracterização do último PTS}

44. Espaço de definição do PTS:
Reunião de equipe:
( 0 ) Não (1) Sim
Consulta individual:
( 0 ) Não (1) Sim
Acolhimento:
( 0 ) Não (1) Sim
Outro:
( 0 ) Não
(1) Sim

Especificar:

45. Quem participa da definição do PTS?
Enfermeiro:
( 0 ) Não
(1) $\operatorname{Sim}$
Médico:
( 0 ) Não
(1) $\operatorname{Sim}$
Psicólogo:
( 0 ) Não
(1) $\operatorname{Sim}$
Assistente social:
( 0 ) Não
(1) Sim
Terapeuta Ocupacional
(0) Não
(1) $\operatorname{Sim}$
Outro:
( 0 ) Não
(1) $\operatorname{Sim}$

Especificar:

46. Identifique se os seguintes itens fazem parte do PTS
Inserção no trabalho voluntário:
( 0 ) Não
(1) $\operatorname{Sim}$
Inserção no trabalho remunerado:
( 0 ) Não
(1) $\operatorname{Sim}$
Iniciativas de geração de renda:
( 0 ) Não
(1) $\operatorname{Sim}$
Inserção comunitária:
( 0 ) Não
(1) $\mathrm{Sim}$
Cuidados pessoais com o corpo:
( 0 ) Não (1) Sim
Grupo de conversação:
( 0 ) Não (1) Sim
Oficinas:
( 0 ) Não (1) Sim
Acompanhamento aos familiares:
( 0 ) Não
(1) $\operatorname{Sim}$
Atendimento individual:
( 0 ) Não (1) Sim
Atividades escolares:
( 0 ) Não (1) Sim
Prescrição de fármacos:
( 0 ) Não (1) Sim 
Visita domiciliária:

( 0 ) Não (1) Sim

Assinatura de concordância do usuário

(0) Não

(1) $\operatorname{Sim}$

47. Psicofármacos em uso e / ou indicados na última prescrição: 
ANEXO 5 - Instrumento para os familiares dos usuários do serviço.

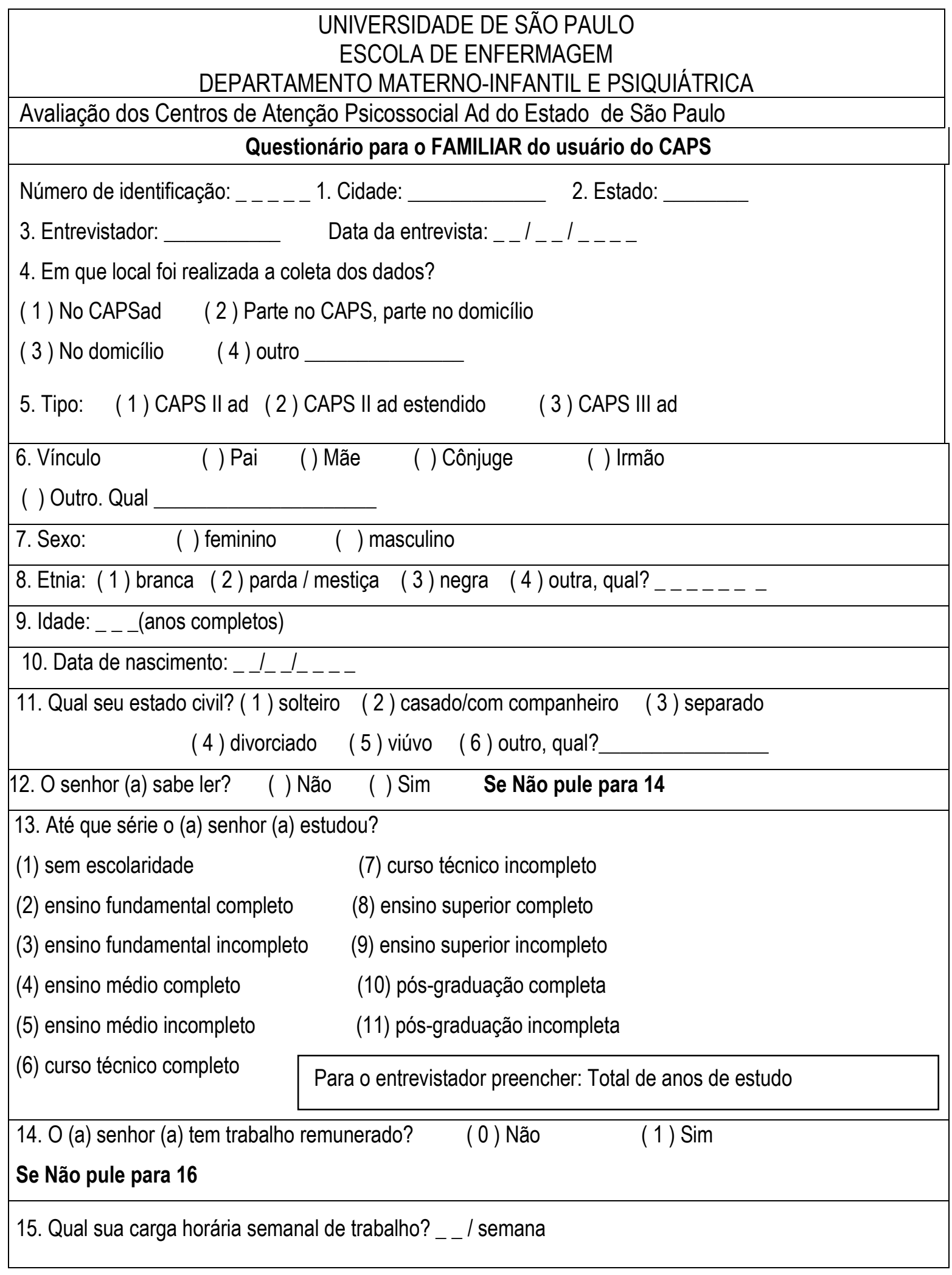


16. Qual sua renda individual no ultimo mês?
(1) Sem renda
(4) Entre 4 a 10 salários mínimos
(2) Até 2 salários mínimos
(5) Entre 10 a 20 salários mínimos
(3) Entre 2 a 4 salários mínimos
(6) Acima de 20 salários mínimos

17. Qual a renda da sua família no último mês?
(1) Até 2 salários mínimos
(4) Entre 10 a 20 salários mínimos
(2) Entre 2 a 4 salários mínimos
(5) Acima de 20 salários mínimos
(3) Entre 4 a 10 salários mínimos

18. Quantas pessoas moram na sua casa?

19. O senhor (a) é o único que cuida de seu familiar?

( 0 ) Não

(1) Sim

Se não, quantas pessoas dividem o cuidado do seu familiar, contando com o sr (a).

20. 0 (a) senhor(a) tem filhos? (1) sim (2) não Se sim, quantos? _-

21. Quantas pessoas da sua família são usuários do CAPSad?

22. Quantos dormitórios há em sua casa? _-

23. Que tipo de moradia o (a) Sr. (a) tem atualmente?
(1) casa / apartamento próprio
(5) rua
(2) casa / apartamento alugado
(6) abrigo de emergência
(3) casa de amigos
(7) pensão (alimentação e moradia)
(4) hospital ou instituição
(999) outro, qual?

24. Dentre os itens abaixo, quais os que o(a) $\mathrm{Sr}$. (a) possui e em que quantidade?

Automóvel

Televisor em cores

Banheiro _-

Empregada doméstica _ -

Rádio (excluindo do carro)

25. O senhor (a) tem problemas de saúde?

Máquina de lavar roupa

DVD _-

Aspirador de pó _-

Geladeira comum ou c/ freezer _ -

Computador _-

Se Não - pule para a questão 1 - perguntas sobre o CAPS ( 3 questões abaixo)

26. Quais:
Diabetes Mellitus
(0) Não
(1) $\operatorname{Sim}$
Hipertensão
(0) Não
(1) $\operatorname{Sim}$
Problemas cardíacos
(0) Não
(1) $\mathrm{Sim}$

Outros:

27. Você está realizando tratamento em algum serviço de saúde? ( )Não ( ) Sim 


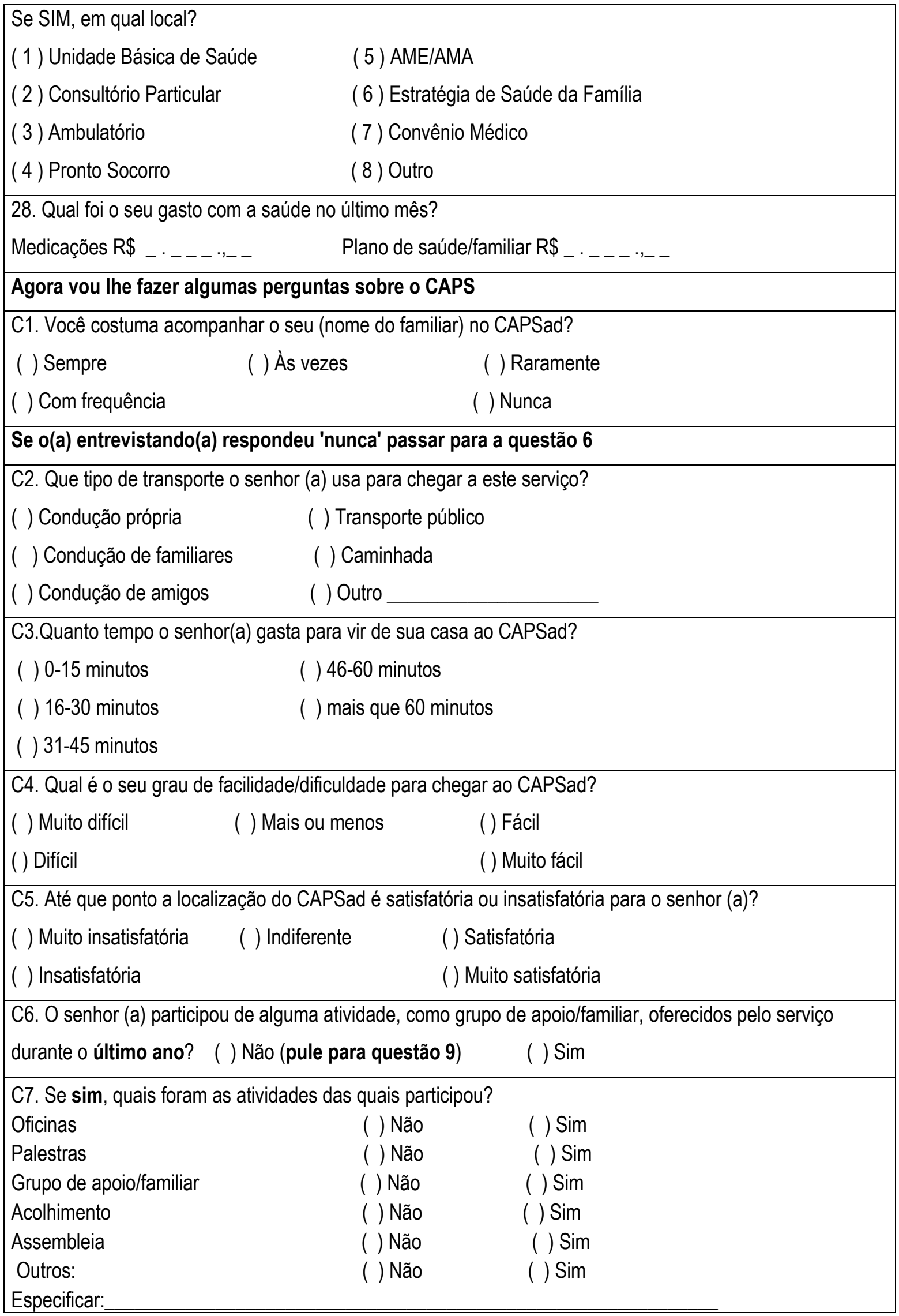




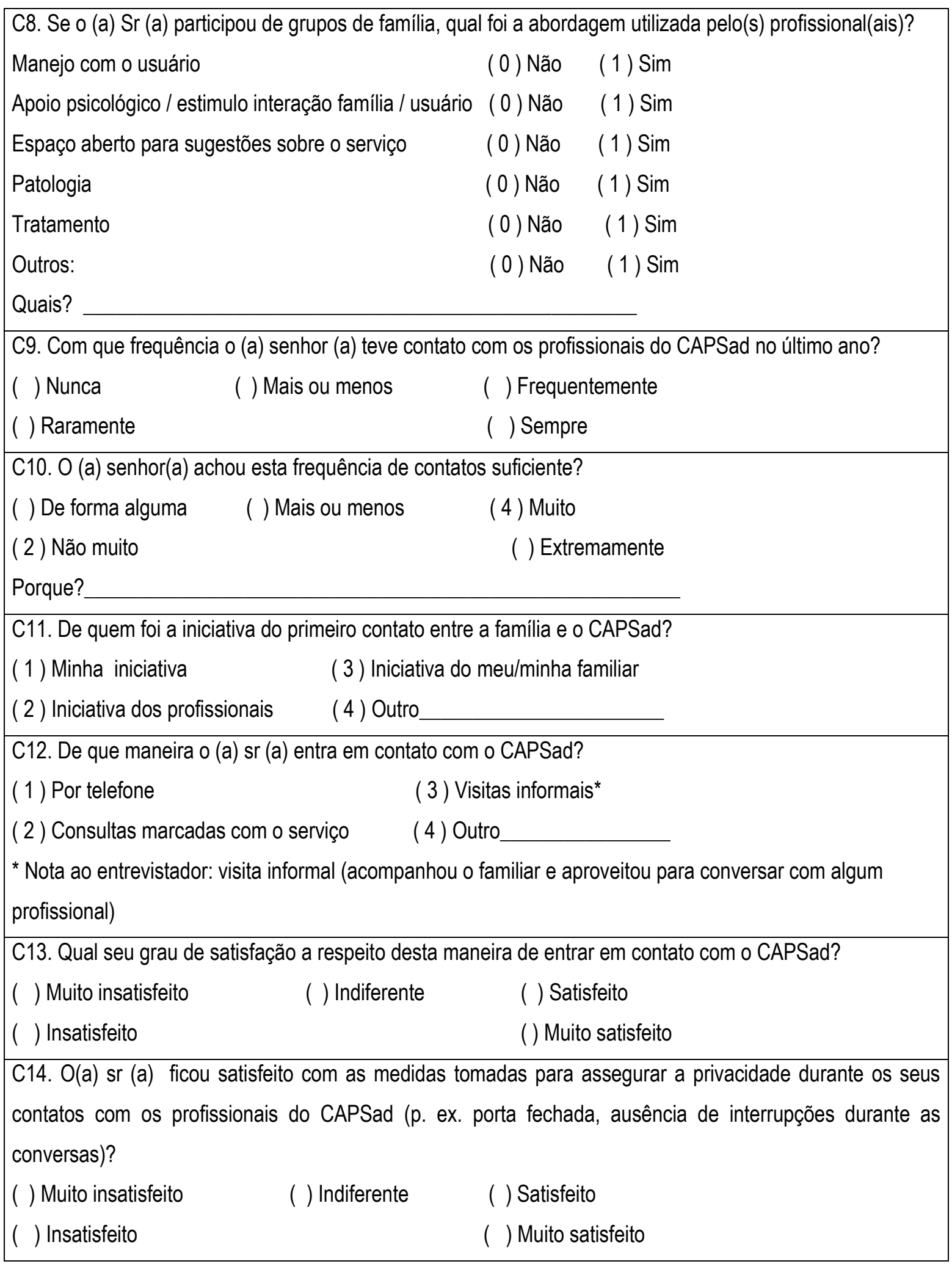


C15. Se o (a) sr (a) solicitou uma consulta com os profissionais do CAPSad, quanto tempo demorou até que fosse atendido?

( ) Não solicitei consulta (Se não solicitou, passar à questão 17)

( 2 ) Fui atendido imediatamente
( ) Menos que 1 dia
( ) Entre 2 semanas e 1 mês
( ) Entre 2 dias e 1 semana
( ) Mais de 1 mês
( ) Entre 1 e 2 semanas
( ) Não fui atendido até agora

C16. O (a) sr (a) achou este período de espera razoável?
( ) Nada razoável
( ) Mais ou menos
( ) Razoável
( ) Não muito razoável
( ) Muito razoável

C17. Em sua opinião, qual foi o grau de flexibilidade do serviço no agendamento de suas visitas, de acordo com sua disponibilidade (dia da semana e horário)?
(1) Muito inflexível
(3) Mais ou menos
( 4 ) Flexível
( 2 ) Inflexivel
( 5 ) Muito flexível

C18. O(a) sr (a) sentiu que foi tratado de forma respeitosa pela equipe do CAPSad?

( 1 ) Nunca me senti respeitado (4) Frequentemente me senti respeitado

( 2 ) Raramente me senti respeitado ( 5 ) Sempre me senti respeitado

( 3 ) Mais ou menos

C19. Em algum momento, aconteceu alguma violação de seus direitos como pessoa, por algum funcionário do CAPSad?
(1) Muito frequentemente
( 3 ) Mais ou menos
( 4 ) Raramente
( 2 ) Frequentemente
( 5 ) Nunca

C20. Em sua opinião, qual era o principal problema que seu familiar tinha quando ele (a) foi admitido no CAPSad? Marcar apenas UMA resposta
( ) Um problema de saúde física
( ) Um problema financeiro
( ) Um problema de saúde mental
( ) Um problema no trabalho
( ) Um problema familiar
( ) Não sei
( ) Um problema social
( ) Outro (especificar)

C21. Quando o senhor (a) falou com a pessoa que admitiu seu familiar no CAPSad, o senhor (a) sentiu que ele (a) 0 (a) escutou?
( ) Não me escutou de forma alguma
( ) Me escutou bastante
( ) Não me escutou muito
( ) Me escutou o tempo todo
( ) Mais ou menos
( ) Não se aplica

C22. A pessoa que admitiu o seu familiar no CAPSad pareceu compreender o seu problema (situação).
( ) Não compreendeu de forma alguma
( ) Me compreendeu bem
( ) Não compreendeu muito
( ) Me compreendeu muito bem 


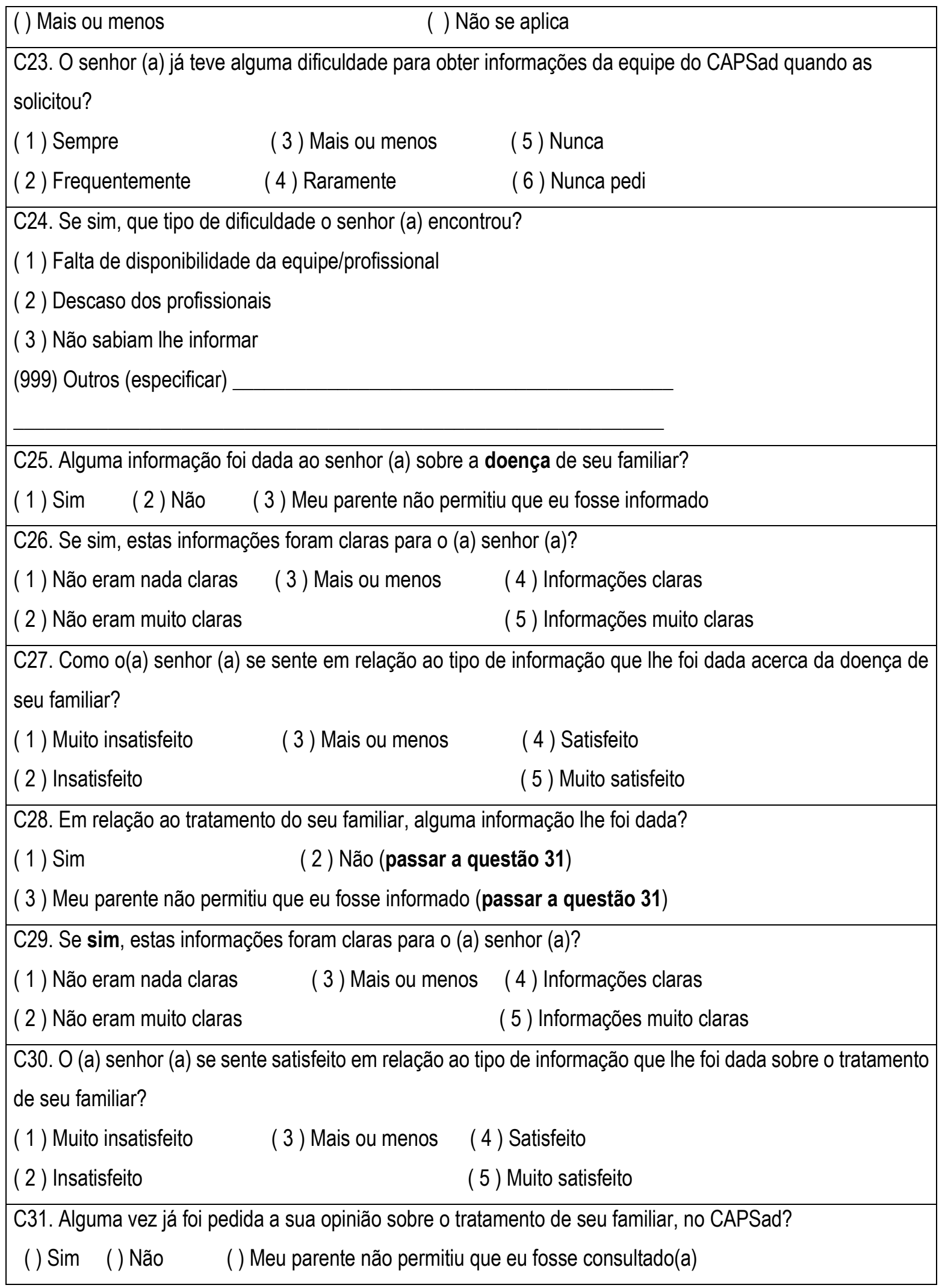


C32. 0 (a) senhor (a) está satisfeito (a) com as discussões a respeito do tratamento de seu familiar no CAPSad?
(1) Muito insatisfeito
( 3 ) Mais ou menos
( 4 ) Satisfeito
( 2 ) Insatisfeito
( 5 ) Muito satisfeito

C33. $\mathrm{O}$ (a) senhor (a) se sente satisfeito com as medidas tomadas para assegurar 0 sigilo acerca dos problemas discutidos com a equipe do CAPSad?
(1) Muito insatisfeito
( 3 ) Mais ou menos
( 4 ) Satisfeito
( 2 ) Insatisfeito
( 5 ) Muito satisfeito

C34. Quando o senhor e/ou seu familiar procuraram o CAPSad, qual o profissional que os recebeu?
( ) Terapeuta Ocupacional
() Médico
() Enfermeiro
() Assistente social () Psicólogo
( ) Não lembro
( )Outro

C35. Quando o (a) senhor (a) falou com a pessoa que admitiu seu familiar no CAPSad, o (a) senhor (a) achou que ele (a) escutou o paciente?
( ) Não escutou nada
( ) Mais ou menos
() Escutou bastante
( ) Não escutou muito
( )Escutou o tempo todo

C36. Em geral, como o (a) senhor (a) acha que a equipe do CAPS ad compreendeu o tipo de ajuda que seu familiar necessitava?
( ) Não compreendeu de forma alguma
( ) Mais ou menos
( ) Compreendeu bem
( ) Não compreendeu muito
( ) Compreendeu muito bem

C37. Você considera os serviços oferecidos pelo CAPSad apropriados?
( ) Muito inapropriados
( ) Mais ou menos
( ) Apropriados
( ) Inapropriados
( ) Muito apropriados

C38. Os cuidados que seu familiar recebeu, o/a ajudaram a lidar mais eficientemente com o problema (situação) dele (a)?
( ) Não, eles pioraram as coisas
( ) Mais ou menos
( ) Sim, eles ajudaram um pouco
( ) Não, eles não ajudaram muito
( ) Sim, eles ajudaram muito

C39. O senhor (a) acha que seu familiar recebeu o tipo de cuidado que o (a) senhor (a) pensa ser o que ele/a necessitava?
( ) Não, de forma alguma
() Mais ou menos
() Em geral, sim
( ) Não, não muito
( ) Sim, com certeza

C40a. O (a) senhor (a) se sente satisfeito (a) com as medidas tomadas para assegurar a privacidade durante o tratamento de seu familiar no CAPSad? (ex: porta fechada, ausência de interrupção durante conversas com 0 profissional.)
() Muito insatisfeito
() Mais ou menos
() Satisfeito
( ) Insatisfeito
( ) Muito satisfeito 
C40b. O (a) senhor (a) se sente satisfeito (a) com as medidas tomadas para assegurar a confidencialidade dos problemas de seu familiar, e os cuidados que ele/a recebeu no CAPSad?
() Muito insatisfeito
( ) Mais ou menos
( ) Satisfeito
( ) Insatisfeito
() Muito satisfeito

C41. De maneira geral, como o (a) senhor (a) classificaria a recepção da equipe do CAPSad?
( ) Nada amigável
( ) Mais ou menos amigável
( ) Amigável
( ) Não muito amigável
( ) Muito amigável

C42. No momento em que o (a) senhor (a) e/ou o seu familiar entrou em contato com o CAPSad, tinha conhecimento de outros serviços/atendimentos disponíveis na comunidade?
(1) $\operatorname{Sim}$
( 3 ) Não tenho certeza (pule para 45)
( 2 ) Não (pule para 45)
( 4 ) Não sei (pule para 45)

C43. Se sim, quais eram as opções?
(1) Hospital Psiquiátrico
( 4 ) Hospital geral
( 2 ) Grupo em Posto de Saúde
( 5 ) Comunidade terapêutica
( 3 ) Grupo de apoio
(999) Outros

C44. Existindo outras opções de serviço, por que o (a) senhor (a) e seu familiar escolheram o CAPSad? (Marcar até 3 opções)

( 1 ) Ele/ela já tinha estado lá no passado

( 2 ) 0 serviço foi muito recomendado por alguém

( 3 ) Conheci alguém que fazia tratamento lá

( 4 ) Confiamos na instituição/pessoa de referência

( 5 ) A localização e muito conveniente

(6) Estava dentro de nossas possibilidades financeiras

( 7 ) Não tivemos outra escolha

( 8 ) Serviço mais indicado

(998) Não sei

( ) Outro (especificar)

C45. No seu entendimento, qual a competência e conhecimento da pessoa que 0 atendeu/atende no CAPSad?
(1) Muito incompetente
( ) Mais ou Menos
( 3 ) Competente
( 2 ) Incompetente
( 4 ) Muito competente

C46. Em geral, como o (a) senhor (a) classificaria o grau de competência da equipe do CAPSad?
( ) Muito incompetente
() Mais ou Menos
( ) Competente
( ) Incompetente
( ) Muito competente 
C47. O (a) senhor (a) participou de alguma decisão relacionada ao planejamento e/ou realização de atividades no CAPSad?
( ) Nunca (Pular para 50)
( ) Às vezes
( ) Frequentemente
( ) Raramente
( ) Muito frequentemente

C48. O senhor acha que suas opiniões e pontos de vista acerca do planejamento e/ou realização de atividades no serviço foram levados em consideração?
( ) Nunca
( ) Às vezes
( ) Frequentemente
( ) Raramente
( ) Muito frequentemente

C49. O (a) senhor (a) está satisfeito com sua participação no planejamento e/ou realização de atividades no CAPSad?
( ) Muito insatisfeito
( ) Mais ou menos
() Satisfeito
( ) Insatisfeito
() Muito satisfeito

C50. $O$ (a) senhor (a) participou de alguma decisão relacionada à avaliação das atividades no CAPSad?
() Nunca (Pular para 53)
() Às vezes
() Frequentemente
( ) Raramente
() Muito frequentemente

C51. 0 senhor (a) sente que suas opiniões e pontos de vista referentes à avaliação das atividades foram levados em consideração?
(1) Nunca (Pular para 53)
(3) Às vezes
( 4 ) Frequentemente
( 2 ) Raramente
( 5 ) Muito frequentemente

C52. O senhor(a) ficou satisfeito com sua participação neste processo de avaliação?
(1) Muito insatisfeito
(3) Mais ou menos
( 4 ) Satisfeito
(2) Insatisfeito
( 5 ) Muito satisfeito

C53. 0 (a) senhor (a) acha que seu familiar se beneficiou com 0 atendimento no CAPS?
( ) Não, de forma alguma
( ) Mais ou menos
( ) Sim, de alguma forma
( ) Não, não muito
( ) Sim, com certeza

C53a. Como você classificaria, de um modo geral, a qualidade do serviço que seu familiar recebeu?
() Péssima
() Mais ou menos
() Boa
() Ruim
() Excelente

C54. Como o (a) sr (a) se sente em relação ao tempo dedicado ao seu familiar?

(1) muito insatisfeito
( 2 ) moderadamente insatisfeito
( 5 ) um pouco satisfeito
( 3 ) um pouco insatisfeito
(6) moderadamente satisfeito
( 4 ) nem satisfeito nem insatisfeito
( 7 ) muito satisfeito 
55. Como o (a) sr (a) se sente em relação a maneira como dedica seu tempo com seu familiar?

(1) muito insatisfeito

( 2 ) moderadamente insatisfeito (5) um pouco satisfeito

( 3 ) um pouco insatisfeito $\quad$ (6) moderadamente satisfeito

( 4 ) nem satisfeito nem insatisfeito $(7)$ muito satisfeito

56. Quanto o (a) sr (a) está satisfeito ou insatisfeito com o seu relacionamento com o seu familiar?

( 1 ) muito insatisfeito

( 2 ) moderadamente insatisfeito (5) um pouco satisfeito

(3) um pouco insatisfeito $\quad$ (6) moderadamente satisfeito

( 4 ) nem satisfeito nem insatisfeito (7) muito satisfeito

57. 0 (a) senhor (a) se sente sobrecarregado com os cuidados ao seu familiar?

( 0 ) Não ( se não, passe para 60) (1) Sim

58. Se sim, quanto: ( 1 ) Muito sobrecarregado (3) Às vezes sobrecarregado

( 2 ) Pouco sobrecarregado

Em que situações o senhor se sente sobrecarregado?

59. Quando o (a) senhor (a) se sente sobrecarregado, os profissionais do CAPSad escutam suas dificuldades e the oferecem suporte? ( 0 ) Não $\quad$ (1) Sim

60. 0 (a) senhor (a) procura apoio em outros locais?

$\begin{array}{lc}\text { Líder religioso } & \text { ( } 0 \text { ) Não (1) Sim } \\ \text { Grupos de ajuda fora CAPSad? } & \text { ( } 0 \text { ) Não (1) Sim } \\ \text { Outros: } & \text { ( } 0 \text { ) Não (1) Sim }\end{array}$

Qual?

61. O senhor (a) está satisfeito com a quantidade de ajuda que seu familiar recebeu no CAPSad?
(1) Muito insatisfeito
( 3 ) Mais ou menos
( 4 ) Satisfeito
( 2 ) Insatisfeito
( 5 ) Muito satisfeito

62. O senhor (a) esta satisfeito com o conforto e a aparência do CAPSad?
(1) Muito insatisfeito
( 3 ) Mais ou meno
(4) Satisfeito
( 2 ) Insatisfeito
( 5 ) Muito satisfeito

63. Como o (a) senhor (a) classificaria as condições das instalações (p. ex. instalações de banheiro e cozinha, refeitório, o prédio em si, etc.)?
( ) Péssimas
( ) Regulares
( ) Boas
( ) Ruins
( ) Excelentes 
64. Suponhamos que seu familiar precisasse novamente de ajuda, o (a) senhor (a) o traria novamente a este CAPSad?
( 1 ) Não, de forma alguma
( 3 ) Talvez
( 4 ) Sim, acho que sim
( 2 ) Não, acho que não
( 5 ) Sim, com certeza

65. Se um amigo ou familiar estivesse necessitando de ajuda semelhante, o (a) senhor (a) o encaminharia a este CAPSad?
(1) Não, de forma alguma
( 3 ) Talvez
( 4 ) Sim, acho que sim
( 2 ) Não, acho que não
( 5 ) Sim, com certeza

66. De maneira geral, qual é o seu grau de satisfação com relação aos cuidados que seu familiar recebeu no CAPSad?
( ) Muito insatisfeito
( ) Nem satisfeito, nem insatisfeito
() Satisfeito
( ) Insatisfeito
( ) Muito satisfeito

67. Do que o (a) senhor (a) mais gostou neste serviço?
(1) Atendimento
(5) Atividades
( 2 ) Estrutura física
(6) Colegas do grupo
( 3 ) Horários
(7) Relacionamento com a equipe
( 4 ) Regime terapêutico
(8) Assembleias

(999) Outro

68. Qual é o aspecto que o (a) senhor (a) menos gostou neste serviço?
(1) Atendimento
(5) Atividades
( 2 ) Estrutura física
(6) Colegas do grupo
( 3 ) Horários
(7) Relacionamento com a equipe
( 4 ) Regime terapêutico
(8) Assembleias
(999) Outro

69. Em sua opinião, este serviço poderia ser melhorado?
(1) $\operatorname{Sim}$
( 2 )Não
(998) Não sei

70. Se sim, de que forma?

\section{AGORA LHE FAREI ALGUMAS PERGUNTAS ACERCA DE SEU FAMILIAR}

Nota ao entrevistador: Para os itens abaixo, dizer:

"Desde que_(Nome) começou a se tratar aqui ......dele(a) está(ão)......"

\begin{tabular}{|l|c|c|c|}
\hline 1. Os problemas pessoais & $\begin{array}{c}\text { Pior do que } \\
\text { antes }\end{array}$ & $\begin{array}{c}\text { Sem } \\
\text { mudanças }\end{array}$ & $\begin{array}{c}\text { Melhor do } \\
\text { que antes }\end{array}$ \\
\hline 2. humor & $(0)$ & $(1)$ & $(2)$ \\
\hline 3. A estabilidade das emoções & $(0)$ & $(1)$ & $(2)$ \\
\hline 4. O sentimento de confiança em si próprio & $(0)$ & $(1)$ & $(2)$ \\
\hline 5. O sentimento de interesse pela vida & $(0)$ & $(1)$ & $(2)$ \\
\hline 6. A capacidade de suportar situações difíceis & $(0)$ & $(1)$ & $(2)$ \\
\hline
\end{tabular}




\begin{tabular}{|l|c|c|c|}
\hline 7. O apetite & $(0)$ & $(1)$ & $(2)$ \\
\hline 8. A energia (disposição para fazer as coisas) & $(0)$ & $(1)$ & $(2)$ \\
\hline 9. O sono & $(0)$ & $(1)$ & $(2)$ \\
\hline 10. A saúde física (Dores, tremores) & $(0)$ & $(1)$ & $(2)$ \\
\hline 11. A sexualidade (satisfação sexual) & $(0)$ & $(1)$ & $(2)$ \\
\hline 12. A convivência com a família & $(0)$ & $(1)$ & $(2)$ \\
\hline 13. A convivência com os amigos ou amigas & $(0)$ & $(1)$ & $(2)$ \\
\hline 14. A convivência com as outras pessoas & $(0)$ & $(1)$ & $(2)$ \\
\hline $\begin{array}{l}\text { 15. O interesse em trabalhar ou se ocupar com } \\
\text { alguma atividade }\end{array}$ & $(0)$ & $(1)$ & $(2)$ \\
\hline $\begin{array}{l}\text { 16. As atividades de lazer (as coisas que ele gostava } \\
\text { de fazer) }\end{array}$ & $(0)$ & $(1)$ & $(2)$ \\
\hline $\begin{array}{l}\text { 17. As tarefas de casa (ex: cozinhar, fazer compras } \\
\text { para a casa, lavar roupa, arrumar o quarto ou a casa, } \\
\text { consertar coisas, etc). }\end{array}$ & $(0)$ & $(1)$ & $(2)$ \\
\hline $\begin{array}{l}\text { 18. A capacidade de cumprir as obrigações e tomar } \\
\text { decisões }\end{array}$ & $(0)$ & $(1)$ & $(2)$ \\
\hline $\begin{array}{l}\text { Impressão geral: Finalizando, eu gostaria de saber se: } \\
\text { 19.Desde que_ (Nome) começou a se tratar } \\
\text { no_(Nome do local), em geral, ele(a) está }\end{array}$ & $(0)$ & $(1)$ & $(2)$ \\
\hline
\end{tabular}

Agradecimento ao familiar 


\section{ANEXO 6 - Autorização para utilização dos instrumentos.}

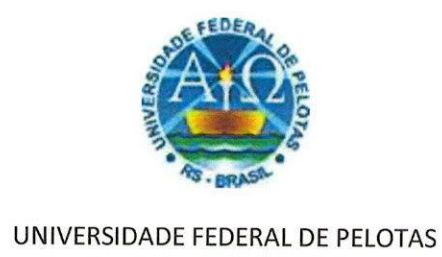

FACULDADE DE ENFERMAGEM

AUTORIZAÇÃO

Eu, Professora Doutora Luciane Prado Kantorski vinculada a Faculdade de Enfermagem da Universidade Federal de Pelotas, coordenadora do Projeto de Avaliação dos Centros de Atenção Psicossocial do Sul do Brasil - CAPSUL I e II autorizo a Professora Doutora Márcia Aparecida Ferreira de Oliveira, pesquisadora responsável principal pelo projeto intitulado "Avaliação dos CAPS ad do Estado de São Paulo e Minas Gerais", o qual pertence ao Grupo de Estudos em Álcool e outras Drogas, do Departamento de Enfermagem Materno Infantil e Psiquiátrica da Escola de Enfermagem da Universidade de São Paulo (GEADEEUSP), composto por alunos de graduação e pós-graduação, professores e profissionais da área de Saúde, a utilizar os instrumentos de coleta de dados aplicados aos coordenadores, profissionais, usuários e familiares com o objetivo de adaptação e aplicação nessa mesma população do referido projeto. Solicito que nas publicações derivadas do referido projeto quando os resultados forem obtidos a partir dos questionários do CAPSUL (em versão original ou adaptada) seja feita explícita referência a utilização dos instrumentos.

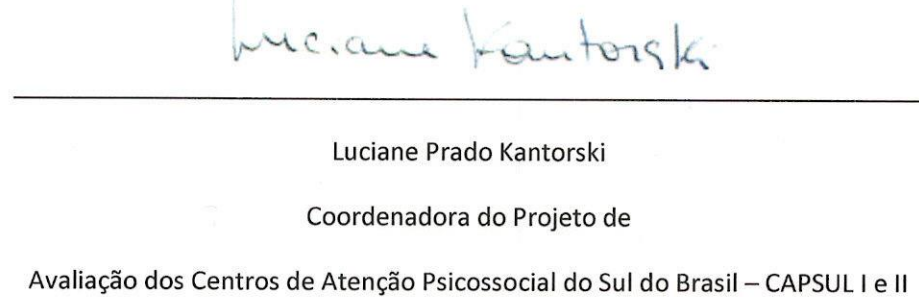

